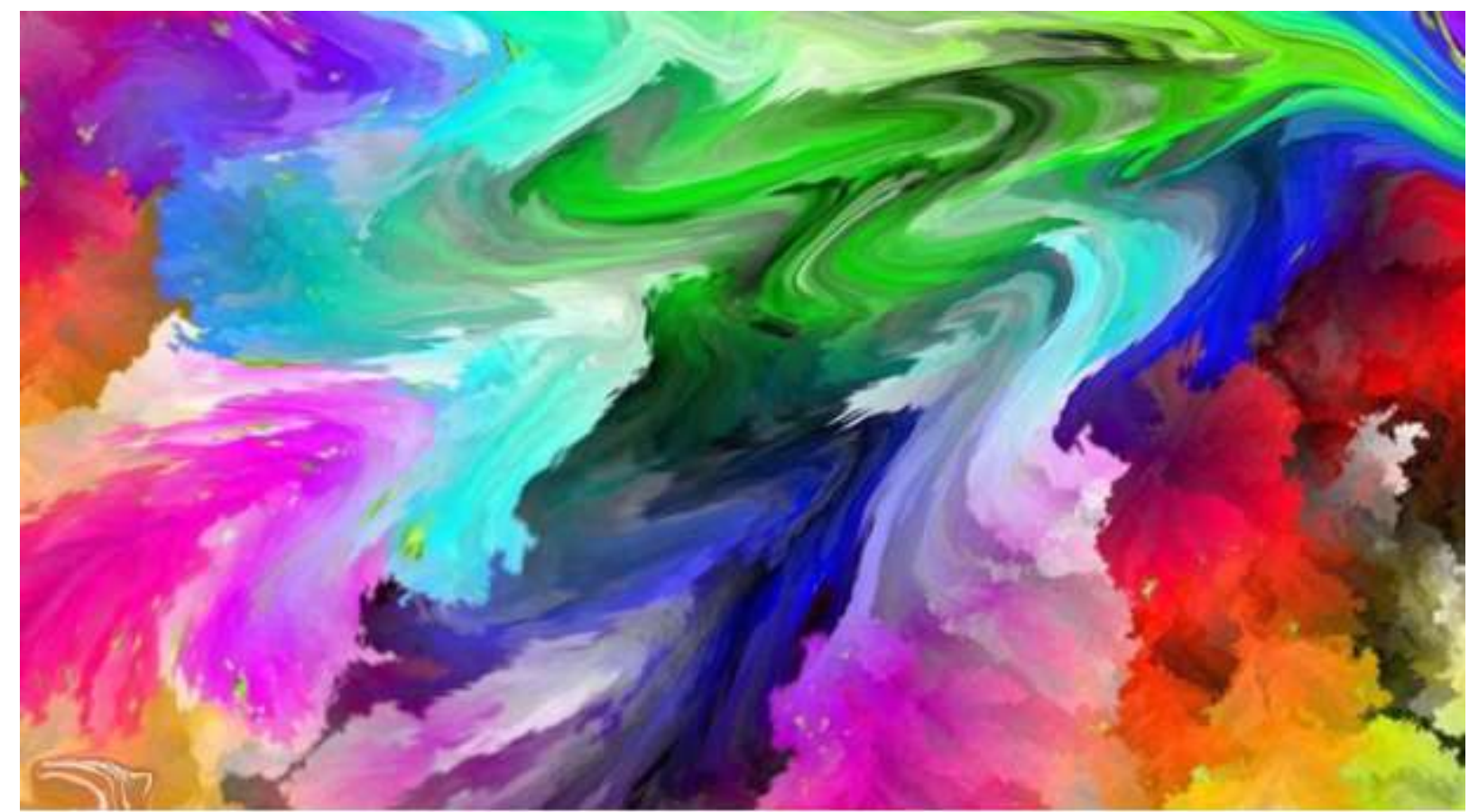

COLOUR PSYCHOLOGY IN RETIREMENT HOMES

BY

DALISHA SEBASTIAN

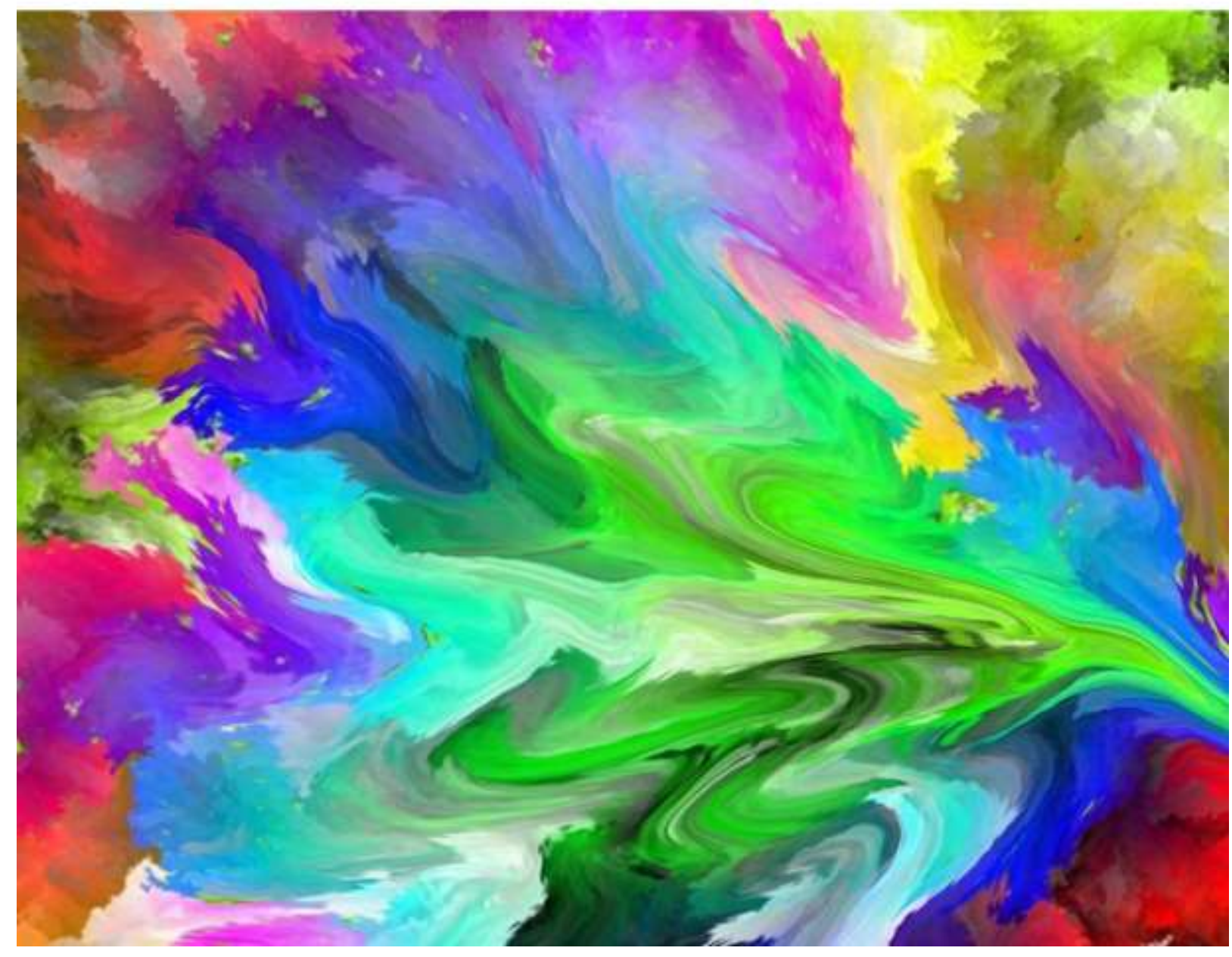




\title{
COLOUR PSYCHOLOGY IN RETIREMENT HOMES
}

BY

\author{
DALISHA SEBASTIAN
}

\author{
A 120-point thesis \\ submitted to the Victoria University of Wellington \\ in partial fulfilment of the requirements for the \\ degree of Master of Interior Architecture
}

Victoria University of Wellington Wellington School of Architecture 2020 


\section{ACKNOWLEDGMENTS}

To my parents, Sebastian and Reetha, Thank you for your never-ending love and support throughout the duration of my studies financially and emotionally. Thanks for making me emotionally strong and taking care of my new born when I was struggling to cope up with baby blues and thesis. Thank you amma for coming to New Zealand with me to look after Gabriel for few months so that I could complete my work on time.

To my supervisors Antony Pelosi and Emina Petrovic, thank you for understanding the struggle of being a full-time mom and a full-time student. Thanks for the Zoom sections when I was stranded in India for the first four months of thesis due to the visa issues of the baby. Thank you, your on-going support, guidance and motivation during this thesis project has been invaluable

Last but not the least I would like to thank my husband Nithin Titus and my fourteen months old Gabriel for your understanding, unwavering encouragement and positivity. 


\section{ABSTRACT}

As the population of New Zealand ages demand and popularity of retirement homes is increasing. This thesis argues that interior spaces of retirement homes can become more interesting and stimulating through the use of colour, and that a simple colour redesign of the common shared areas could achieve great benefits for the users. The main aim of this study is to explore how to create healing and comforting environment in retirement homes using colour as the main design driver. Based on the literature review it was possible to establish four key design colour strategies of healing; Views of nature, natural light, soothing colours and colours promoting interaction. Based on these, a series of design experiments were undertaken, developing a new set of approaches of how colour can be used in the interior design. Some of the design explorations were not focused on a particular site, but some considered the limitations of a possible site. The study succeeded in redesigning the selected site through a creative application of the four key design strategies of healing, but also supported development of a set of findings on how to use colour strategies more effectively in retirement homes. One of the key findings of this study is that the use of bright and saturated colour could prevent adverse effect of sensory deprivation associated with aging. This could have broader applications in interior architecture. 


\section{Table of Contents}

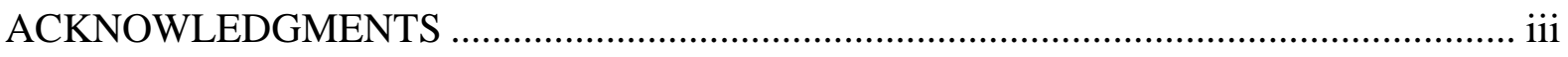

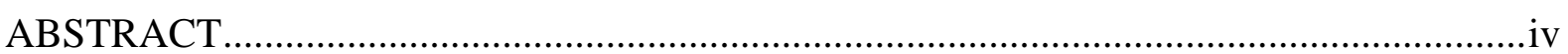

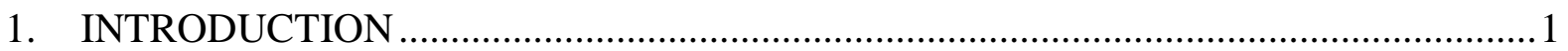

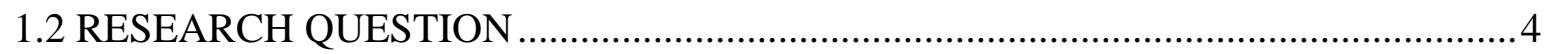

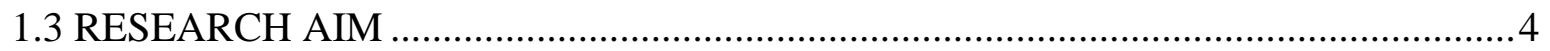

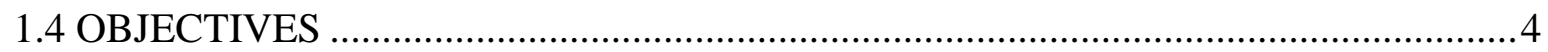

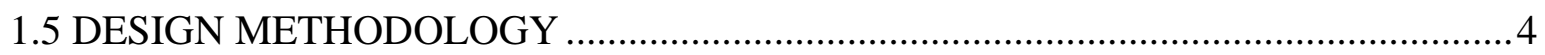

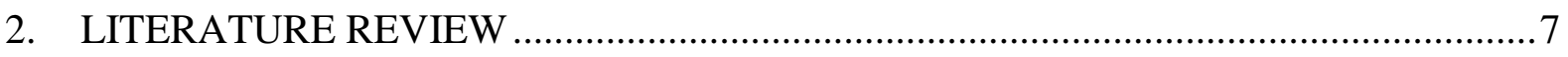

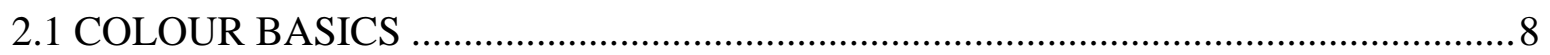

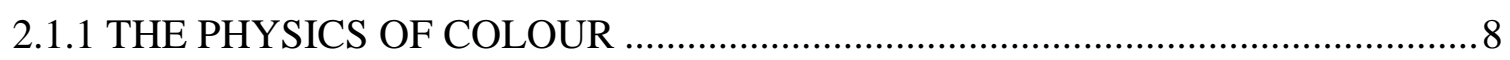

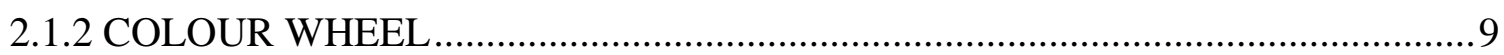

2.2 PSYCHOLOGICAL AND PHYSIOLOGICAL IMPACTS OF COLOUR .................. 10

2.3 IMPACTS OF INDIVIDUAL COLOURS ON PEOPLE.......................................... 11

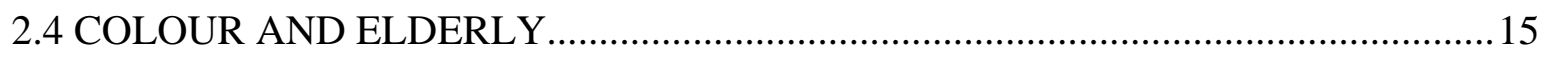

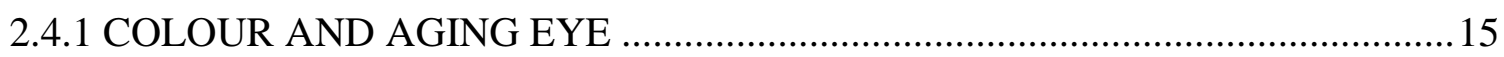

2.4.2 COLOUR INTERVENTIONS FOR ELDERLY ................................................ 16

2.5 HEALING AND COMFORTING ENVIRONMENT ................................................. 18

2.5.1 THE IMPACT OF NATURAL LIGHT AND NATURAL ELEMENTS ON

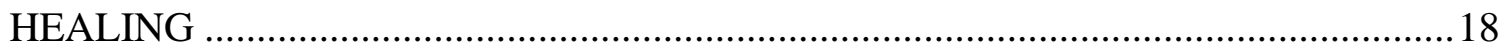

2.5.2 COLOUR AND HEALING ENVIRONMENT .................................................. 19

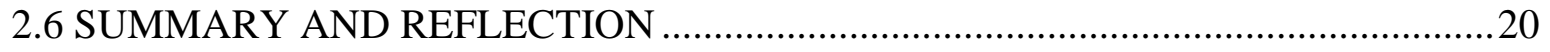

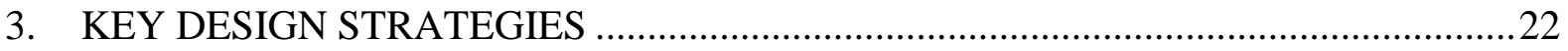

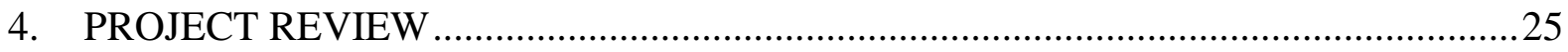

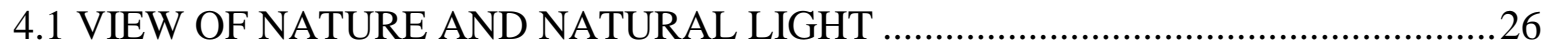

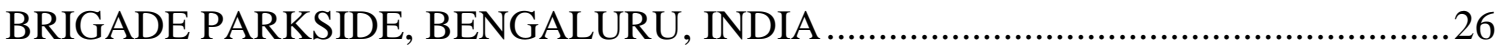

ESSIE SUMMERS RETIREMENT VILLAGE, CHRISTCHURCH ..........................28

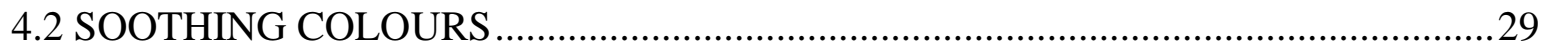

SHINJUEN NURSING HOME (2014), KAWAGOE (JAPAN) ..................................29

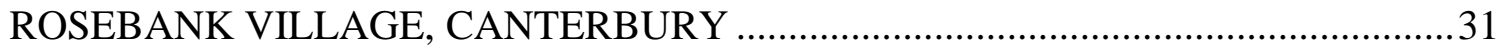

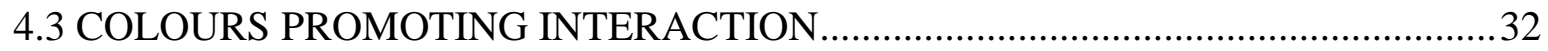

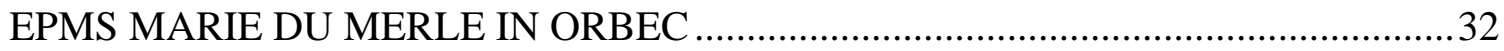

POSSUM BOURNE RETIREMENT VILLAGE, AUCKLAND ................................... 33

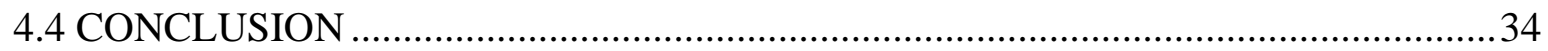




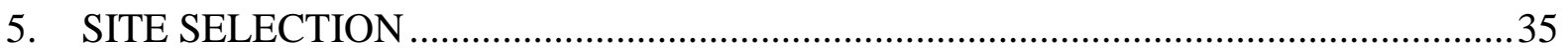

5.1 COLOUR AND RETIREMENT HOMES IN NEW ZEALAND ...............................36

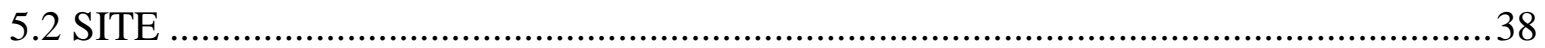

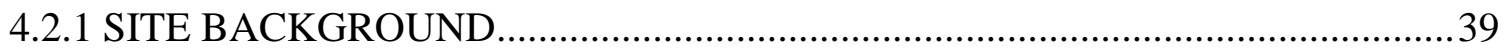

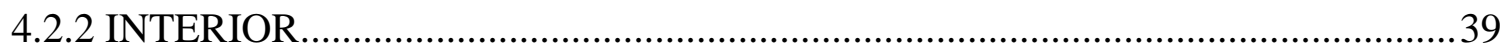

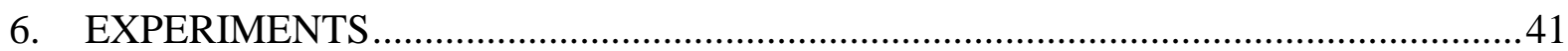

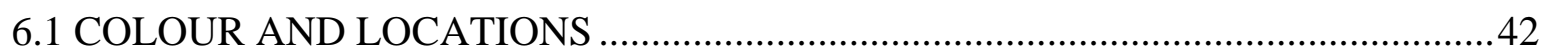

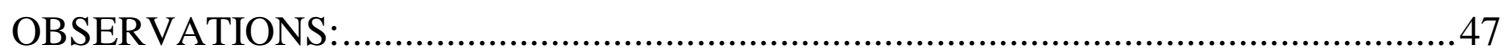

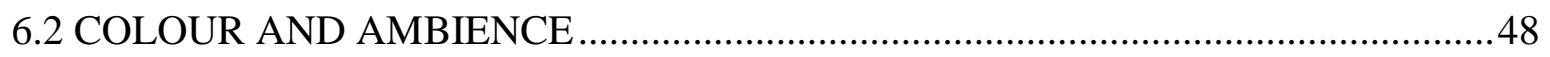

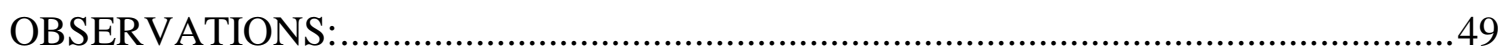

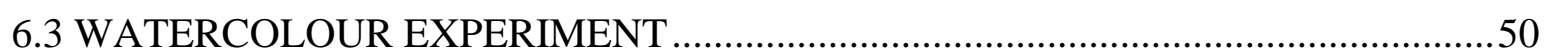

OBSERVATIONS:

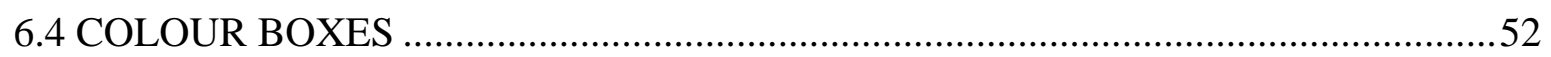

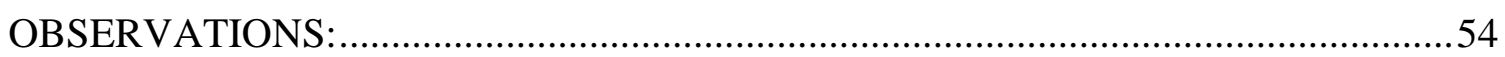

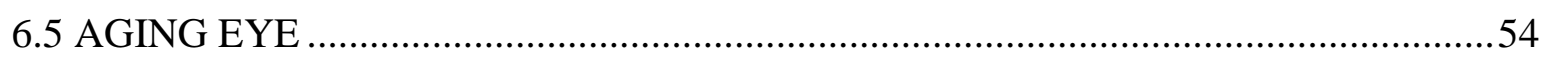

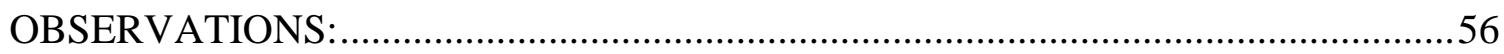

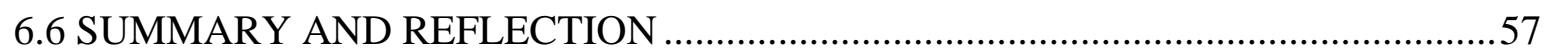

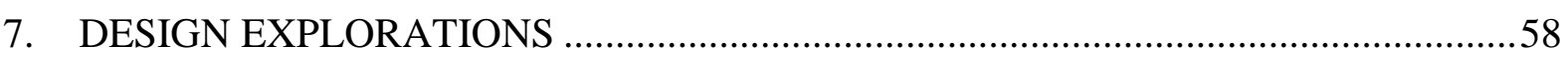

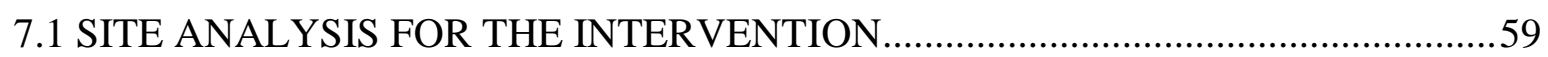

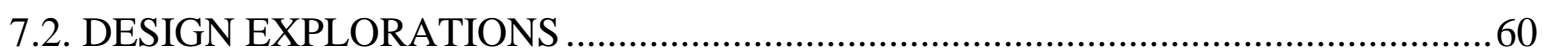

7.2.1 HOW TO INCREASE IDENTIFIED DESIGN OBJECTIVES?...........................60

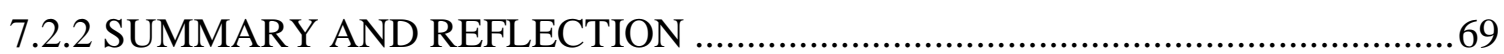

7.3 HOW TO BRING IN COLOURS NATURALLY? ................................................. 70

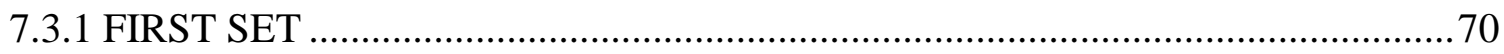

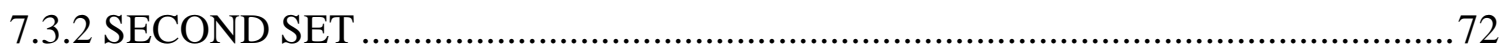

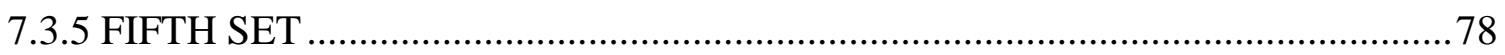

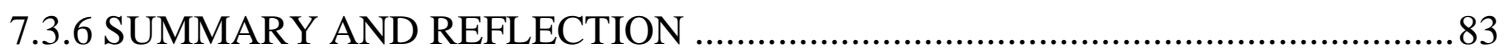

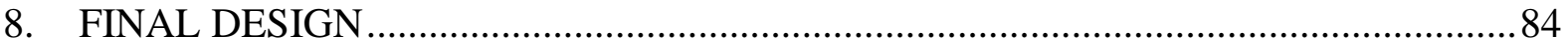

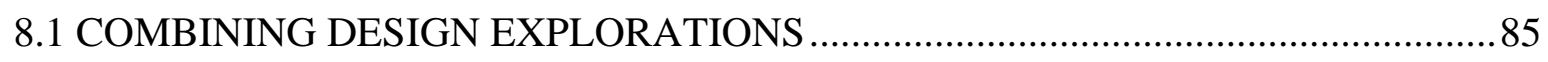

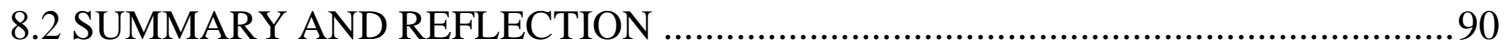

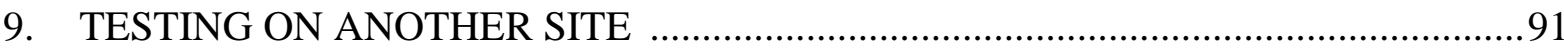

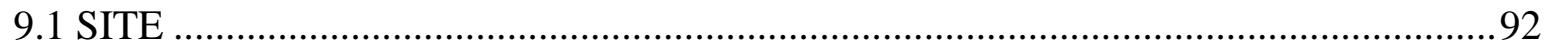

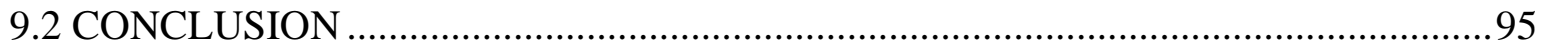

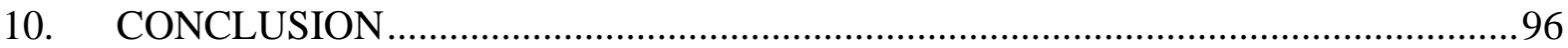

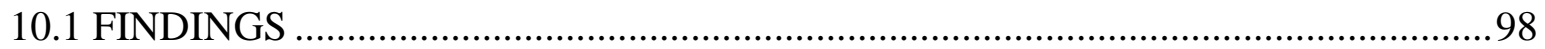




\section{Table of Figures}

Figure 1: Methodology ...................................................................................................6

Figure 2: Colour wheel showing Tint, Tone and Sade; reprinted from (Cartwright, 2018 ) ....9

Figure 3: Brigade Parkside Retirement home; Reprinted from Archdaily.............................27

Figure 4: Essie Summers Retirement Village; Reprinted from Google images ......................28

Figure 5: Shinjuen nursing home; Reprinted from Emmanuelle moureaux architecture +

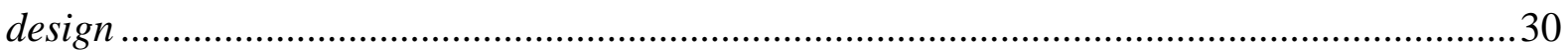

Figure 6: Rosebank Village; Reprinted from Rosebank village website .................................. 31

Figure 7: EPMS Marie du Merle; Reprinted from Archdaily and EPMS Marie du Merle website

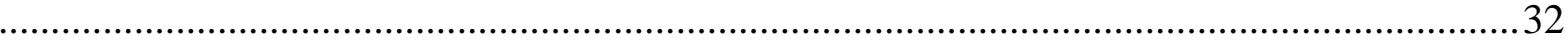

Figure 8: Possum Bourne Retirement village; Reprinted from village guide .......................... 33

Figure 9: Interior view; reprinted from Sprott house Karori website ...................................... 39

Figure 10: Figure showing site location, orientation and surroundings ............................... 40

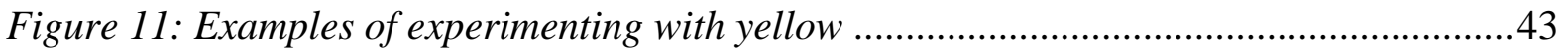

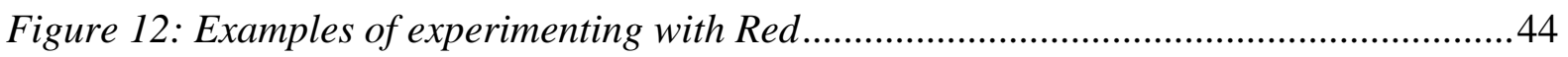

Figure 13: Examples of experimenting with Orange .......................................................... 45

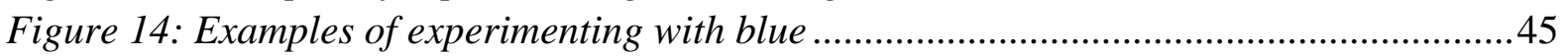

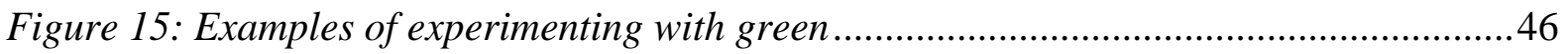

Figure 16: Examples of experimenting with purple ........................................................... 46

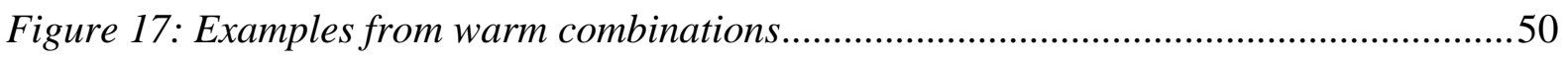

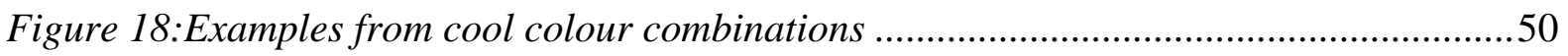

Figure 19: Examples from warm and cool colour combinations ........................................51

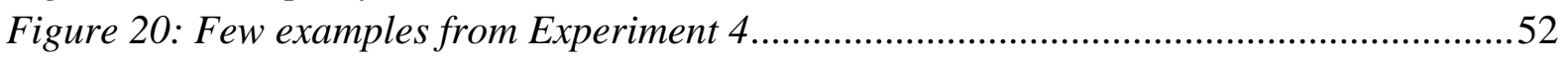

Figure 21: examples from combinations of warm colours to an aging eye...............................55

Figure 22: Examples from warm-cool combinations to an aging eye .....................................55

Figure 23: Examples from cool colour combinations to an aging eye .....................................56

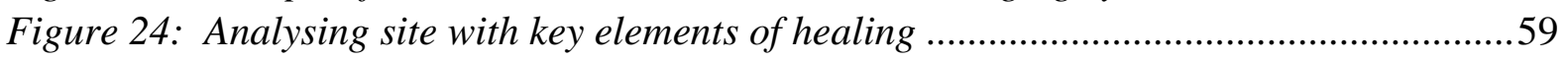

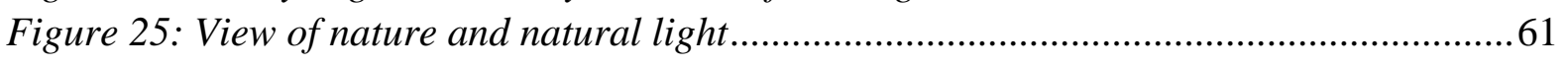

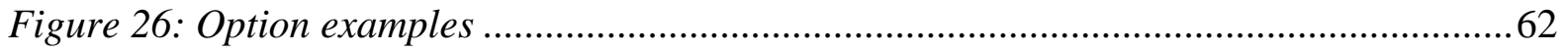

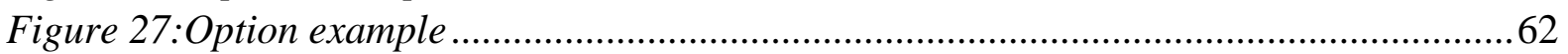

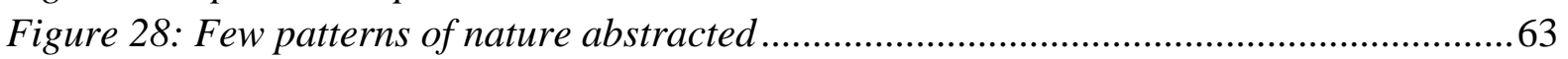

Figure 29: Example of abstracted patterns of wood used as a wall feature and .....................64

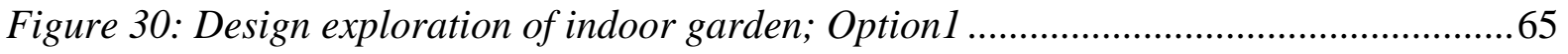

Figure 31: Design exploration of indoor garden; Option 2 .................................................. 65

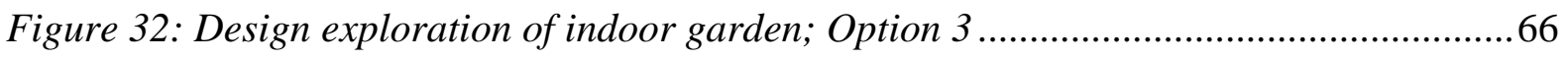

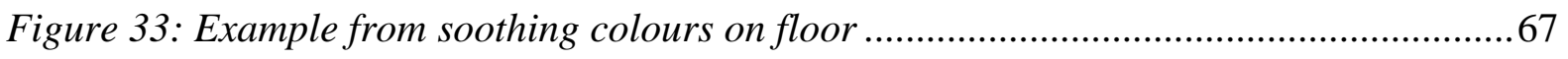

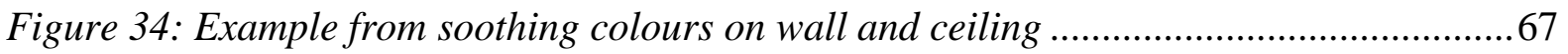

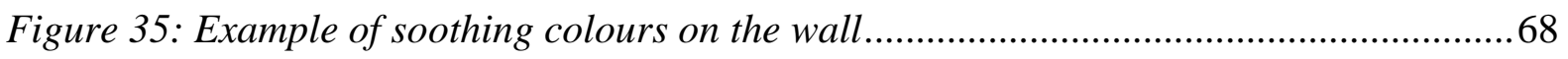


Figure 36: Snapshot of design explorations with colours promoting.....................................69

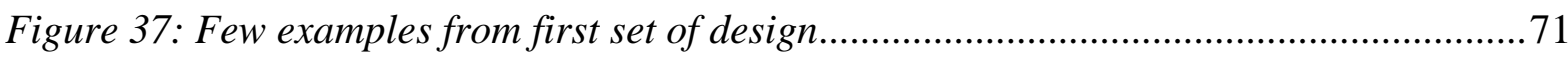

Figure 38: Selected design from first set of design exploration ............................................ 72

Figure 39: Examples from second set of explorations considering patterns of nature........... 73

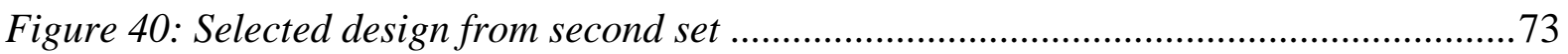

Figure 41: Examples from third set of explorations considering zoning of space ................... 74

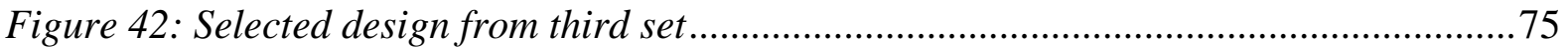

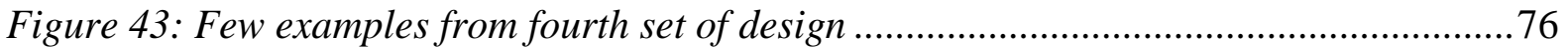

Figure 44: Selected design from fourth set; colours from the roof ....................................... 77

Figure 45: Selected design from fourth set; Colours from the glass wall ............................... 77

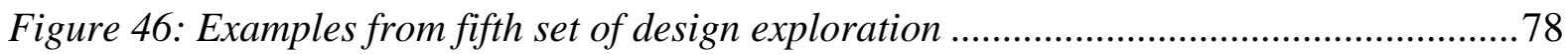

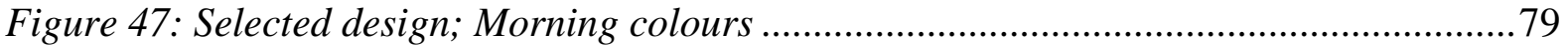

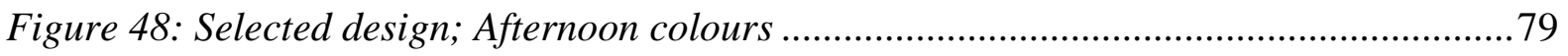

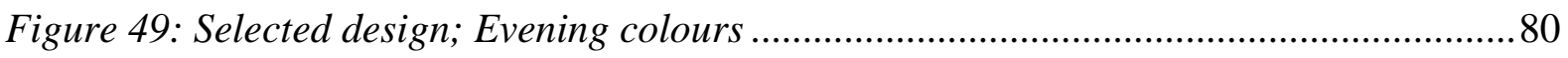

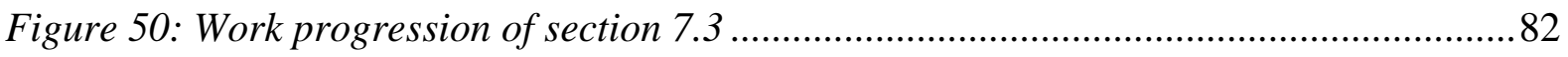

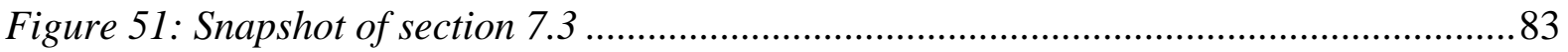

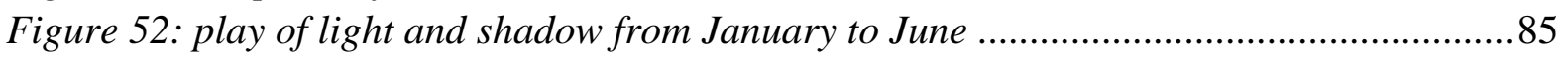

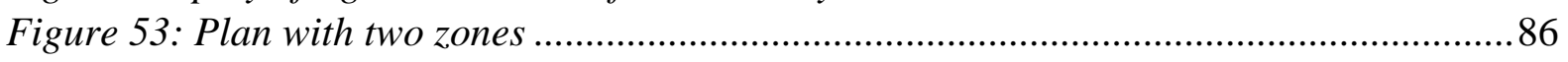

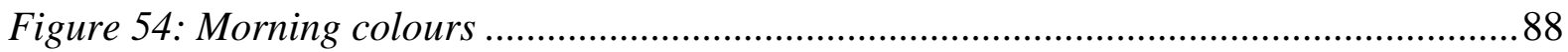

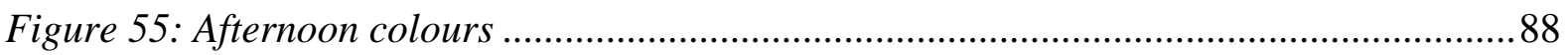

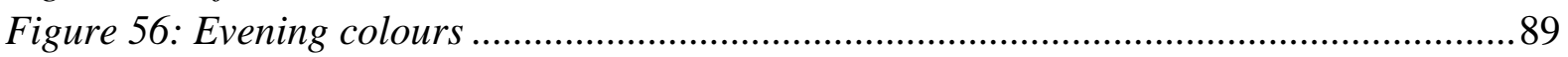

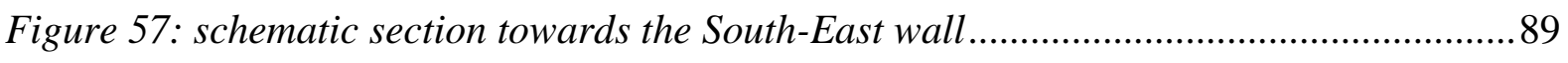

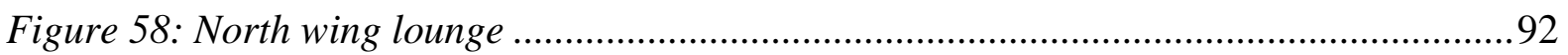

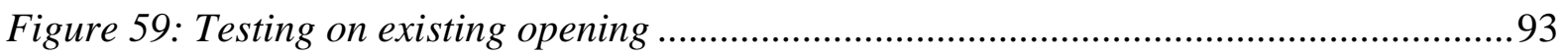

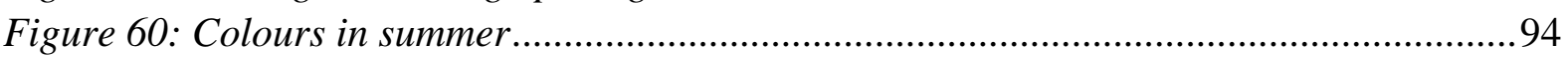

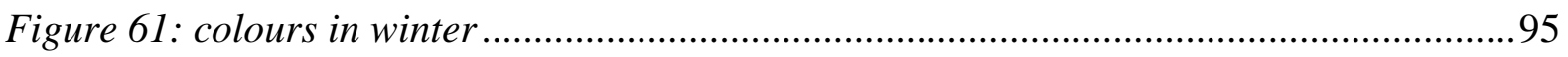


A retirement village can breathe new life and a sense of community into old bones. New Zealand retirement village database 2016, estimate there will be demand for an additional 1,654 retirement village units every year in New Zealand between 2016 and 2043 (Collyns, New Zealand Retirement Village Database (NZRVD) November,2016, 2016). According to Retirement Village Association New Zealand, about 13.5 percent of over 75-year olds lived in retirement villages in 2017, compared with 9.8 percent in 2008 (Edmunds, 2018). A recent article by Stuff compared the population of retirement villages as equivalent to that of Gisborne: 40,000 people call retirement villages (Collyns, 2019).

Baby boom generation is just beginning to reach their golden years. Today's seniors are more independent active and staying on trend than their predecessors. Just because they have retired does not mean they want to slow down. Rather, many in this generation want to stay active and social. "Nonetheless, boomers seem determined to prolong their adolescence and resist the future" says Mackay (1997) (as cited in Hamilton \& Hamilton (2006)). There is a sense of a generational shift, and everybody seeks an environment for life's golden age to be fascinating, interesting and vibrant.

Yet, many of the currently available retirement spaces seem visually unexciting or possibly even dull. To improve this, a range of interventions could theoretically be possible. However, this project chooses to examine opportunities for interventions using colour as the primary focus. On that basis, this thesis proposes that colour can provide an important role in creating visually more exciting spaces. After all:

“Colour is a power which directly influences the soul." -Wassily Kandinsky (Kandinsky, 2012, p. 25)

Just like colours of nature or a painting creates certain reactions in mood, so too the colours of the interior environment can deeply influence the mood of the people who use it (Cao, 2019). It is proven according to various researches that colours surrounding us on our daily lives greatly influences our mood, emotions and wellbeing (Amber, 1980) ( Jalil, Yunus, \& Saidc, 2012). People see the world around us through colours and colours can carry meaning. Colour is capable of enriching our environment and to add beauty and excitement to the objects around us (Tofle, Schwarz, Yoon, \& Max-Royale, 2003). Moreover, it is linked to psychological, physiological, and social reactions of human beings, as well as aesthetic and technical aspects 
of human-made environments (Dalke \& Matheson, 2007). Therefore, colour can be a powerful device in the built environment.

In addition to this general importance of colour in spaces, colour has higher importance to older people (Moghadam \& Reza Mirzaei, 2017). Human surveys, anatomic studies and scientific evidence demonstrate that visual processes diminish naturally with the age (Cooper, Gowland, \& Mcintosh, 1986). Therefore, older people see the world around them differently, and consequently designing spaces for older people requires designers to see colour in a different way within the context of retirement villages, the latest fashion trends in colour are less important than creating a coloured healing environment that will stand the test of time.

Similar views have been expressed by a number of relevant authors in this area:

"Colour has the potential to change spaces into interesting environments, to add stimulation in an otherwise monotonous space, and can even manage navigation or orientation for people with dementia" (Dalke \& Matheson, 2007).

"Empirical evidence suggests that the functional level of the institutionalized elderly is favourably affected by enriching the environment with the specific use of colour and light." (Cooper, Gowland, \& Mcintosh, 1986).

Therefore, colour is not only powerful design tool which can profoundly influence the experience of interior environments, but also colour constitutes a major role in the relationship between elderly and their surroundings. This thesis brings those notions together, by investigating how to use the colour most effectively in the interiors of the retirement homes in New Zealand. This research proposes spaces of a retirement home can become more interesting and stimulating through the use of colour, and that a simple colour redesign the common shared areas could achieve this.

This is an especially important area of study, because as the analysis in section 4.1 shows, interiors of the retirement homes in New Zealand tend to use very little colour, missing out on the opportunities to more actively engage with the colour design. This thesis develops a set of possible design interventions, which can be used for direct real-life benefits in the existing retirement homes. 


\subsection{RESEARCH QUESTION}

Can colour drive design interventions to create healing and comforting interior environment in retirement homes?

\subsection{RESEARCH AIM}

- The main aim of this thesis is to explore opportunities for creating healing and comforting environments in retirement homes using colour.

\subsection{OBJECTIVES}

1. To study what colour can do to support the aging eye and needs.

2. To study how colours can stimulate the emotion of people in space.

3. To design spaces which encourage users to be active and social.

4. To develop new approaches to design focused on colour driven design.

\subsection{DESIGN METHODOLOGY}

This thesis structure follows a design through research approach. Utilizing the University library and other online searches of existing bibliographies and databases in multiple disciplines, systematic research was conducted. In addition, resources from colour industries that are available to the public are examined to the possible extent. Existing literature with evidence-based theories are examined, to support design implications for the use of colours in retirement homes and to give a strong basis for using colour according to the colour psychology. An interdisciplinary literature review about psychological and physiological impacts of colour, impacts of individual colours on people, colour and elderly and elements of healing were undertaken. This helped to choose colours according to the function of the space and the characteristics of the users: older people in social spaces of retirement homes. From the literature review four key elements of healing in terms of colour were identified as reported on chapter 3. 
Concurrently with the literature review, a series of design experiments were undertaken. These are reported on in chapter 6 , and used watercolour, scaled physical models and digital explorations to study how colours influence different mood and possibly meaning when applied on different surfaces. Some of the explorations aimed to understand how aging eye effects colour vision.

In order to further develop the design approach, a specific site was introduced. Key design elements of healing in terms of colour identified in the literature review were used to evaluate existing site and also these give a basis to the design process. A range of design explorations specific to the site were undertaken to explore different possible approached to introduce colours into the space. (See chapter 7)

The first set of site-specific design explorations (see section 7.2) was based on how to increase the elements of healing within the specific site. The second set of design explorations (see section 7.3) considered natural light is as the main design element to bring in colours. In section 7.3 different ways of bringing in colours through coloured glass is explored.

Throughout the process, the additional literature review and design experiments helped refine and evaluate the process. In this project, due to time limitation, the experiments and explorations were evaluated based on personal observations and analysis informed by the reviewed literature. The study could be improved and taken one step further by engaging a participatory method for the final evaluations and conclusions. 


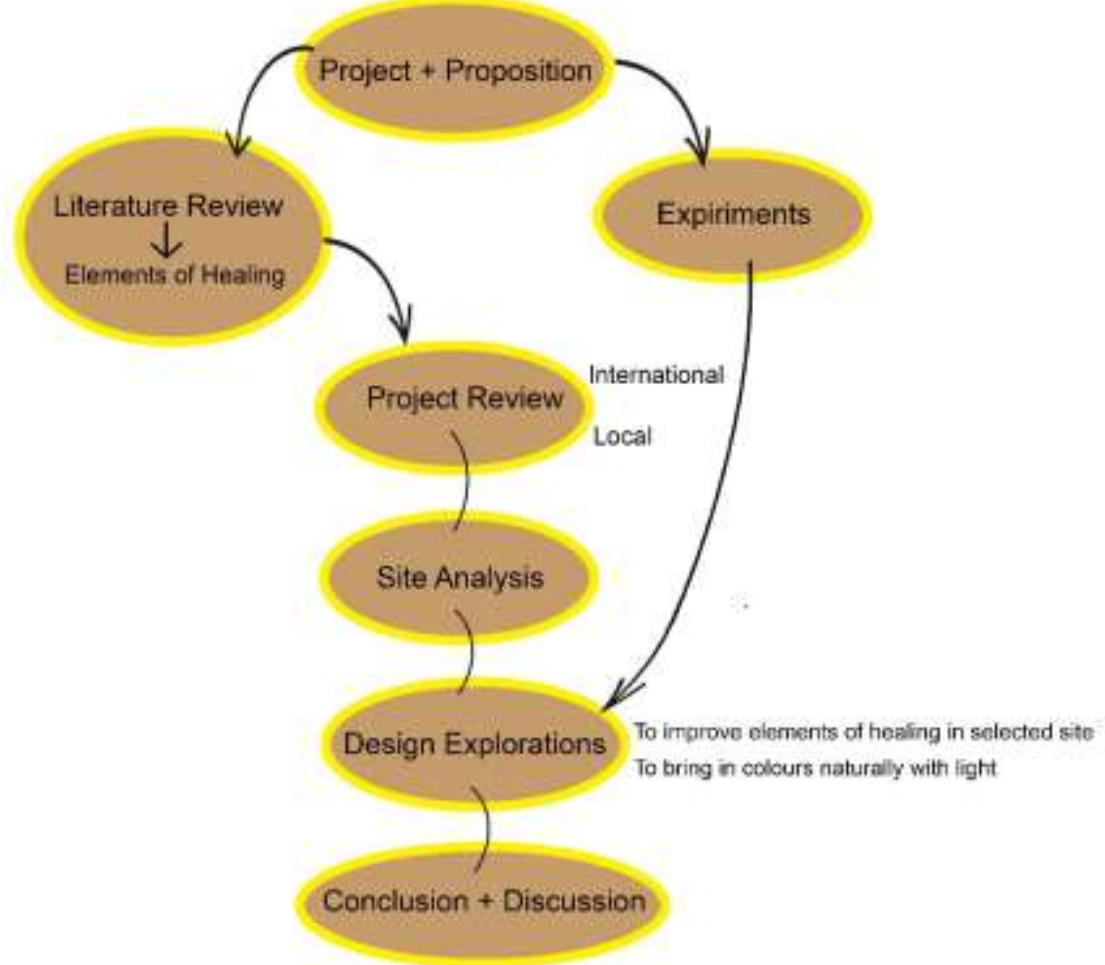

Figure 1: Methodology 


\section{LITERATURE REVIEW}

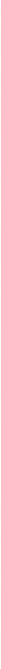

$7 \mid \mathrm{P}$ ag e 


\subsection{COLOUR BASICS}

\subsubsection{THE PHYSICS OF COLOUR}

Scientifically, colour is defined as "a specific visual sensation produced by visible radiation, or colour stimulus that occurs when light from a natural or artificial source is interrupted by an object or a dust particle” (Meervein, Rodeck, \& Mahnke, 2007, p. 4). According to its definition in physics colour is how our eyes and brain read different wavelengths of light when it is reflected from an object. The perception of colour depends on the colour light, the surface of the material, but also the health and age of the viewer's eyes and our brain functioning.

All colours have three dimensions: hue, saturation and value (Tofle, Schwarz, Yoon, \& MaxRoyale, 2003). Hue is the attribute of the colour by which it is distinguished from another colour. Saturation is the purity or intensity of a hue (sometimes it is called chroma). Value is synonymous with the lightness or darkness of the hue (Tofle, Schwarz, Yoon, \& Max-Royale, 2003). Saturation is also related with tints. Raskin (1986), explains while adding white to a colour decreases its saturation and produces a tint" and "adding black to a colour decreases its brightness and produces a shade". Tone is slight darkening a colour by adding grey.

Red, yellow and blue are the basics of all colours known as primary colours. All other colours can be obtained by mixing these colours, but it is impossible to create these colours by mixing other colours. Secondary colours are the colours that are formed by combining any two of the three primary colours listed above. There are three secondary colours: orange, purple, and green. Tertiary colours are created by mixing a primary colour with secondary colour. There are six tertiary colours. Their names reflect the colour combinations, "blue-green", "redorange", "yellow-green" etc. White, grey and black are considered to be achromatic colours these are considered as colours without hue (Raskin, 1986). 


\section{This content is unavailable due to copyright issues}

Figure 2: Colour wheel showing Tint, Tone and Sade; reprinted from (CARTWRIGHT, 2018 )

\subsubsection{COLOUR WHEEL}

The colour wheel or colour circle is the basic tool for combining colours. The first circular colour diagram was designed by Sir Isaac Newton in 1666 and ever since it has been used and further developed by artists and scientists. When choosing colours for a colour scheme, the colour wheel gives opportunity to create brighter, lighter, softer, and darker colours by mixing white, black, and grey with the original colours (Cartwright, 2018 ).

On that level, the colour wheel can be seen as a road map for understanding colour combinations and how the human brain processes these combinations (Color Theory $\&$ Interior Design, 2016). There is a wide range of colour combinations available in the colour wheel.

By using the colour wheel principles, it is possible to articulate some core basic approaches to developing colour schemes. Monochromatic colour scheme is the use of only one colour, colour and add white, black, or grey to create various hues. Analogous colours are pairing of three colours that sit alongside one another on the colour wheel. Red-violet, violet, and blueviolet is one example. Complementary colours use hues which are directly opposite to each other in a colour wheel example: green and red. Choosing two complementary colours creates an energizing, high-contrast colour scheme (Palermo, n.d.) 
Split colours scheme is developed by selecting a colour, and the two colours that are adjacent to its opposite in the colour wheel. Such colour schemes are also energizing but with a higher level of interest, and a less explicit colour contrast. A triad colour scheme is made up of any three colours evenly spaced on the wheel. This colour scheme creates a vivid contrast, but it's balanced, so it feels a little less intense than a complementary colour scheme (Palermo, n.d.).

Another important feature is that colours on the colour wheel are roughly divided into cool and warm colours and this can be used to create a mood in a room. Blue, greens and purple are cool colours whereas red, orange and yellows are warm colours. Warm colours evoke feelings of activity and passion, and perhaps even anger where as cool colours are associated with calm, harmony, and peace, but also lassitude, inaction, and sadness. Using a warm colour in a tight room could make things feel a little claustrophobic. However, using cool colours in a spacious room could leave things feeling stark. (Mastroeni, 2014)

Greys, beiges, browns, whites and back are non-colours. They are not found on a colour wheel but in real life and in design these are important.

Understanding the physics of colour and the core principles of the colour wheel is important for any work with colour. Throughout the history of design, these principles were given greater or lesser theoretical importance, although the core principles summarised where still apply even when artists and designers attempt to challenge rules of this kind.

\subsection{PSYCHOLOGICAL AND PHYSIOLOGICAL IMPACTS OF COLOUR}

Colour is always present in design, and it plays an important role in all design, regardless how much of an active focus was attributed to it in the design process. Colour attracts attention, helps people make sense of their environments, and affects mood and behaviour (Martinson \& Bukoski, Implication: Seeing colour, 2005). Neuropsychologist Kurt Goldstein confirmed in his classic, The Organism, the skin reads colour, and our bodies, minds, and emotions respond (Cerrato, 2012). Helvacioğlu, (2011) also explains that colour pervades all aspects of the human body, mind, spirit, and emotion. It can be used to create a space which evokes desired mood and emotions or to create a distinct style, or a unique look. Colour presents has a set of physical and psychological characteristics which design should include into their considerations. 
Colour is closely linked to psychological, physiological, and social reactions of human beings, as well as aesthetic and technical aspects of human-made environments (Tofle, Schwarz, Yoon, \& Max-Royale, 2003). "Colours are different from each other and have their own meaning. Many psychiatrists and psychologists have noted that reactions to colour are more impulsive and emotional." (Birren, 1988). On this level, colour plays a major role in the relationship between people and their surroundings.

Understanding and application of colour psychology is very important when designing interior spaces. This is especially the case because each colour and colour combination have its own sensation (Helvacioğlu, 2011). Individual or in relation to each-other, colours have a potential of becoming eye irritants and can even causing headaches. On the other hand, appropriate use of colours "can maximize productivity and relax the whole body" (Shehata, 2000). "It can affect our brain waves, heart rate, blood pressure, and respiratory rate. Colour also affects us emotionally" (Martinson \& Bukoski, Implication: Seeing colour., 2005). Martinson \& Bukoski also states that "exposure to colour has an effect on our biological systems." Others advocate that "visual enhancement by selective use of colour can minimise adverse effect of sensory deprivation and enhance mood, and colour coding and cueing can minimise the adverse effects" (Cooper, Gowland, \& Mcintosh, 1986).

This review shows that there is a substantive body of works agreeing that colour can have beneficial impact on psychological and even physiological wellbeing of people. However, because of the real differences different colours or colour combinations can present, it is important to understand the potential influence of many colours.

\subsection{IMPACTS OF INDIVIDUAL COLOURS ON PEOPLE}

Different colours give off different wavelength frequencies, and these different frequencies have different effects on us (Cerrato, 2012). In this section impacts of primary and secondary colours on humans are discussed.

\subsubsection{RED}

Red is one of the primary colours. "Red is the first 'real' colour with a defined wavelength. It is the third term that emerges in language after white and black" (Petru, 2006) Red stands for energy, war, danger, strength, power and determination, But also passion, desire and love (Pomroy, 2017). Red is considered the physical colour; it has the ability to raise pulses and create the illusion that time is passing faster than it is (Elements of design part 2: Colour, n.d.). 
Red can also alleviate depression. (Olesen, n.d.) In the research paper colour in healthcare environment (Tofle, Schwarz, Yoon, \& Max-Royale, 2003) author says that red colour possesses arousing nature.

Red may include hues of all reds, and hues from the range of oranges, most yellows, browns, pinks, and even purples (Petru, 2006). Red becomes pink when it is reduced to a tint and loses some of its saturation and psychological intensity (Petru, 2006). Pink is associated generally with positive emotions. It can be used to create feel good atmosphere. It signifies romance, love and friendship (Pomroy, 2017). Red increases adrenaline and elevates blood pressure-so avoid using it when the patient is suffering from hypertension. (Olesen, n.d.) It is not advised in area oriented to relaxation. Red can also shorten tempers and increase irritability. (Craig, 2015)

Red stimulates conversation and creates a strong impression (Watson Smyth, 2018, p. 26) (Pomroy, 2017) (Bryant, 2018, p. 2). It enhances human metabolism (Cerrato, 2012). It is also said by colour psychologists that red induces appetite (Elements of design part 2: Colour, n.d.). Therefore, it is a good option for areas related to food and areas requires high energy or in a room which needs to stimulate conversation.

According to Tara Rae Hill, "based on numerous studies by Drs. Morton Walker, Gerard and Faber Birren, the link between colour and physiological response has been well documented. Their research demonstrated that an individual's pituitary gland sends signals to the adrenal gland and adrenaline is released when exposed to red (Hill, 2008).

\subsubsection{YELLOW}

Yellow is the brightest colour of the visible spectrum, and it is the most noticeable of all colours by the human eye (Bryant, 2018, p. 10). Yellow is a colour connected with joy, optimism and energy it is very vibrant colour, warm and welcoming colour (Bryant, 2018, p. 10). Therefore, it is a good option for entrance halls. Yellow is the best colour to boost enthusiasm with greater confidence and optimism (Bryant, 2018, p. 10). Yellow is known as the colour of knowledge and it is connected to the logical side or the left side of the brain, stimulating mentality, new ideas and work out mental challenges (Watson Smyth, 2018, p. 35)

Overuse of yellow can lead to disturbed mind. Yellow reflects more light and excessively stimulate a person's eyes which can lead to irritation. Intense yellow can make people cranky. 
Dull or dinky yellow represents yellow represents caution, decay, and jealousy and it is rarely used in interior rooms (Pomroy, 2017)

Yellow is a good option for kitchen and dining as it increases appetite. It can be used in hall ways as it is a welcoming colour

\subsubsection{ORANGE}

Orange is the feel combination of red and yellow is a mixture of the energy associated with red and the happiness associated with yellow (Bourn, 2011) (Cerrato, 2012, p. 6). It is a warm and welcoming colour that is both physically and mentally stimulating (Fiore, 2010). It makes people think as well as speak as well as increases appetite. Even though orange have similar properties like that of red, it is more subtle than red. Orange will help a person recover from disappointments, a wounded heart, or a blow to one's pride (Bourn, 2011). "Studies show that the orange colour can create physical effects such as increased hunger, heightened sense of activity, increased socialization, boost in aspiration, stimulated mental activity, increased oxygen supply to the brain, increased contentment, and enhanced assurance. Orange also helps aid decision making, and enhances happiness, confidence, and understanding" (Bourn, 2011). Orange increases oxygen supply to the brain, produces an invigorating effect, and stimulates mental activity (Cerrato, 2012, p. 6). Karen Y. Bryant in "The colour Book" says that most "researchers believe that the colour Orange is related to our intuition and provides emotional strength in our difficult times, thus helping us through despair, disappointments and grief." (Bryant, 2018, p. 17)

Like red different shades, tints, or tones of oranges convey different meaning for example when light orange is soothing and friendly dark orange represents deceit and distrust. Golden orange is for wisdom, wealth etc. Red orange represents aggression, craving, passion, supremacy etc

On other hand too much orange causes self-centred and self-serving qualities, including pride, arrogance, and lack of care for others. Too little orange causes loss of motivation, lower selfesteem, and loneliness. (Bourn, 2011). Bright orange adds warmth and adventure, but can be overpowering if used excessively (Pomroy, 2017)

\subsubsection{GREEN}

Green is the colour of balance and harmony (Cerrato, 2012, p. 9). It is the colour of nature. Considered the most restful colour for the eye; It can improve vision (Cerrato, 2012, p. 9). Green can transcend a sense of calmness and security when used in interior design (Pomroy, 2017). Green is soothing, relaxing, and youthful - and is believed to help alleviate anxiety, 
depression, and nervousness (Silva, n.d.). Green can help enhance vision, stability and endurance (Fiore, 2010, p. 165). Green takes up more space in the spectrum visible to the human eye and it is the dominant colour in the natural (Bourn, 2011). Both green and blue samples were favoured for calmness, peacefulness, relaxation, and modernism according to the research conducted by Manav Banu among fifty people from various age group (Manav, 2007)

Interior designer, Shannon Kaye, says, "You can decorate an entire room with greens and have contrast, drama, richness, and balance. It's so versatile." (Pomroy, 2017). It can be used any part of the home to crate relaxing area.

Too much green can cause people to become placid, lazy, slow, moody, depressed, and lethargic at the same time too little green can cause feelings of apathy and fear of rejection (Bourn, 2011). Some shades of green are also associated with boredom, fearfulness, mystery, tiredness, anxiety, and depression (Manav, 2007).

\subsubsection{BLUE}

Blue is the world's famous colour (Watson Smyth, 2018). It is the colour of sky and water. Blue is considered to be a beneficial to the mind and body (Fiore, 2010). The positive characteristics of blue are that has exceptional healing powers, and its calm restful nature can act as a potent sedative, making it a good colour for anyone with sleeping difficulties (Oakey, n.d.). Blue is strongly associated with tranquillity and calmness (Cerrato, 2012). It is an ideal colour for areas meant for relaxation like bedrooms or meditation hall and to calm people under stress. Light or pastel blue can create tranquillity and is associated with health, healing, understanding, and softness, but can come across as 'chilly' on the walls in a room that receives very little natural light (Pomroy, 2017). Blue slows down human metabolism and produces a calming effect (Fiore, 2010). It also slows down heart rate (Bryant, 2018).

Blue is also an appetite suppressant (Fiore, 2010) (Bourn, 2011). So, it is not advisable in dining area. Too much blue can encourage boredom (Cerrato, 2012). It should be avoided by any that suffers from depression or sadness and avoided by anyone that is troubled by the cold and it is not a good colour for playrooms or an area that you want to create a motivating atmosphere (Oakey, n.d.). In some reserches certain colours such as green or blue for mental healthcare has produced results that showed these colours may worsen depression (Dalke \& Matheson, 2007).

According to Tara Rae Hill, when exposed to blue, an individual's brain secretes hormonal neurotransmitters that have a tranquilizing (Hill, 2008). 


\subsubsection{PURPLE}

Visually, purple is one of the most difficult colours to discriminate for old people it seems to be grey after age 70 (Brawley, 1997, p. 110). Purple combines the calm stability of blue and the fierce energy of red (Cerrato, 2012) (Bourn, 2011). Purple is associated with wisdom, dignity, independence, creativity, mystery, and magic (Cerrato, 2012). It is the perfect blend of stimulation and serenity (Cavallaro, 2017, p. 192). Therefore, it retains both warm and cool properties. Purple is known to be calming and soothing like all other cool colours (Bryant, 2018, p. 6). As it connects the mind, body and spirit it's a good colour for meditation areas or relaxation rooms (Oakey, n.d.) Lighter values of purple, such as lavender, can add a restful quality to a bedroom without the risk of being chilly (Colour solutions, 2003) (Pomroy, 2017) Purple, in its darkest values, is dramatic, rich, and sophisticated (Colour solutions, 2003, p. 68). It can give a design scheme depth and is associated with luxury and creativity (Colour solutions, 2003) (Pomroy, 2017)

\subsection{COLOUR AND ELDERLY}

\subsubsection{COLOUR AND AGING EYE}

As people age, their visual decline affects their reading of colour. A study in Optometry and Vision Science, the official journal of the American Academy of Optometry reports that "abnormal colour vision increases significantly with aging, affecting one-half or more of people in the oldest age groups. These changes effect acuity, speed of adaption changes in light, quality of light received by retina, and a verity if perceptual abilities, including figure ground confusion, decreased spatial abilities, loss of brightness and contrast sensitivity, diminished colour discrimination etc" (Wilkins, 2014). ." As a result of all these changes, elderly people's productive visual interaction with environment is reduced.

Thickening and yellowing of lens is one of the major age-related problem. This creates a filtering effect by reducing the number of short-wave lengths (blue) entering the eyes (Cooper, Gowland, \& Mcintosh, 1986). As the lens becomes increasingly yellow and less transparent with the age this effects the visual colour perception and contrast of colours.

Colours with short wavelengths such as blue are particularly difficult for older people to discriminate. Designers therefore need to pay attention to tonal contrast rather than colour contrast when designing for the elderly (Niki, 2011). Similarly, "ageing eyes gradually lose 
the ability to distinguish between similar colour tones, for example between blues and greens or pinks and reds." (Kelly, 2011)

Change in pupil size is another problem noted. The size of our pupils become smaller with age. "The muscles that control our pupil size and reaction to light lose some strength. This causes the pupil to become smaller and less responsive to changes in ambient lighting". (Eifler, 2011). This also reduce the ability to discriminate between colours and surroundings look dimmer (N.Gohar, 2009). This can be solved by ambient lighting and designing with bright colours, these colours bounce back more light than dull colours.

\subsubsection{COLOUR INTERVENTIONS FOR ELDERLY}

Gohar undertook research on colour and use of colour in the environments of elderly and disabled people and found that colour can be used as a design tool for improvement of vision, sight and clarity of the environment, improvement of spatial orientation, memory enhancement, mood enhancement, enhanced ability to function independently in the living environment (N.Gohar, 2009). He identified four main interventions in colour for improving these factors: colour contrast and colour cueing, use of bright colours, colour coding and selective use of colour. For this investigation it is useful to review each of these.

\section{COLOUR CONTRAST}

Colour contrast in one of the major factors which determines the clarity of visual stimuli. Colour contrast is the relation between adjacent colours. It is the ability to differentiate the dark and light areas. Enhancing the contrast between the object and its background is the simplest and effective way to make an object more visible.

Rules to create colour contrast were established for artists by Itten while he was teaching at the Bauhaus (Cooper, Gowland, \& Mcintosh, 1986). According to Itten colour contrast can be achieved by using:

1. Contrast of hue: It is the contrast between the identified spectral colours such as contrast between red and yellow

2. Contrast of Light and dark: This contrast is created when tints and shades are next to each other. For example, contrast between red and pink. Dark hues are analogous to black and white to light.

3. Cold-warm contrast: when warm colours are placed next to cool colours cold warm contrast is achieved. For example, red and blue. 
4. Complementary contrast: contrast formed by complementary colours in a colour wheel. Example green and red.

\section{COLOUR CUEING AND CODING}

A viewer makes an associate between an object and a colour when it is consistently seen together. This association is called coding. Colour that flags without causing association can be used for cueing (Cooper, Gowland, \& Mcintosh, 1986). Colour cueing can help the elderly in distinguishing the various environmental elements (N.Gohar, 2009). According to Gohar effective colour cueing largely employs principles of contrasts.

\section{USE OF BRIGHT COLOUR}

Bright colours are generally the easiest to see because of their ability to reflect light. "Applying bright colours in health care environments to help create a friendly environment, lift spirits, enhance patient's way finding and spatial orientation abilities and stimulate the patient's sense of sight" (N.Gohar, 2009). Older people may prefer pastel colours but colour may not be bright enough to stimulate the mind and mood. For interiors Arditi (2005)specifically proposes bright colours especially the mid spectrum colours from the colour wheel and she also propose pale or dark colours in restricted areas (E.g. staff areas, exits) or to prevent patients from wandering. (Arditi, 2005)

\section{SELECTIVE USE OF COLOUR}

Colour preference is very important factor to be considered while designing for any particular age group of people. It is possible to notice changes in the colour perception and preferences of people as they get older. "In a study conducted by Mather, Stare, and Brenin (1971) the colour preferences of the elderly patients were blue, red/green and yellow respectively. The preference for the colour blue has also been determined in a study conducted on 80-year-olds by Wijk, Berg, Sivik, and Steen (1999). Red/green colour choice ranked first in another study conducted by Dittmar (2001)" (Colour preference in the elderly, 2017) .

It is a commonly known fact that people can feel better if they are in a preferred and known environment similarly people feel better and may attend better to a cue if it is in a favoured colour rather than a less preferable one. Moreover, people may have certain colour associations, this can be used for colour coding and cueing as a means of creating desired atmosphere (N.Gohar, 2009). 
It is known that visual enhancement by selective use of colour can reduce adverse effects of sensory deprivation and can enhance mood (Cooper, Gowland, \& Mcintosh, 1986). In turn this improve productive interaction with environment.

This shows that understanding what colour means to elderly and how colour vision changes with aging eyes is very important part to be considered while designing for elderly. These colour interventions are very useful and are to be considered as an integral part while designing for aging eyes.

\subsection{HEALING AND COMFORTING ENVIRONMENT}

Winston Churchill concisely expressed the effect of architecture and our surroundings with the comment that: "We shape our buildings and later they shape us" (Judd, 2008). Although colour has a powerful influence on experience of interior spaces, a range of other aspects also contribute. It is known that views of nature, natural light, soothing colours, therapeutic sounds, and the interaction of family members can enhance healing (Altimier, 2004) (Stichler, 2001)

\subsubsection{THE IMPACT OF NATURAL LIGHT AND NATURAL ELEMENTS ON HEALING}

The study published in Science magazine in 1984 showed that when hospital wards looked out to nature the patients healed faster (Keystone, et al., 2018, p. 371) It was modernist architect, Roger Ulrich who performed the experiments that proved that window views could affect healing. Ulrich chose 46 patients, 23 of which had beds near windows that overlooked a landscape of trees and the other 23 looked onto a brick wall (Ulrich, 1984) (Strenernberg, 2009, p. 215). Among the many possible reasons for this healing effect: exposure to sunlight creates vitamin D, which plays a key role in boosting the immune system (Persaud, 2009)

According to Roger Ulrich "laboratory and clinical studies have shown that viewing nature produces stress recovery quickly evident in physiological changes, for instance, in blood pressure and heart activity. By comparison, considerable research has demonstrated that looking at built scenes lacking nature (rooms, buildings, parking lots) is significantly less effective in fostering restoration and may worsen stress." (Zimring, Joseph, \& Choudhary, 2004).

Similarly, in a hospital garden post occupancy study show that patients and family who use hospital gardens report positive mood change and reduced stress (Zimring, Joseph, \& Choudhary, 2004) 
Lighting is very important while designing interiors. Without a proper lighting design, human beings cannot carry out their intended activities effectively, efficiently and comfortably (Albert \& Leung, 1998). Cognitive disturbances can occur if there is a deficiency of natural light for patients (Altimier, 2004). Daylight, and bright artificial light exposure contributes to the relief of stress and the increase in physical activities for elderly patients in general (Yoo, 2015). Natural light also influences the sleep quality, In a study among 61elderly persons living in nursing home suggested that opportunities for elderly person-s to get direct sunlight exposure through institutions architectural settings and providing social opportunities can help increase the sleep quality of older persons (Düzgün \& Durmaz , 2017)

Studies such as these continue to confirm the powerful influence of nature, natural elements and natural light in recovery, stress reduction, comfort etc. Therefore, for the purpose of this project it is important that the interior designs aspire to integrate natural elements and natural light in order to create a more relaxing and create healing atmosphere.

\subsubsection{COLOUR AND HEALING ENVIRONMENT}

\section{SOOTHING COLOURS}

Although, the scientific evidence is less strong for colours, culturally, people have been trained to associate certain colours with calm. Blues and greens are deemed more soothing and environments with these colours may help reduce the stress response (Persaud, 2009). Science also proves us blue and green are colours with shorter wavelength thus it is easy to be perceived by our eyes, thus these colours are soothing and restful to eyes. "The use of cool colours that are calm from the blues or blue-greens make the residents feel at ease with a more pleasing atmosphere.” (Hurhundee \& Ramsamy-Iranah, 2017)

Tara Rae Hill says that "Evidence-based design shows a strong correlation between healing and interiors that are stimulating - spaces that are not overly neutral, have interesting use of colour, and introduce positive distractions that focus on nature and colour. The days of drab interiors that lack pleasing contrast levels and colour, or which rely on artificial lighting that can dull the senses, are increasingly considered antiquated." (Hill, 2008) 
Therefore, use of these colours in nursing homes would render inhabitants peaceful and make them feel at home.

\section{INTERACTION}

Interaction is a critically important contributor to good health and longevity. The Harvard Women's Health Watch reported, "Dozens of studies have shown that people who have satisfying relationships with family, friends and their community are happier, have fewer health problems, and live longer" (The health benefits of strong relationships, 2010). From section 2.3 it is known that certain colours can promote interaction, especially red and orange.

Red stimulates conversation and creates a strong impression (Pomroy, 2017). It is also said by colour psychologists that red induces appetite (Elements of design part 2: Colour, n.d.). Therefore, it is a good option for areas related to food and areas requires high energy.

Orange is a warm and welcoming colour that is both physically and mentally stimulating (Olesen, n.d.). It makes people think as well as speak as well as increases appetite. Even though orange have similar properties like that of red, it is more subtle than red. Orange will help a person recover from disappointments, a wounded heart, or a blow to one's pride. (Bourn, 2011)

Roger Ulrich has investigated the effects of visual stimulation and how it impacts patient recuperation rates and found that patients surrounded in "vibrant" surroundings recovered three-quarters of a day faster, and needed fewer pain killers, than those who did not." (Hill, 2008)

In conclusion, this review shows that soothing colours and colours promoting interaction could favourably contribute to promoting healing.

\subsection{SUMMARY AND REFLECTION}

This literature review aimed to use the reviewed existing knowledge to develop a recommendation of which approaches to colour could be useful for the social spaces of the elderly. In order to achieve this, the chapter reviewed the basics of physics of colour and colour psychology in relation to the colour wheel. It articulated how each colour could affect the occupant's mood and emotions. This information could be useful while deciding colours according to the function and users of a space. 
Literature review explains how effective colour could be as a means of influencing mood and function in the living environments of elderly and how important is colour for elderly. Lack of colours could reduce elderly people's productive interaction with environment and in turn this could make them less active and make them feel older. Colour have proven ability to sharpen the clarity of objects and support the elderly vision. Literature suggests the use of bright colours, contrasting colours, and preferred selective colours in order to improve vision and enhance mood of the residents.

Furthermore, this review has identified that nature and natural elements plays an important role in creating healing and comforting environment. It is also clear that colours previously considered "too bright for health care and retirement settings," are now thought to be vital relaxing tools that directly promote healing.

Based on this review, it was possible to establish three key design colour strategies for promoting healing according in retirement village context:

1) Views of nature and natural light

2) Soothing colours

3) Colours promoting interaction

These present effective means of influencing mood and function in the living environments of the elderly. Therefore, this project focuses on using this range of core strategies to enhance the social spaces for elderly. This project consists of a series of design explorations of how best to retrofit existing interiors of the living areas of retirement villages in New Zealand, to create improvements in these core strategies for promoting wellbeing. 


\section{KEY DESIGN STRATEGIES}

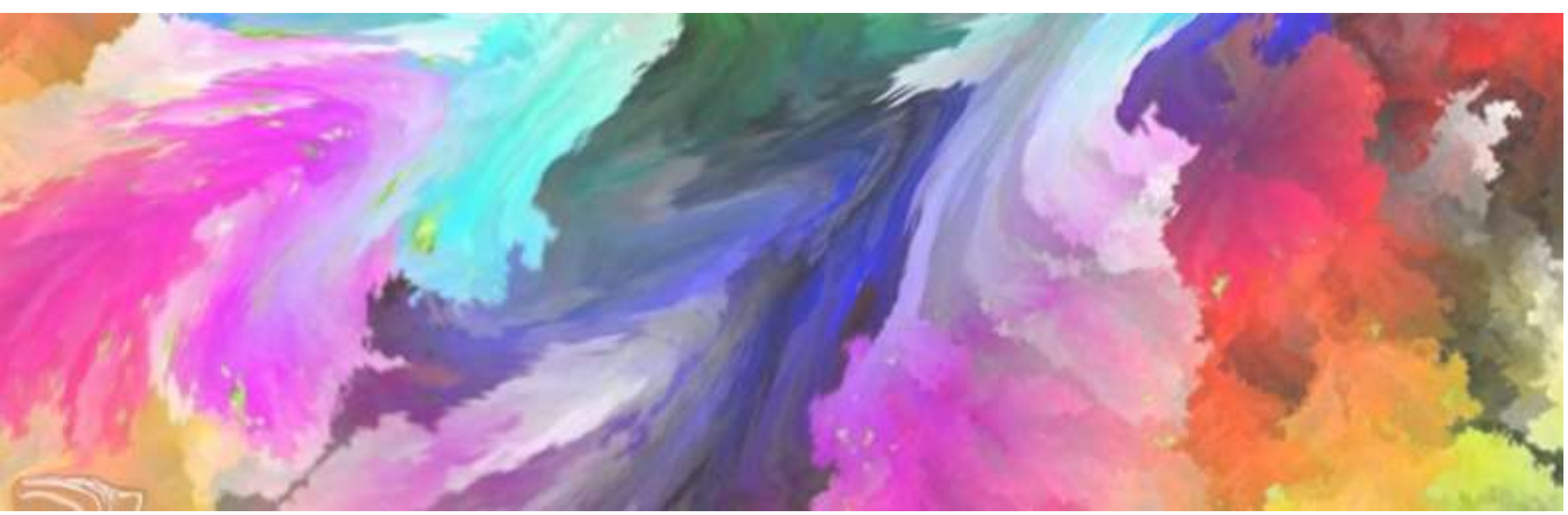

$22 \mid \mathrm{P}$ a g e 
Chapter 2 identified four key design strategies to enhance healing and to create comforting environment within interiors: View of nature, natural light, soothing colours, colours promoting Interaction.

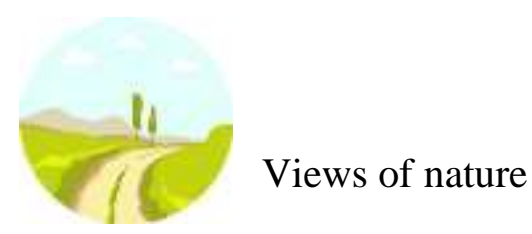

Nature is believed to have healing powers. Viewing nature have proven ability to "reduce stress, improved attention capacity, facilitating recovery from illness, ameliorating physical well-being in elderly people, and behavioural changes that improve mood and general wellbeing" (Velarde, 2007). Colours of nature are also important. Low-arousal, low-anxiety, and highly preferred colours like blue and green predominate in nature (Valdez \& Mehrabian, 1994).

Natural light

Natural light is known to have healing power, presence of natural light is proven to reduce the length of hospital stay of patients (Park, Chai, Lee, Moon, \& Noh , 2018). Exposure to natural light also related to sleep quality, and more general the amplitude of sleep-wake cycle in elderly people (Aarts, Schoutens, \& Stapel., 2006).

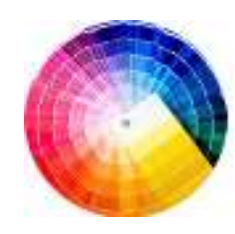

Soothing colours

Green and blue are known as soothing colours. "Green is a balancing colour and brings a feeling of renewal and new life. It affects the heart and blood pressure, as well as our emotions. Blue brings peace to the whole being, it's a vitality builder and relieves burns and fevers" ( Strawn, 1999). 
Colours promoting interaction

"Healing is a social activity; it involves interaction among people who are playing various social roles" (Gesler, 2003 , p. 14). From section 2.3 and section 2.5 it is known that colours have a potential to promote interaction; Red and Orange are the colours known to promote interaction among people.

Red reflects energy and motivate an individual to take action it can also stimulate people to make a quick decision (Othman, Elmasry, \& Shaker, 2015). Orange is said to increase supply to the brain, produces an invigorating effect, and stimulates mental activity (Othman, Elmasry, \& Shaker, 2015). It also creates enthusiasm and stimulates social conversation (Othman, Elmasry, \& Shaker, 2015), 


\section{PROJECT REVIEW}

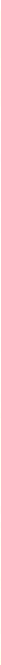

$25 \mid \mathrm{P}$ a g e 
This chapter presents and analyses the design examples which have used some of the key design strategies for promoting healing identified in the literature review.

\subsection{VIEW OF NATURE AND NATURAL LIGHT}

Throughout the century nature is believed to have a healing potential. Being in touch with nature and being exposed to greenery, flowers, sky is proved to be very therapeutic and beneficial to an older person's mental health by many researchers.

Many architects and designers around the world have considered this factor while designing for elderly.

\section{BRIGADE PARKSIDE, BENGALURU, INDIA}

Architects: Mindspace architects

Location: Bangalore, India

Year: 2018

One international example of retirement working with the elements of nature, is Brigade Parkside, Bengaluru, India by Mindspace architects. The design philosophy is working with the elements of nature, respecting the five senses and attempting to use light and air as building elements says Ar. Sanjay Mohe. 


\section{This content is unavailable}

\section{Due to copyright issues.}

\section{Figure 3: Brigade Parkside Retirement home; Reprinted from Archdaily}

Strength: In this project architect have tried to imbibe nature into the interiors. This gives a positive energy to the occupants, brings in soothing colours such naturally to the interiors as well as enable building to breathe.

Weakness: lack sense of homeliness 


\section{ESSIE SUMMERS RETIREMENT VILLAGE, CHRISTCHURCH}

Company: Ryman Healthcare

Location: Christchurch, New Zealand

Year: Unknown
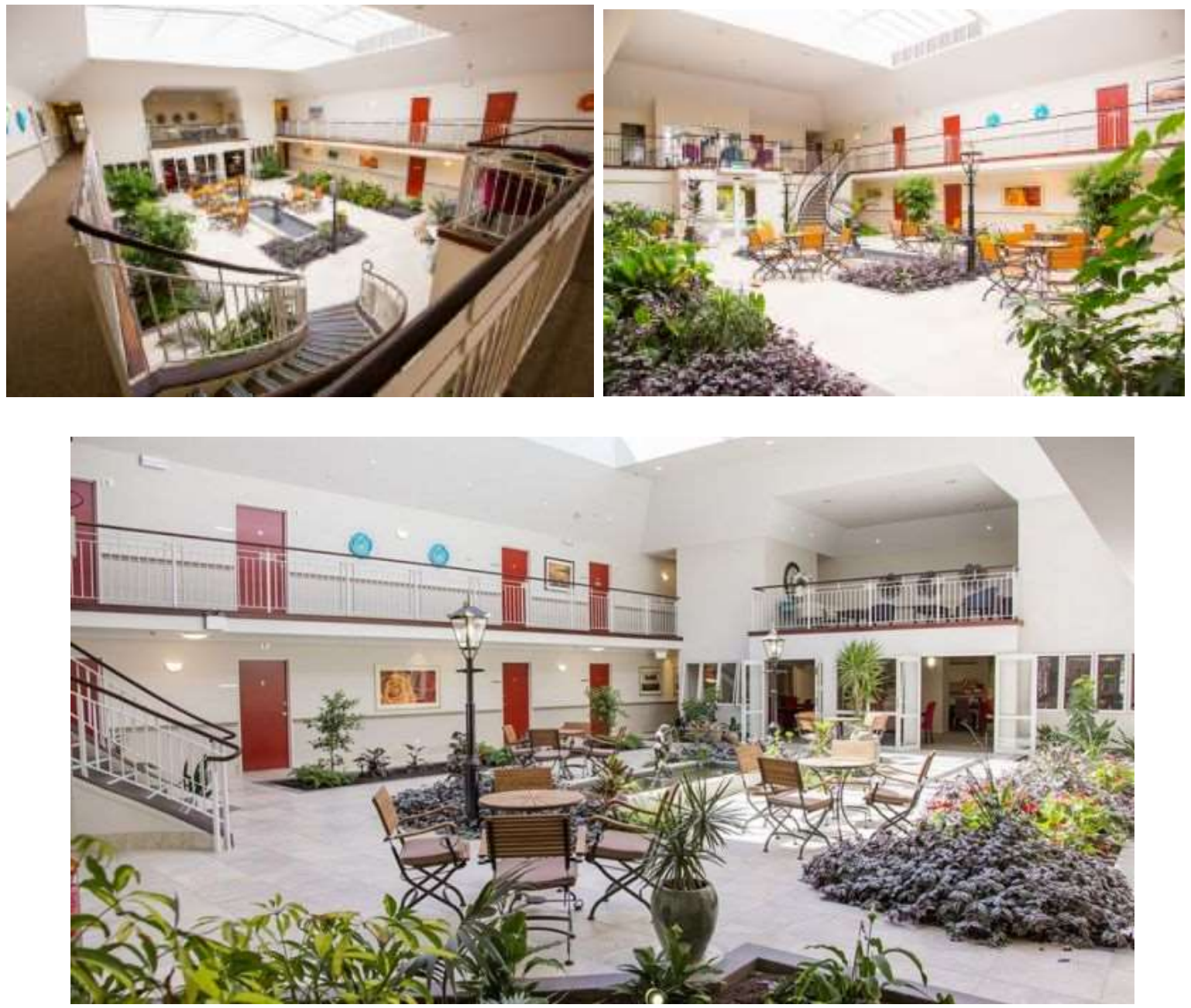

Figure 4: Essie Summers Retirement Village; Reprinted from Google images

Strength: Skylight helps to bring in lots of natural light into the space which can positively affect psychologically resulying in improved sleep, mood and behaviour. Indoor garden and water body brings in the presence of nature

Weakness: Since it is a courtyard typology it is limiting the public inteface between the residents and the outer world. 


\subsection{SOOTHING COLOURS}

\section{SHINJUEN NURSING HOME (2014), KAWAGOE (JAPAN)}

Architects: Emmanuelle Moureaux Architecture + Design

Location: Kawagoe, Japan

Year: 2014

Concept: Dancing bubbles

Above the lounge of Shinjuen nursing home, there are 225 spheres in 15 colors creating gentle circular motion in the air. Residents can feel the essence of nature, such as the green, the sky, and the moving wind, being absorbed in the gently dancing bubbles forgetting all about the time.

Strength: well-balanced use of colours. Sometimes too much of soothing colours like blur or green may lead to depression, in this case they have tried to include tints warm colours to balance this. Overall colours used in the interior are soothing and restful to eyes. At the same time, it spreads energy.

Weakness: lack of natural lights and views of nature. 


\section{This content is unavailable}

Due to copyright issues.

Figure 5: Shinjuen nursing home; Reprinted from Emmanuelle moureaux architecture + design 


\section{ROSEBANK VILLAGE, CANTERBURY}

Company: Rosebank

Location: Ashburton, New Zealand

Year: Unknown

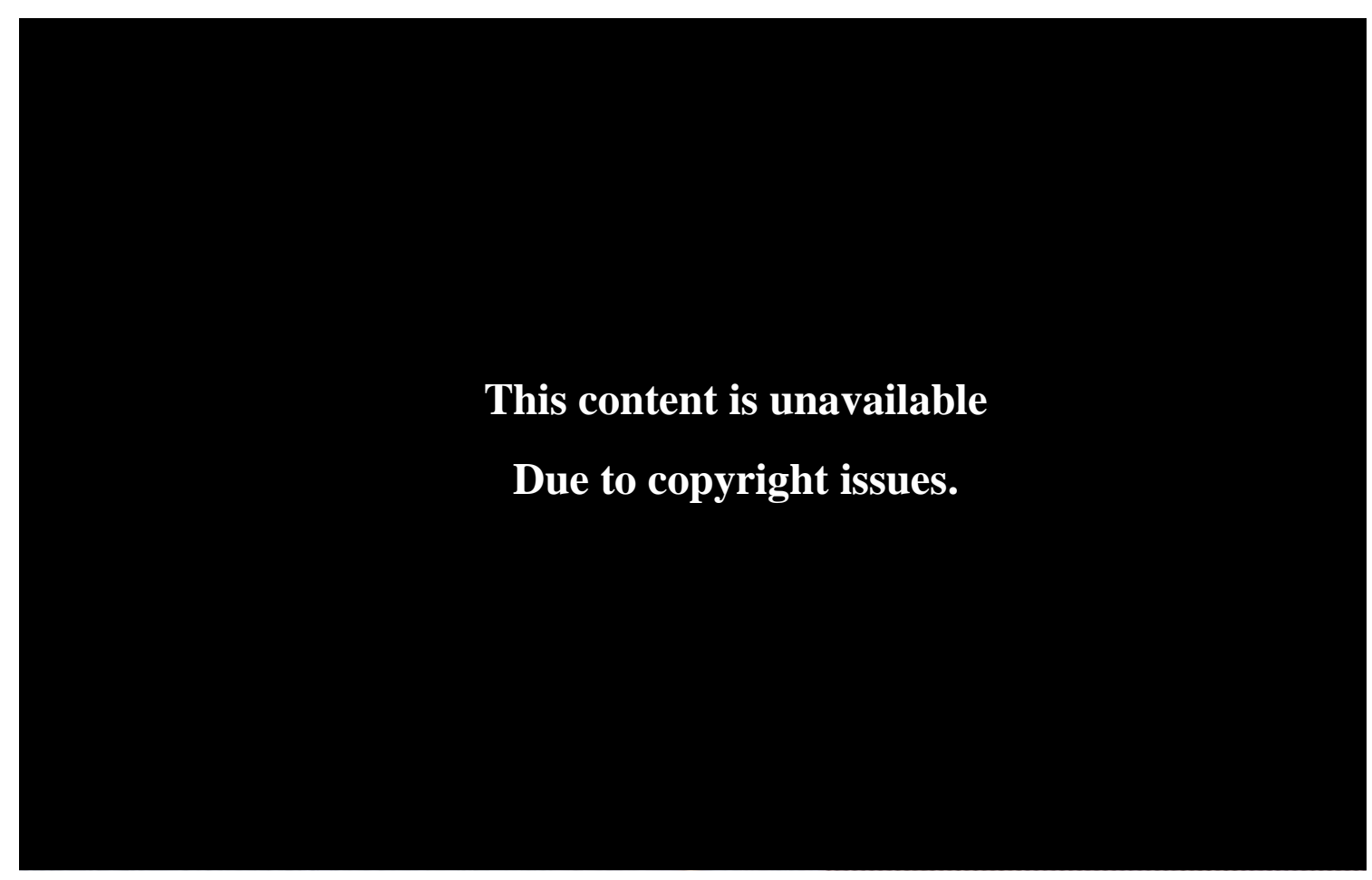

Figure 6: Rosebank Village; Reprinted from Rosebank village website

Strengths: Relaxing and restful to eye. Large windows brings in plenty of natural light and ventilation to the room. It also creates a visual connection between indoor and outdoors.

Weakness: Recearches says that too much Blue can also create feelings of sadness or aloofness. Another drawback of this colour palate is, this may not be as pleasing to an aging aye with yellowing of lens, like it is to a young person since the use of tonal difference in colour is less. 


\subsection{COLOURS PROMOTING INTERACTION}

\section{EPMS MARIE DU MERLE IN ORBEC}

Architects: Dominique Coulon \& associés

Location :16 Le Ravillon, 89140 Pont-sur-Yonne, France

year : 2015

This content is unavailable

Due to copyright issues.

Figure 7: EPMS Marie du Merle; Reprinted from Archdaily and EPMS Marie du Merle website

Strength: Conventional colours of the hospital environment are avoided by the architect and colour red has been used to 'destructure' the interiors and adds dynamic. Sitting areas in warm shades of pink and red where ergonomically designed banquettes are conducive to group 
conversations among the residents. large wide windows introduce the nature and natural light into the interior. All these factors create a bright and colourful atmosphere for the elderly users.

Weakness: Lack sense of homeliness. Moreover, too much red has resulted in dull looking interior in some areas.

POSSUM BOURNE RETIREMENT VILLAGE, AUCKLAND

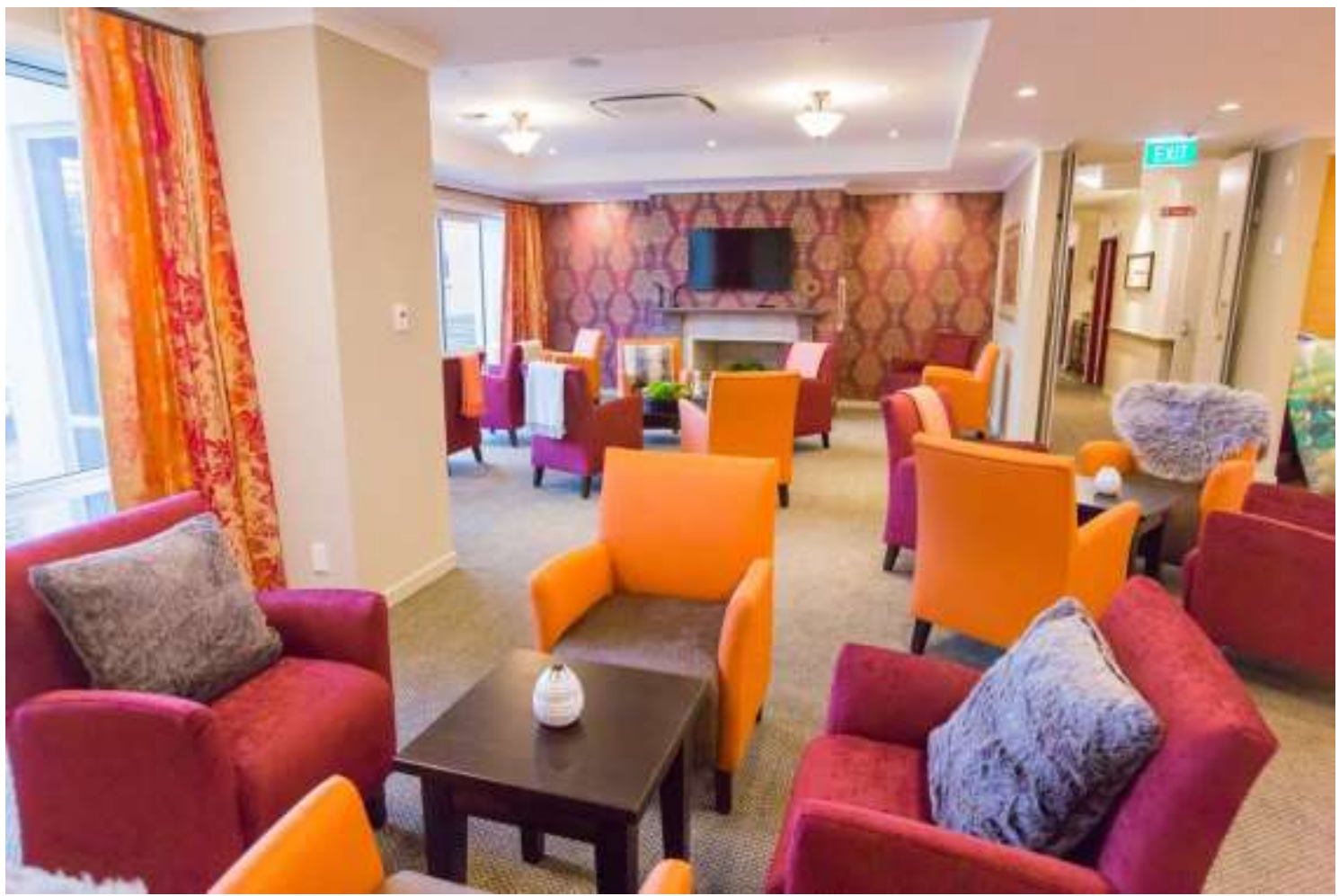

Figure 8: Possum Bourne Retirement village; Reprinted from village guide

Strengths: looks vibrant and cheerful. Large openings bring in plenty of natural light and ventilation into the room. Can encourage conversation among people and make them active.

Weakness: Too much warm colour may not be suitable for residents when they wish for a calm and quite atmosphere. 


\subsection{CONCLUSION}

These case studies provided insight on the way local and international retirement homes have used the colour. These case studies follow on from the literature review in chapter two to give a further understanding on the ways different key design strategies identified in the literature review can be used in retirement to promote soothing atmosphere, interaction among residents and make it lively. These case studies examined strengths and weakness each precedent. 


\section{SITE SELECTION}

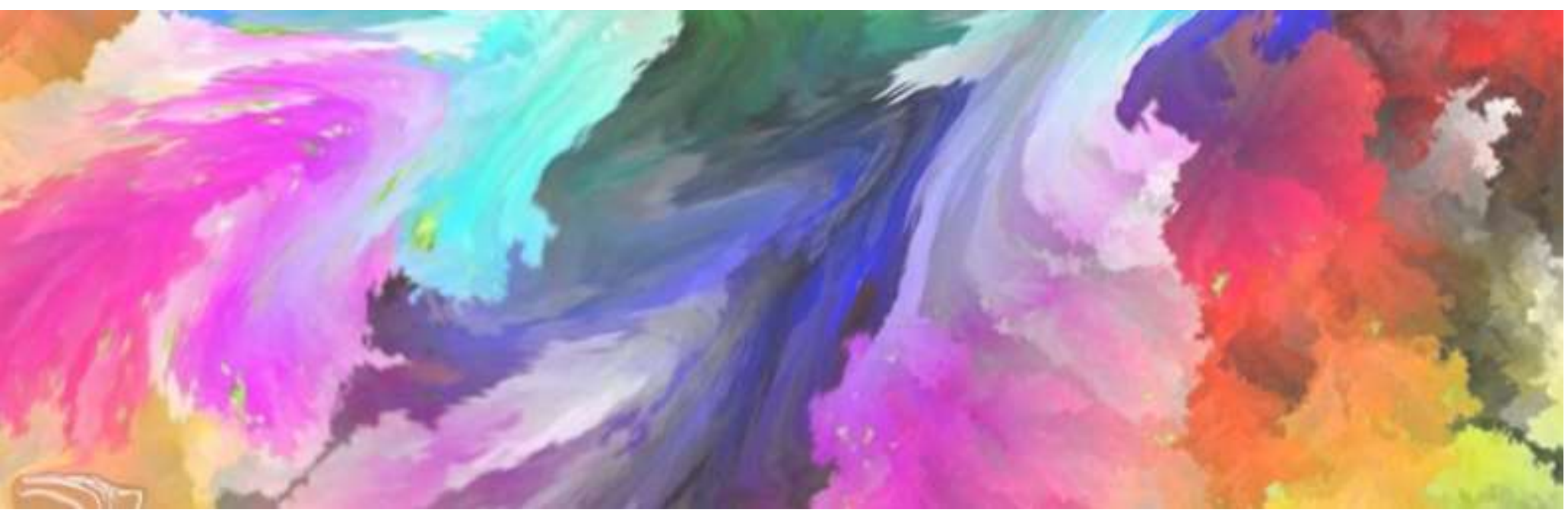

35 |P a g e 


\subsection{COLOUR AND RETIREMENT HOMES IN NEW ZEALAND}

To understand how colour is used in the interiors of retirement homes in New Zealand, a photographic survey of shared community lounges of ten retirement homes were done. Out of selected ten retirement homes one was selected as the site for conducting experiments. Tables below show selected ten retirement homes. All the images were taken from the website of respective retirement homes. 


\begin{tabular}{|c|c|c|c|c|c|}
\hline $\begin{array}{l}\text { RETIREMENT } \\
\text { HOMES }\end{array}$ & WALLS & FLOOR & CEILING & FURNITURE & IMAGE \\
\hline $\begin{array}{l}\text { Rita Angus } \\
\text { Retirement }\end{array}$ & $\begin{array}{l}\text {-Beige walls } \\
\text { - colourful floral } \\
\text { wallpaper }\end{array}$ & Grey & White & $\begin{array}{l}\text { Pastel colours, } \\
\text { green, brown }\end{array}$ & $\log _{0,2}$ \\
\hline $\begin{array}{l}\text { Whitby Lakes, } \\
\text { Porirua }\end{array}$ & -Beige walls & $\begin{array}{l}\text { Brownish } \\
\text { with } \\
\text { white } \\
\text { lines }\end{array}$ & White & $\begin{array}{l}\text { Yellow green, } \\
\text { sap green and } \\
\text { brown }\end{array}$ & 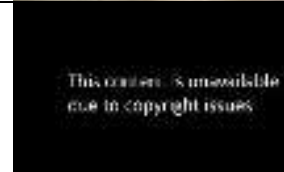 \\
\hline $\begin{array}{l}\text { Village at the } \\
\text { park }\end{array}$ & $\begin{array}{l}\text {-Beige walls, large } \\
\text { windows` }\end{array}$ & Grey & White & $\begin{array}{l}\text { Purple floral } \\
\text { patten chairs, }\end{array}$ & \\
\hline $\begin{array}{l}\text { Greeneich } \\
\text { gardens care } \\
\text { home, Auckland }\end{array}$ & $\begin{array}{l}\text {-Beige walls } \\
\text {-Large windows to bring } \\
\text { in natural lights and } \\
\text { colours }\end{array}$ & $\begin{array}{l}\text { Wooden } \\
\text { floor, } \\
\text { brown } \\
\text { carpet } \\
\text { with } \\
\text { patterns }\end{array}$ & White & $\begin{array}{l}\text { Brown, Orange, } \\
\text { Green }\end{array}$ & 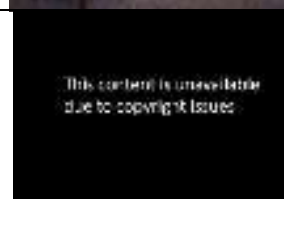 \\
\hline Huntleigh, Karori & $\begin{array}{l}\text {-Beige walls } \\
\text { - Brown curtains }\end{array}$ & $\begin{array}{l}\text { Dark } \\
\text { brown }\end{array}$ & White & Purple, Orange & 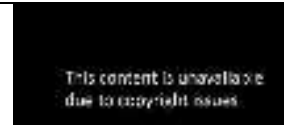 \\
\hline Malvina major & $\begin{array}{l}\text {-Beige walls } \\
\text { - Walls highlighted with } \\
\text { green } \\
\text {-Colourful paintings } \\
\text {-Large windows }\end{array}$ & Grey & White & Purple, Beige & \\
\hline $\begin{array}{l}\text { Ascot Retirement } \\
\text { village }\end{array}$ & $\begin{array}{l}\text {-Beige walls } \\
\text {-Large windows to bring } \\
\text { in natural lights and } \\
\text { colours }\end{array}$ & $\begin{array}{l}\text { Brownish } \\
\text { grey }\end{array}$ & White & Blue and grey & 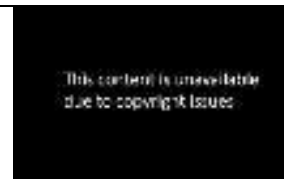 \\
\hline $\begin{array}{l}\text { Bert Sutcliffe } \\
\text { Retirement } \\
\text { Village, }\end{array}$ & $\begin{array}{l}\text {-Floral patterns on } \\
\text { curtains and wall paper } \\
\text {-Large windows to bring } \\
\text { in natural lights and } \\
\text { colours } \\
\text {-Colourful paintings } \\
\text { On wall }\end{array}$ & Grey & White & Purple, orange & $\pi$ \\
\hline $\begin{array}{l}\text { Bupa St.Andrews } \\
\text { Village Hamilton }\end{array}$ & $\begin{array}{l}\text {-Beige walls and } \\
\text { curtains } \\
\text {-Large windows to bring } \\
\text { in natural lights and } \\
\text { colours }\end{array}$ & $\begin{array}{l}\text { Green, } \\
\text { blue, and } \\
\text { white } \\
\text { geometric } \\
\text { patterns }\end{array}$ & White & $\begin{array}{l}\text { Green, brown } \\
\text { and beige } \\
\text { furniture, } \\
\text { colourful pillows }\end{array}$ & 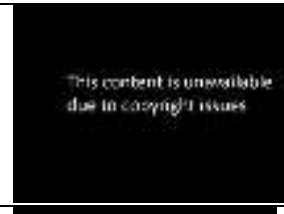 \\
\hline $\begin{array}{l}\text { Sprott house } \\
\text { karori }\end{array}$ & $\begin{array}{l}\text { Beige walls with large } \\
\text { windows. }\end{array}$ & Grey & white & Beige & 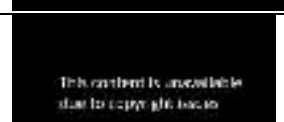 \\
\hline
\end{tabular}

Table 1: Photographic survey of selected ten retirement homes 


\begin{tabular}{|c|c|c|c|}
\hline Retirement homes & $\begin{array}{c}\text { Views of nature and } \\
\text { natural light }\end{array}$ & Soothing colours & $\begin{array}{c}\text { Colours promoting } \\
\text { interaction }\end{array}$ \\
\hline $\begin{array}{c}\text { Rita Angus } \\
\text { Retirement }\end{array}$ & & $\checkmark$ & \\
\hline $\begin{array}{c}\text { Whitby Lakes, } \\
\text { Porirua }\end{array}$ & & $\checkmark$ & \\
\hline $\begin{array}{c}\text { Village at the park } \\
\text { Greeneich gardens } \\
\text { care home, Auckland }\end{array}$ & $\checkmark$ & $\checkmark$ & \\
\hline $\begin{array}{c}\text { Huntleigh, Karori } \\
\text { Malvina major }\end{array}$ & $\checkmark$ & $\checkmark$ & \\
\hline $\begin{array}{c}\text { Ascot Retirement } \\
\text { village }\end{array}$ & $\checkmark$ & & \\
\hline $\begin{array}{c}\text { Bert Sutcliffe } \\
\text { Retirement Village, }\end{array}$ & $\checkmark$ & & \\
\hline $\begin{array}{c}\text { Bupa St.Andrews } \\
\text { Village Hamilton }\end{array}$ & $\checkmark$ & & \\
\hline $\begin{array}{c}\text { Sprott house Karori } \\
\text { Table 2: Analsing kej }\end{array}$ & $\checkmark$ & & \\
\hline
\end{tabular}

Table 2: Analysing key design strategies derived in literature review

These retirement homes were selected randomly based on seeing some colours in them. From the above tables it is clear that many of the retirement homes in New Zealand have not experimented with colours to make the build environment interesting.

Beige is commonly used colour for walls. Colour is brought into the interiors mainly through furniture or as a painting on the wall.

Colour is an ideal design element and an influential design facet that can be easily applied and manipulated in a variety of design materials. However, there is a lack of systematic research on the use and effect of colour on the living environment of elderly populations.

\subsection{SITE}

Selwyn Sprott Village is chosen as the site from the survey because use of colour is comparatively less in Sprott house than other nine retirement villages. 


\subsubsection{SITE BACKGROUND}

Selwyn Sprott Village, ideally located in the residential heart of Karori in Wellington stands in just over 3/4 of a hectare, surrounded by established trees and mature gardens (Selwyn Foundation, 2018).

It was established over 100 years ago. Previously Sprott House, the village was first established in 1898 by the Anglican Diocese of Wellington to provide care for young women and children, becoming a residential aged care home in 1951 (Selwyn Foundation, 2018). The Selwyn Foundation took ownership of Sprott House in October 2018 and now comprises a 73-room care facility (rest home and hospital), a purpose-built, dedicated secure dementia care unit for 24 people and 13 independent living villas (Selwyn Foundation, 2018).

\subsubsection{INTERIOR}

Selected multipurpose lounge is one of the main lounges located in the south wing of the home. It is designed for accommodating 25 people at a time. This lounge is used as a TV lounge, dining doom and also as an optional activity room. In terms of colours the existing space is not interesting or stimulating, due to predominant use of dull, pale colours for the interior (Figure 9).

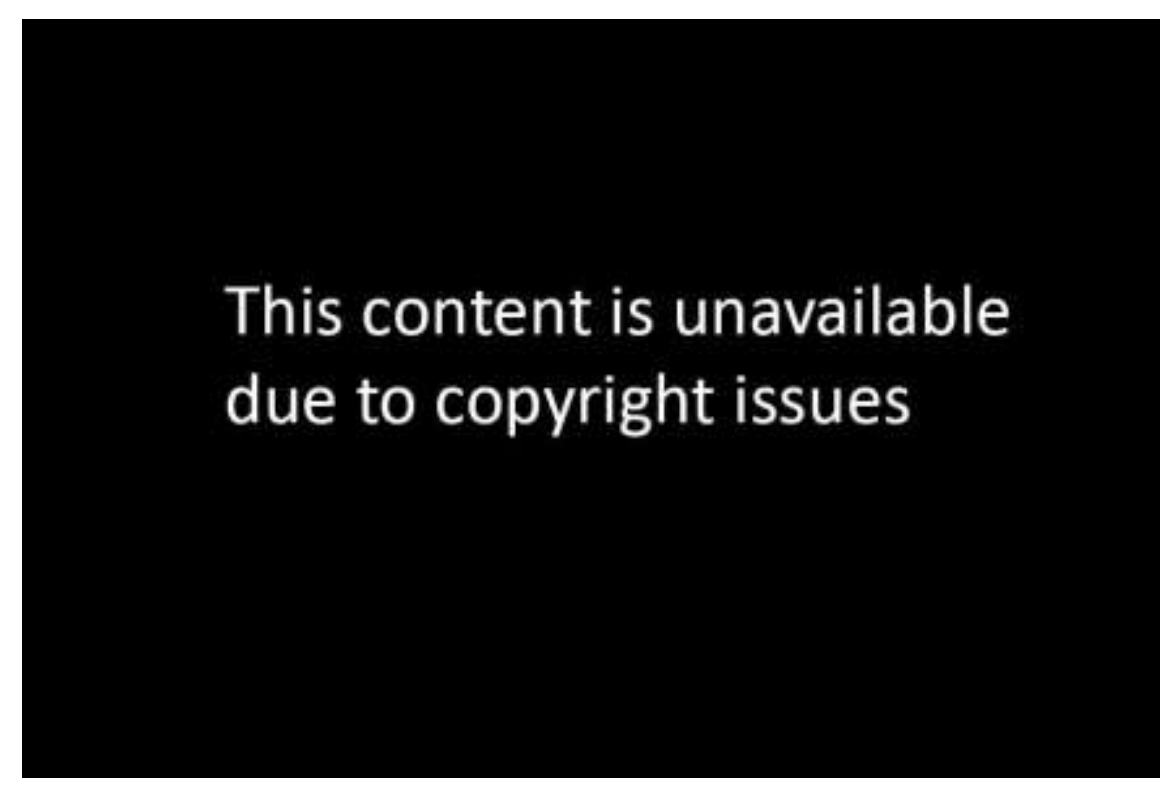

Figure 9: Interior view; reprinted from Sprott house Karori website

Lounge is located at the southern corner of the building, have windows on the south west wall and south east wall. This allows natural light throughout the day. All the windows have a view towards the garden as well as the car parking. 

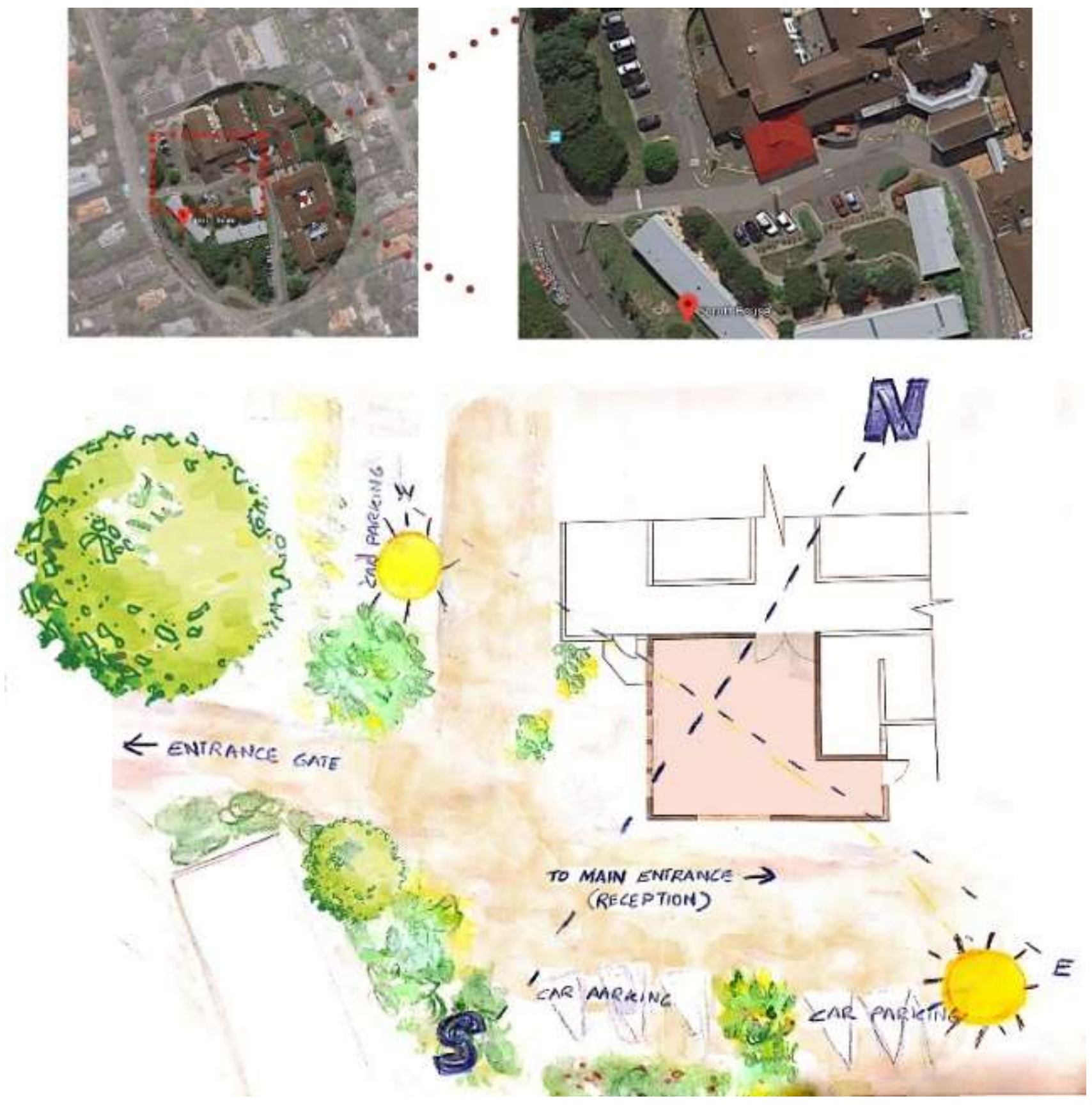

Figure 10: Figure showing site location, orientation and surroundings 
6. EXPERIMENTS

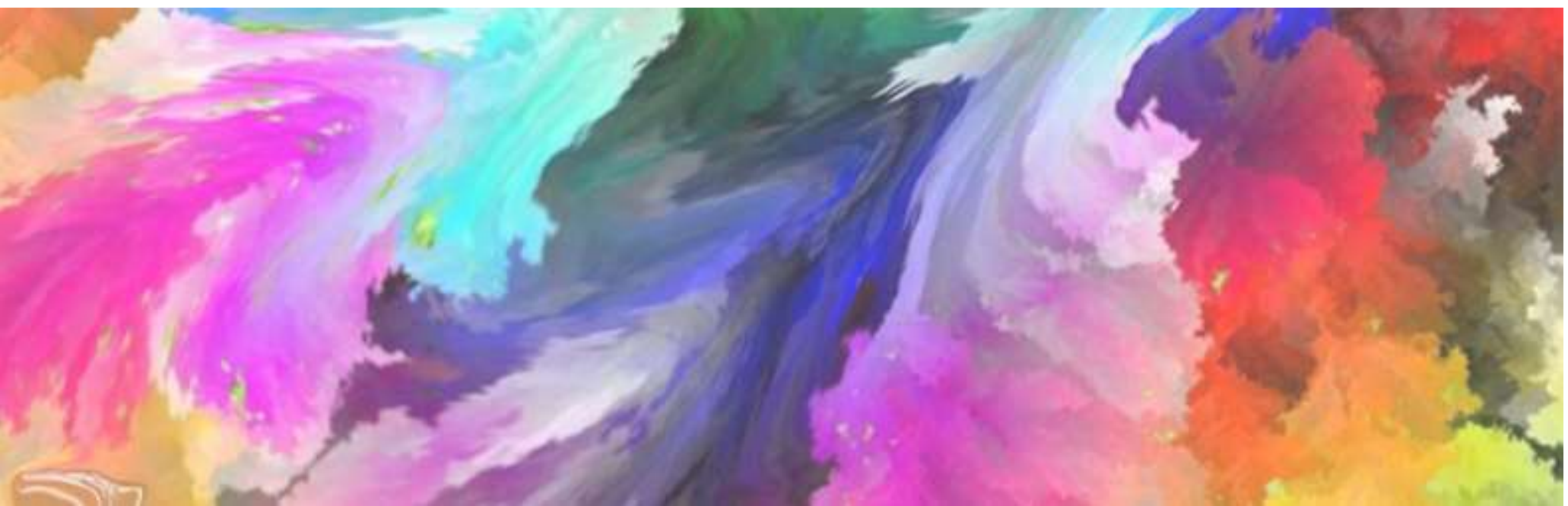

$41 \mid \mathrm{P}$ a g e 
In order to more fully understand the design opportunities offered by colour, a series of experiments were undertaken to explore the interaction between colours, colour placement, and the use of larger or smaller amounts of colour.

\subsection{COLOUR AND LOCATIONS}

The first experiment was done to view the effect of a colour when applied at different locations such as ceiling, walls, floor or furniture. Character of an interior space is greatly influenced by total area covered by a colour and location where it is applied. Effect of hue on the walls may be different from the effect of hue on the floor. However, the views may change depending on tint, shade and tone of the hue. Personal preferences and cultural influences also pay an important part in defining the character of the space based on the colour usage.

A 3D view of an interior space with walls, floor, ceiling and furniture was selected and a single colour was applied at different locations. Experiment was repeated with all colours in a colour wheel and observations were noted. (See the figures 11, 12, 13, 14, 15 and 16)

In real life colour is reflected off things, so this experiment is not fully capturing that aspect as it is done digitally. 


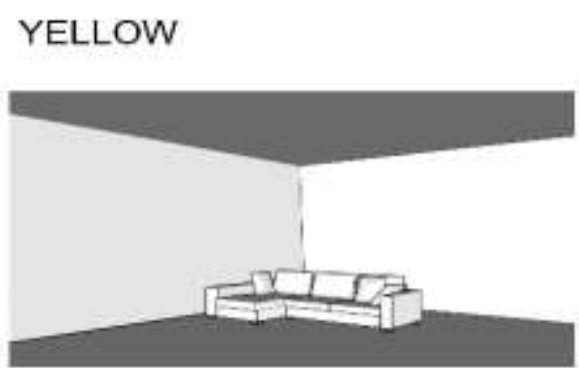

emptyness

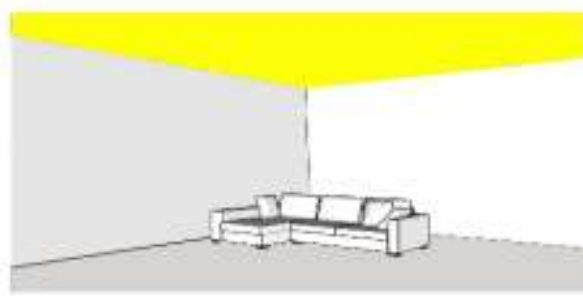

Ceiling: Luminous
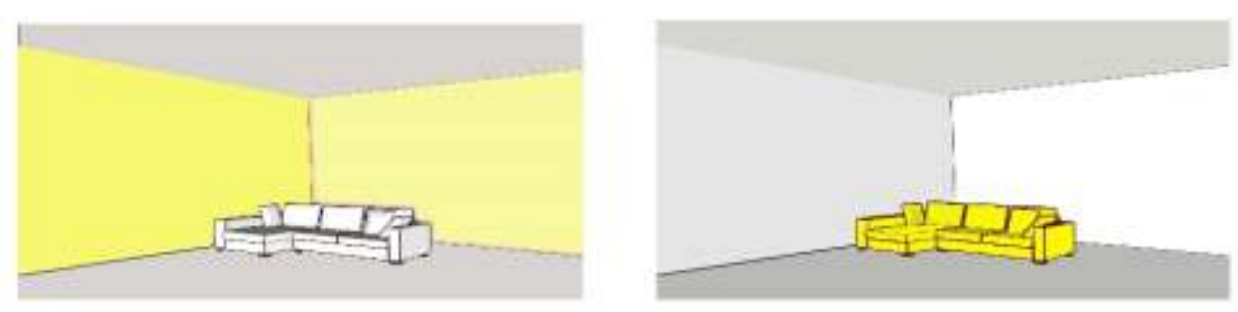

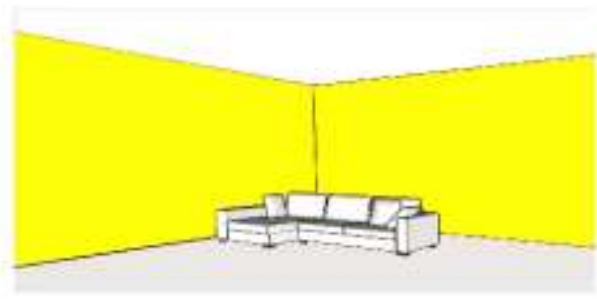

Walls: Exiting to irritating

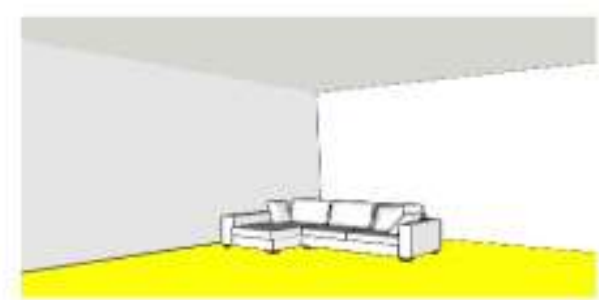

Floor Elevating, diverting

Bright and cheerfull

Figure 11: Examples of experimenting with yellow 
RED

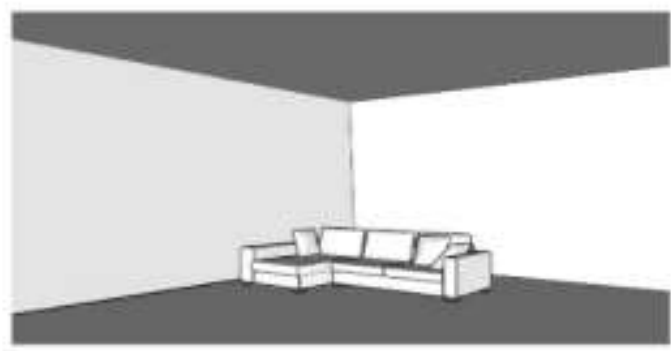

emptyness

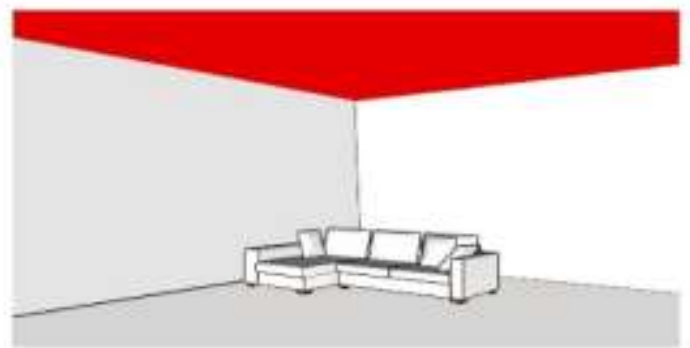

Red on ceiling: Heavy, Intruding

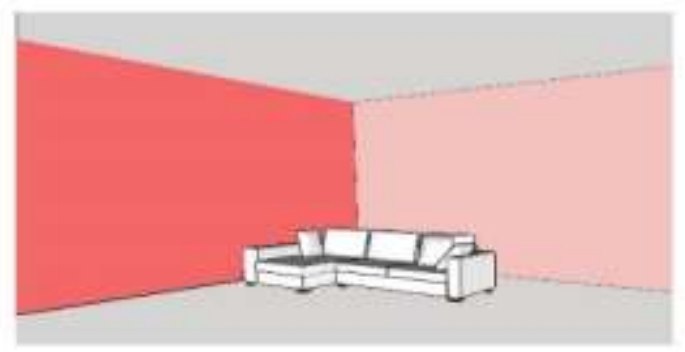

Focussing, addingg colour to room, active

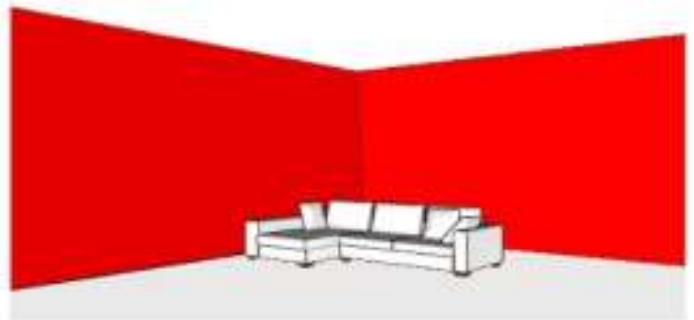

Red on walls: clumsy, aggressive

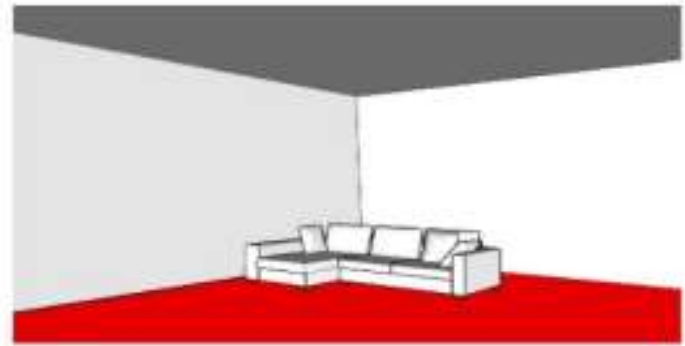

Red on ceiling: Alert

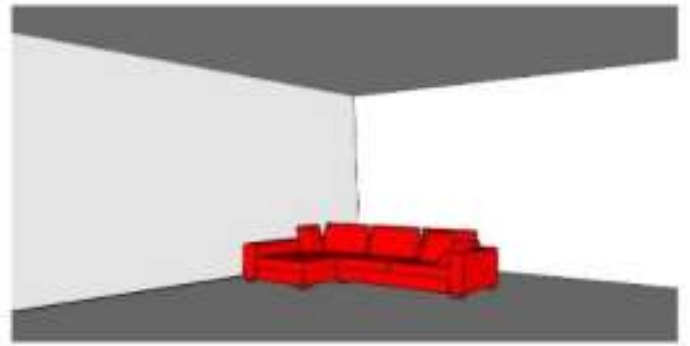

Figure 12: Examples of experimenting with Red 

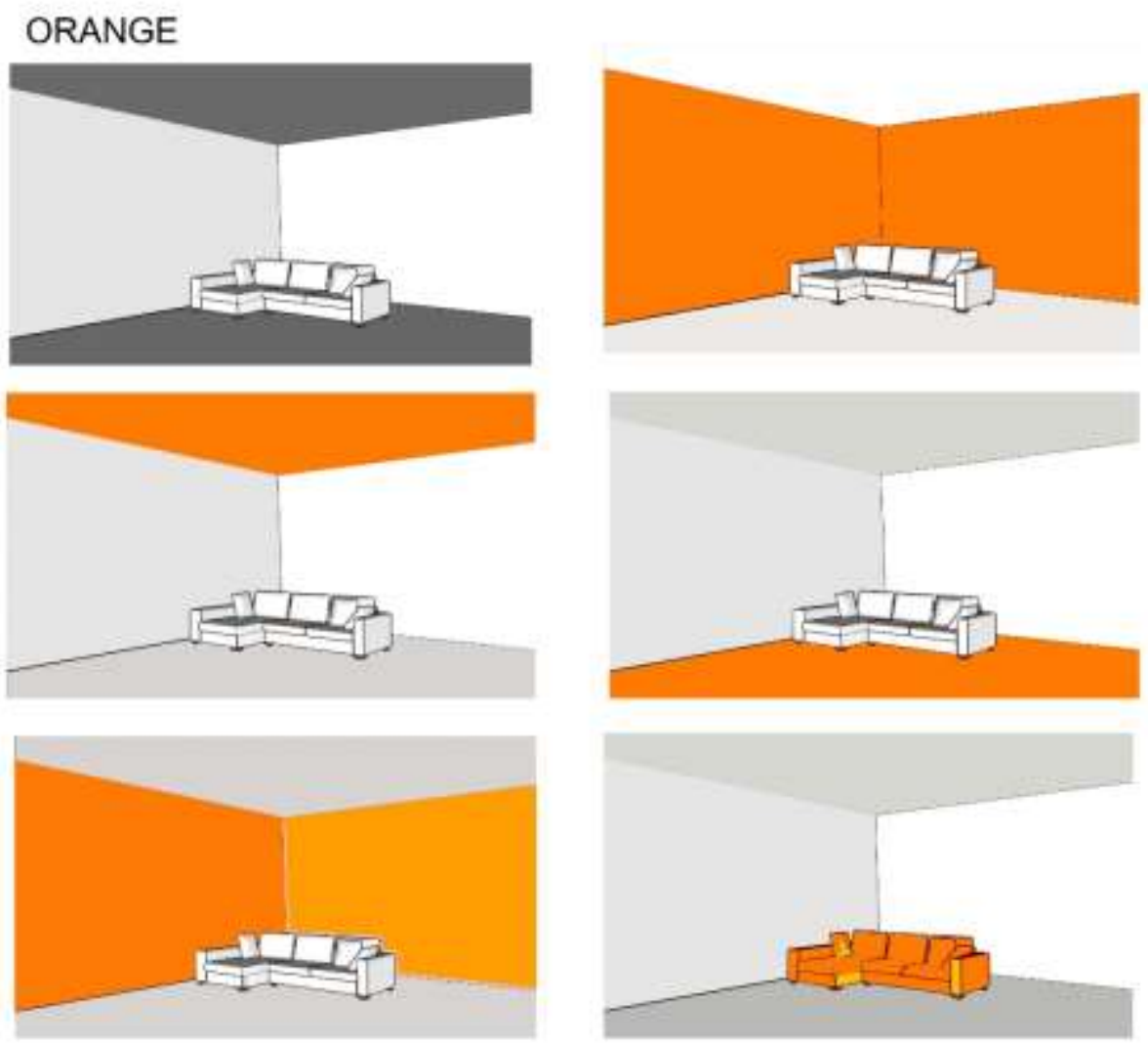

Figure 13: Examples of experimenting with Orange
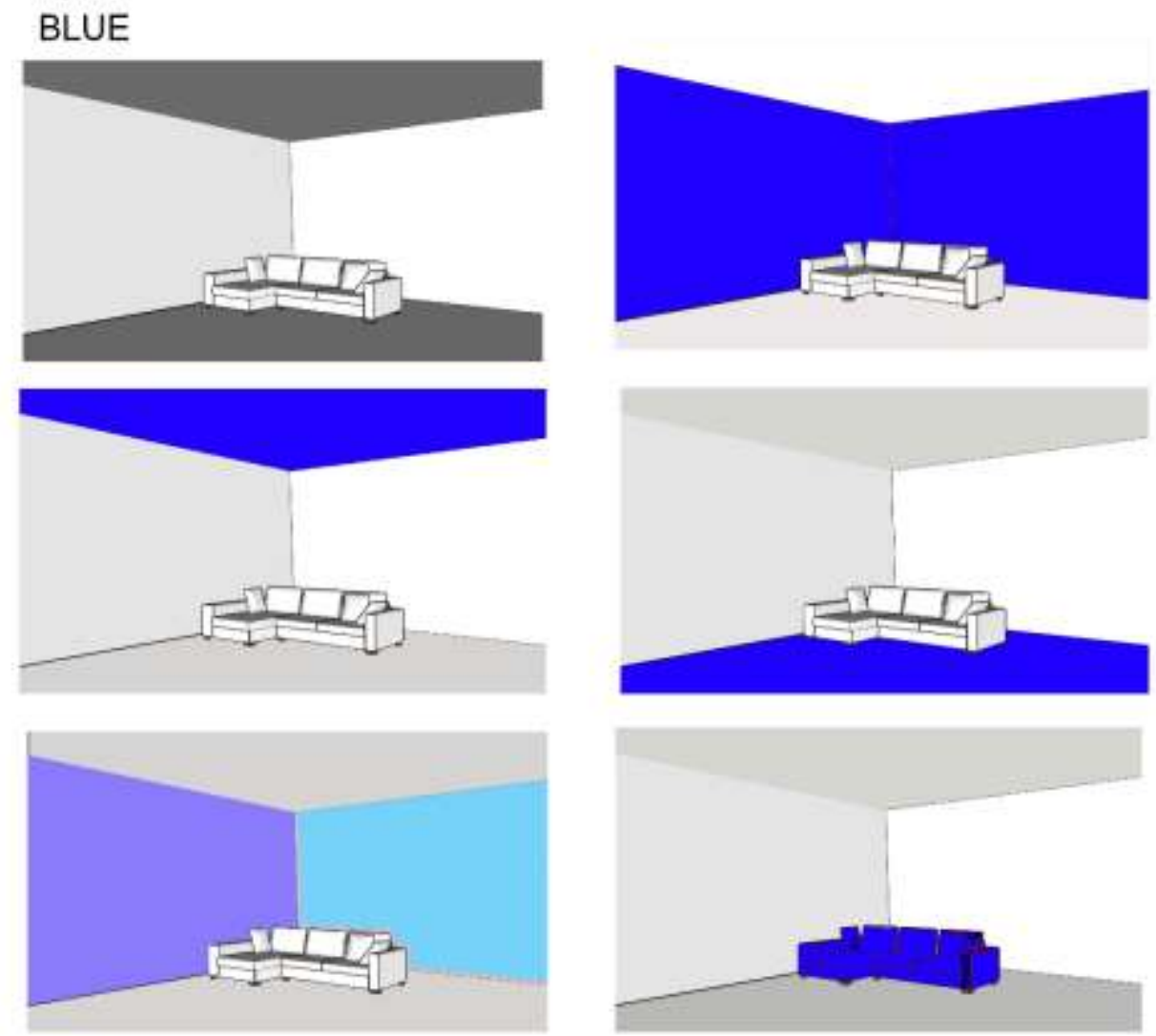

Figure 14: Examples of experimenting with blue 

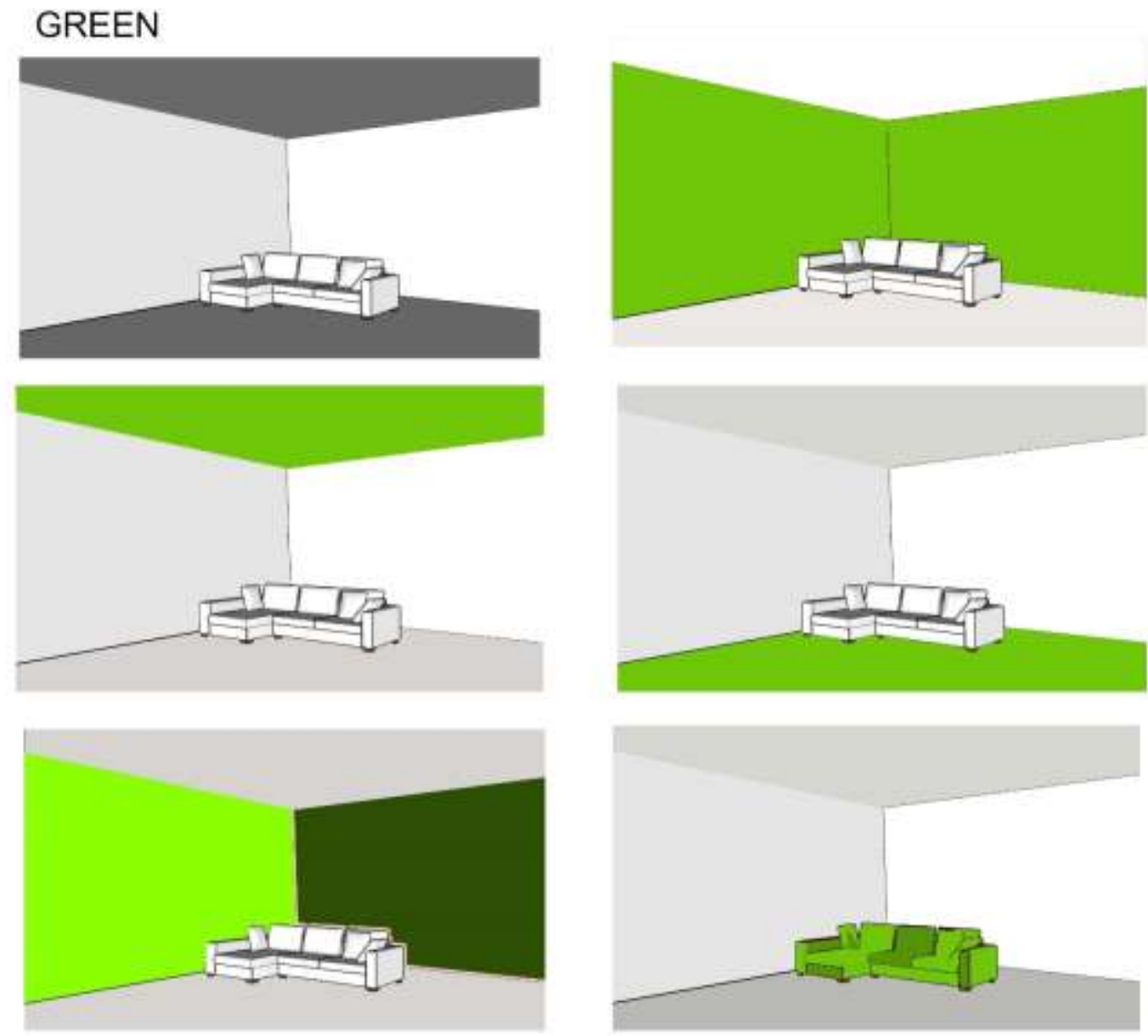

Figure 15: Examples of experimenting with green

\section{GREEN}
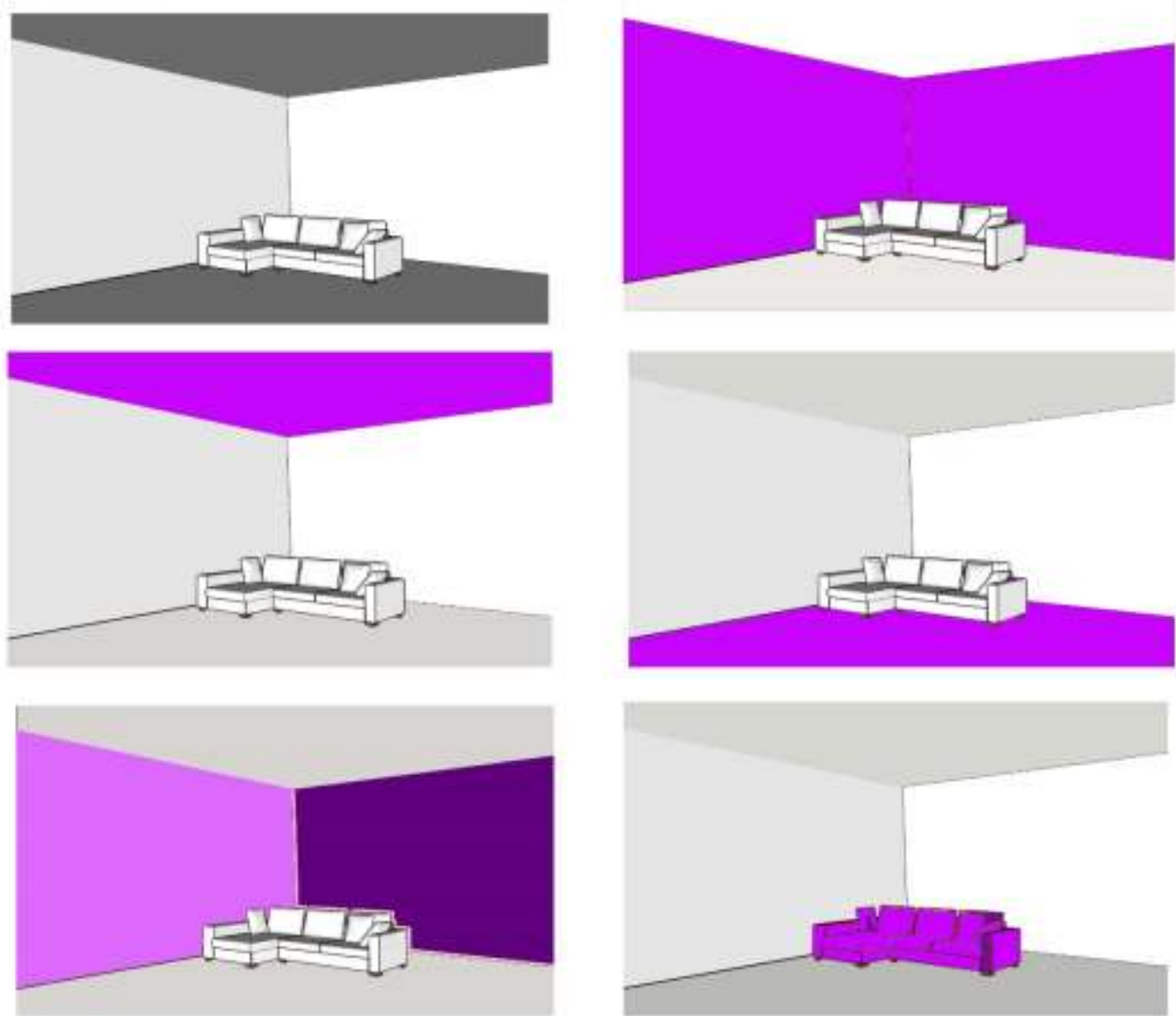

Figure 16: Examples of experimenting with purple 


\section{OBSERVATIONS:}

\begin{tabular}{|c|c|c|c|c|}
\hline COLOUR & WALL & FLOOR & CEILING & FURNITURE \\
\hline RED & $\begin{array}{l}\text { Aggressive, } \\
\text { clumsy, active, } \\
\text { energy }\end{array}$ & Alert & $\begin{array}{l}\text { Intruding, } \\
\text { disturbing, } \\
\text { heavy }\end{array}$ & $\begin{array}{l}\text { Adds colour to } \\
\text { the room, active }\end{array}$ \\
\hline YELLOW & $\begin{array}{l}\text { Exiting to } \\
\text { irritating, } \\
\text { welcoming }\end{array}$ & $\begin{array}{l}\text { Elevating, } \\
\text { diverting }\end{array}$ & Luminous & $\begin{array}{l}\text { bright and } \\
\text { cheerful, fresh }\end{array}$ \\
\hline ORANGE & $\begin{array}{l}\text { Warm and } \\
\text { luminous }\end{array}$ & Activating & $\begin{array}{l}\text { Stimulating, } \\
\text { attention- } \\
\text { seeking. }\end{array}$ & $\begin{array}{l}\text { attention } \\
\text { seeking, } \\
\text { attractive }\end{array}$ \\
\hline BLUE & $\begin{array}{l}\text { Cool, distant if } \\
\text { light; } \\
\text { encouraging, }\end{array}$ & $\begin{array}{l}\text { Feeling of } \\
\text { effortless } \\
\text { movement if } \\
\text { light, water }\end{array}$ & $\begin{array}{l}\text { heavy, } \\
\text { domineering; } \\
\text { cool }\end{array}$ & $\begin{array}{l}\text { cool, calm, } \\
\text { restful }\end{array}$ \\
\hline GREEN & $\begin{array}{l}\text { Walls: Cool and } \\
\text { calm if mild }\end{array}$ & Soft, relaxing & disturbing & $\begin{array}{l}\text { soothing and } \\
\text { relaxing, restful } \\
\text { to eye, youthful }\end{array}$ \\
\hline PURPLE & Cool, powerful & Delicate & Soft & Royal \\
\hline
\end{tabular}

\section{Table 3: observations}

Personal observational studies were undertaken, which is also influenced by the literature review in order to summarise and make conclusions.

It was possible to observe that total area covered by a colour and location it is applied within an interior affects character and appearance of a space. Also, it was observed that based on hue, tint and shade appearance of the space changes. 


\subsection{COLOUR AND AMBIENCE}

Main aim of this experiment was to practically test and observe how different colours change the mood and ambience of a room.

For this experiment a room was selected and a single coloured soft furnishing was given at a time. Observations were made and room was photographed. This experiment was done with both warm, cool and white colour.

However, views may change upon personal preference, culture, type of room and furnishings etc. This experiment could act as an example of how ambience and appearance of an interior space changes with different colours.

In contrast to the experiment 1 , where the colours were solid, in this experiment there were some variations in colour, which sets the transition for the next experiment. 
OBSERVATIONS:

Personal observational studies are made for the conclusion. These may vary from person to person.

\begin{tabular}{|c|c|c|c|}
\hline COLOUR & MERIT & DEMERIT & PICTURE \\
\hline white & $\begin{array}{l}\text { Spacious, Airy, calm } \\
\text { Visually expands the } \\
\text { room }\end{array}$ & No energy & \\
\hline Yellow & $\begin{array}{l}\text { Bright, Cheerful } \\
\text { Energetic, Fresh, } \\
\text { Lively }\end{array}$ & Disturbing & \\
\hline Light yellow & calm & $\begin{array}{l}\text { Dull, Gloomy, Low } \\
\text { energy }\end{array}$ & \\
\hline Red & $\begin{array}{l}\text { Energetic, bold, } \\
\text { warm, cosy }\end{array}$ & Visually reduces area & \\
\hline Blue and Green & $\begin{array}{l}\text { Calming, relaxing, } \\
\text { soothing to eye, } \\
\text { Pleasing }\end{array}$ & $\begin{array}{l}\text { Visually reduces area } \\
\text { of the room }\end{array}$ & \\
\hline
\end{tabular}

\section{Table 4: observations}

From this experiment it was possible to observe that different colours convey different mood to the space. It is also noted that observations in this experiment contrasted some of the observations made in the experiment 1 which was done digitally. 


\subsection{WATERCOLOUR EXPERIMENT}

In order to explore the impact of mixing of colours, a series of watercolour experiments were undertaken. Watercolour was used as a main tool in this series of experiments as it gives more flexibility in producing different colours of different shades and tints by adding and mixing of pigments. Choosing the first colour and adding colours in sequence with a constant attempt to achieving satisfying relations is the aim of this exercise. Few examples from the range are shown in the figure 17,18 and 19
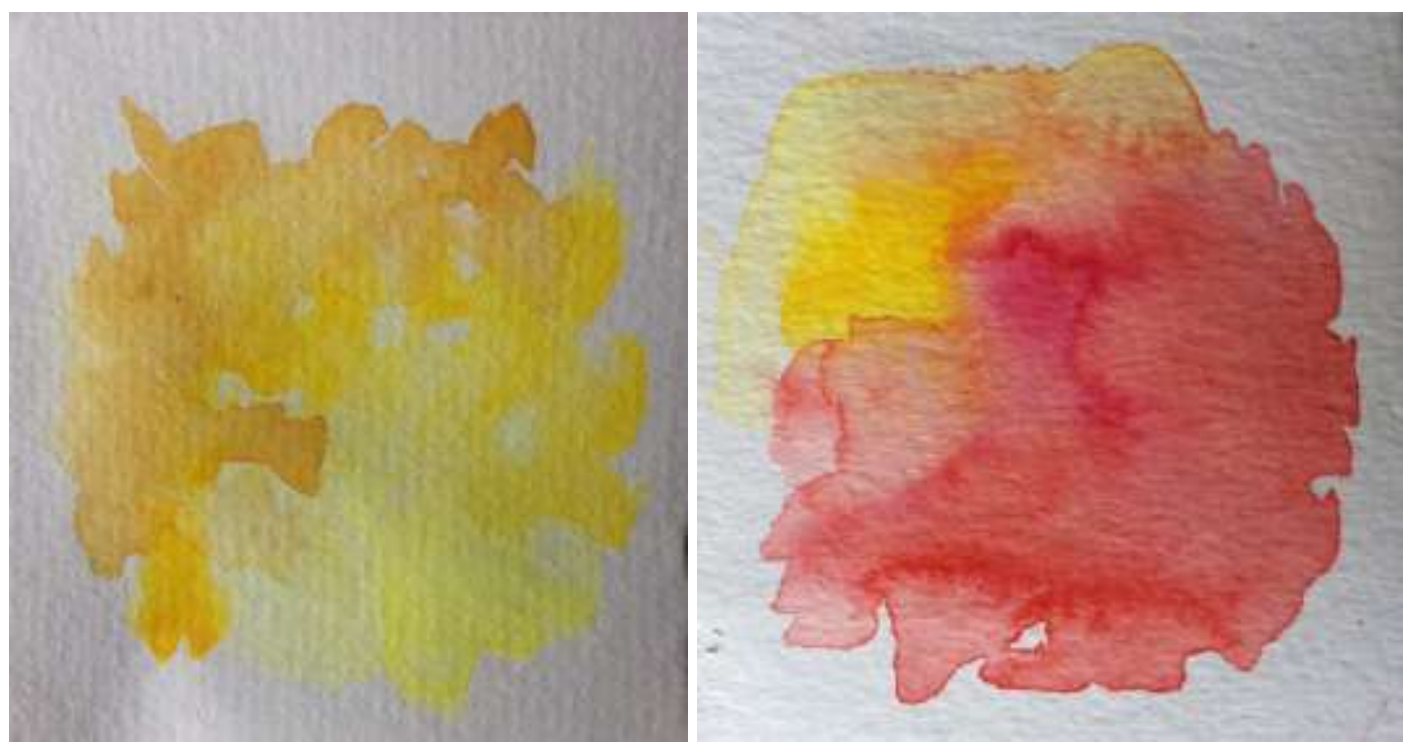

Figure 17: Examples from warm combinations
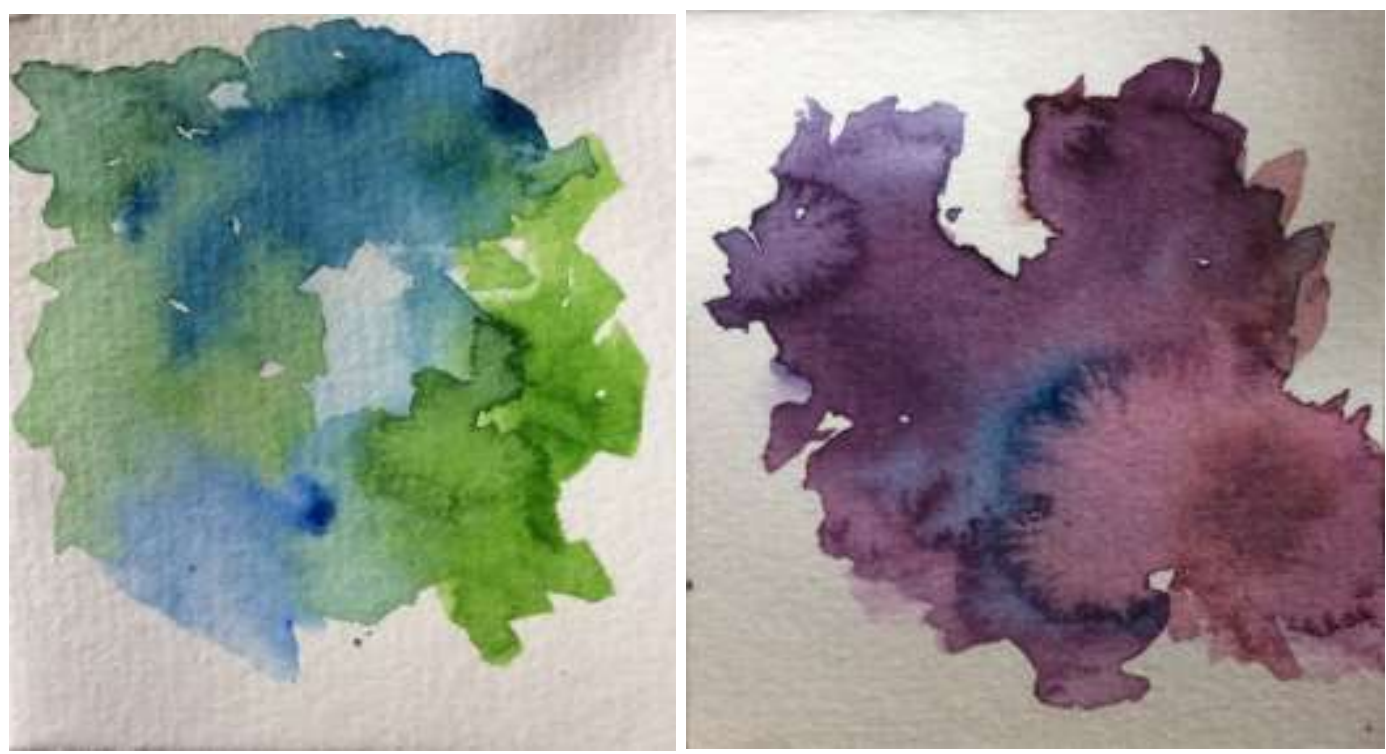

Figure 18:Examples from cool colour combinations 

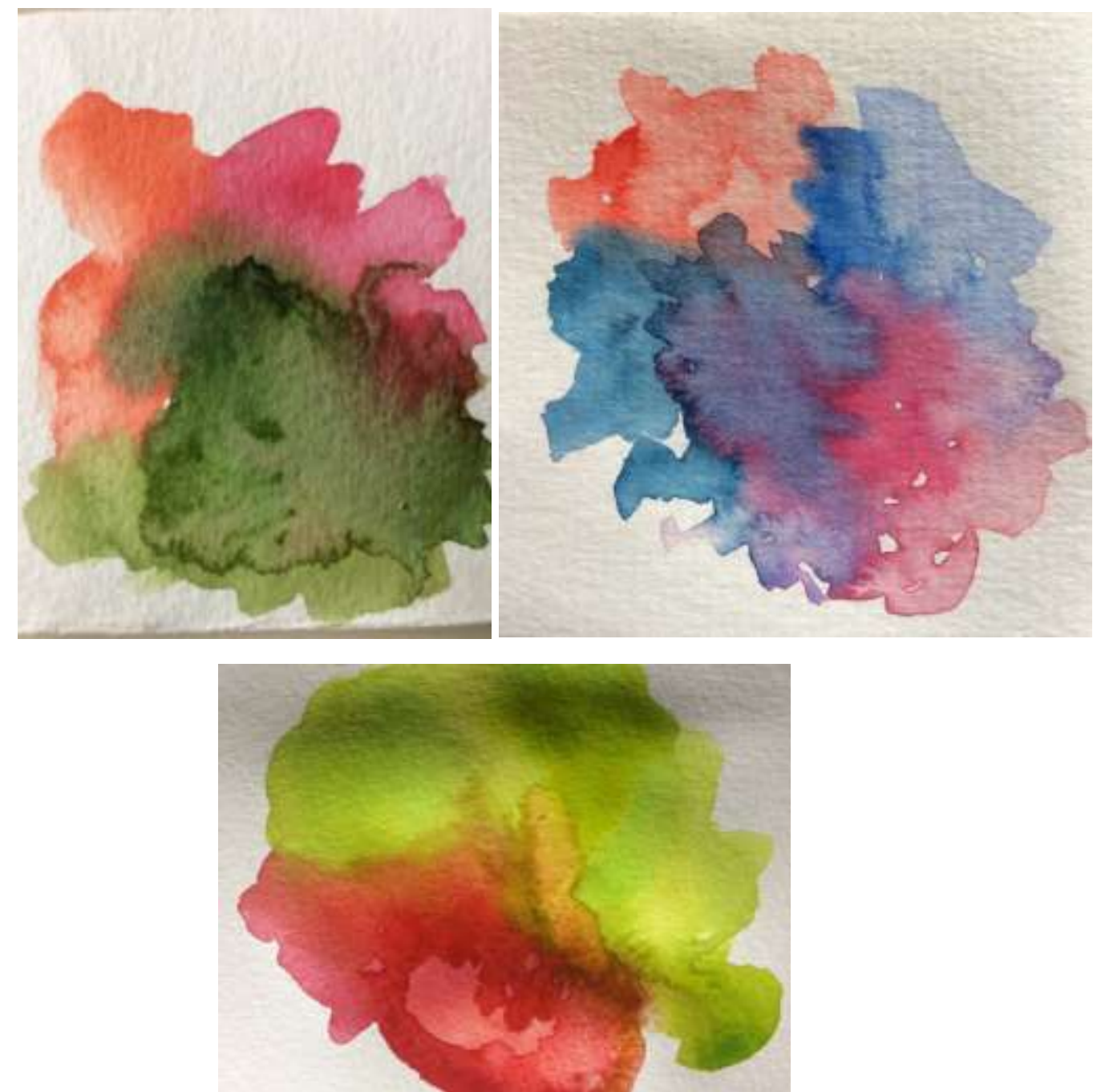

Figure 19: Examples from warm and cool colour combinations

\section{OBSERVATIONS:}

The most important factor in determining colour harmony was lightness contrast. The greater the lightness contrast the more pleasant the colour combinations. It is also noted that combinations of warm colours alone are vibrant than cool colour combinations. A warm-cool combination is a blend of both vibrancy and calmness. 


\subsection{COLOUR BOXES}

Aim of this experiment was to find the relationship between these foreground and background. In this experiment combinations made in the watercolour experiment are kept inside different coloured boxes. Few examples are given in the figure 20
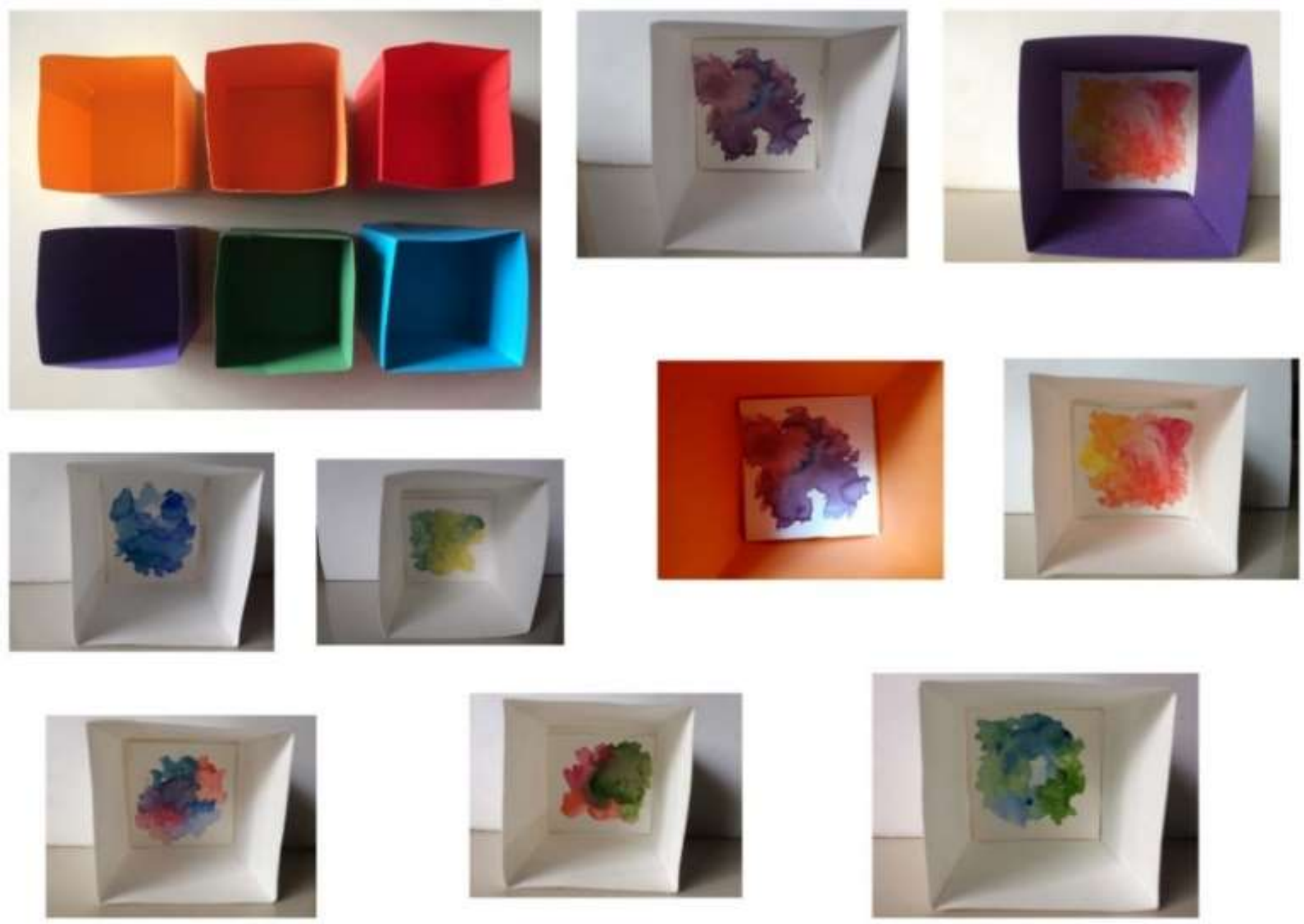

Figure 20: Few examples from Experiment 4 

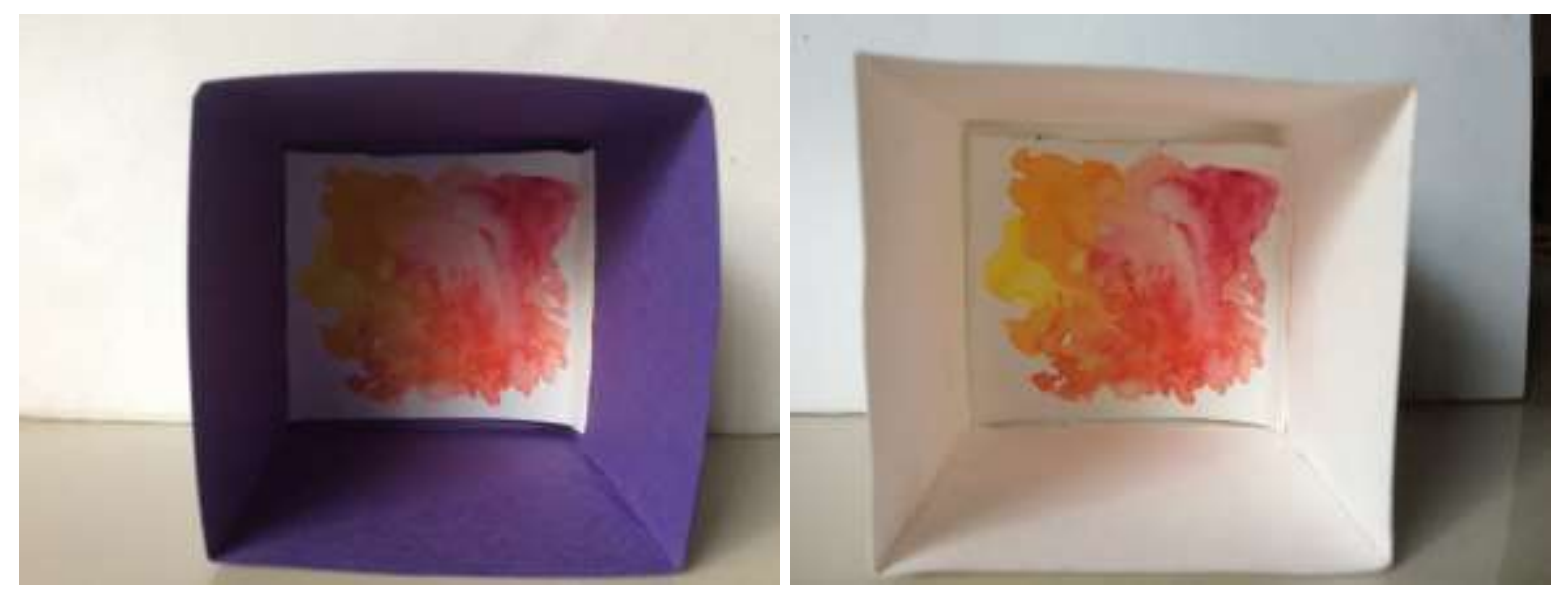

Figure 20 a: Impacts of background colour and light
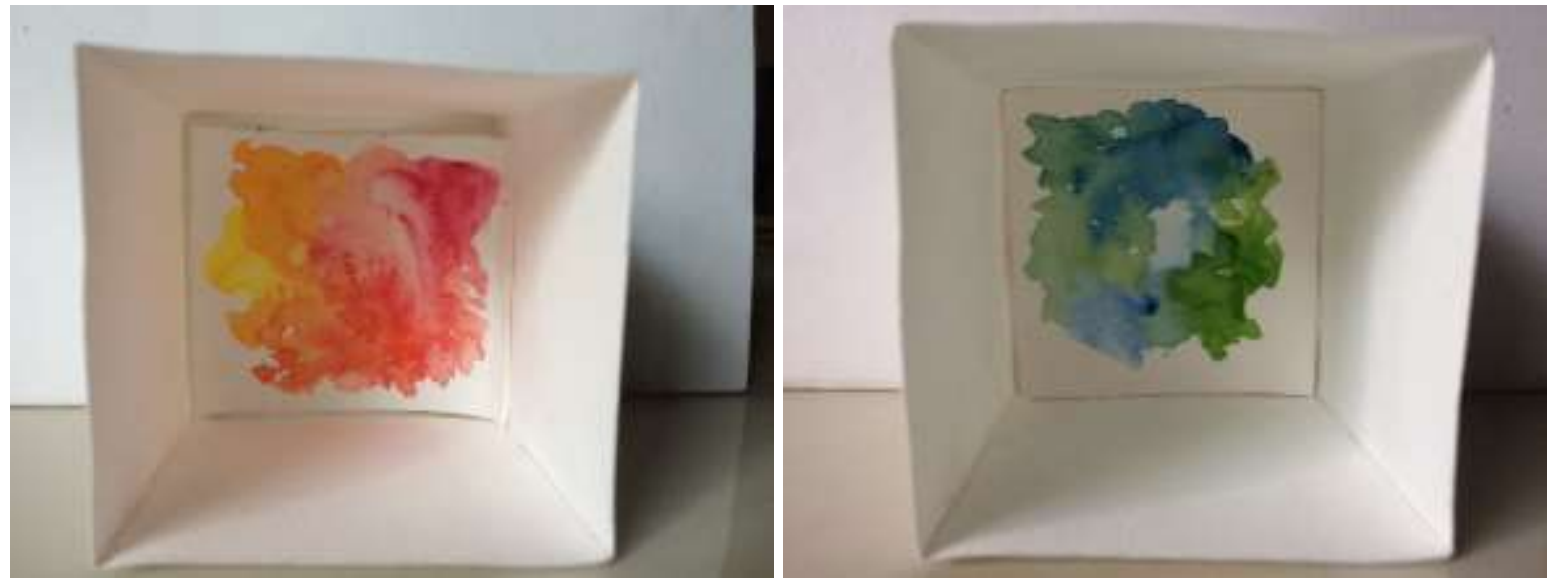

Figure 20 b: Difference in ambiance created by warm colours and cool colours
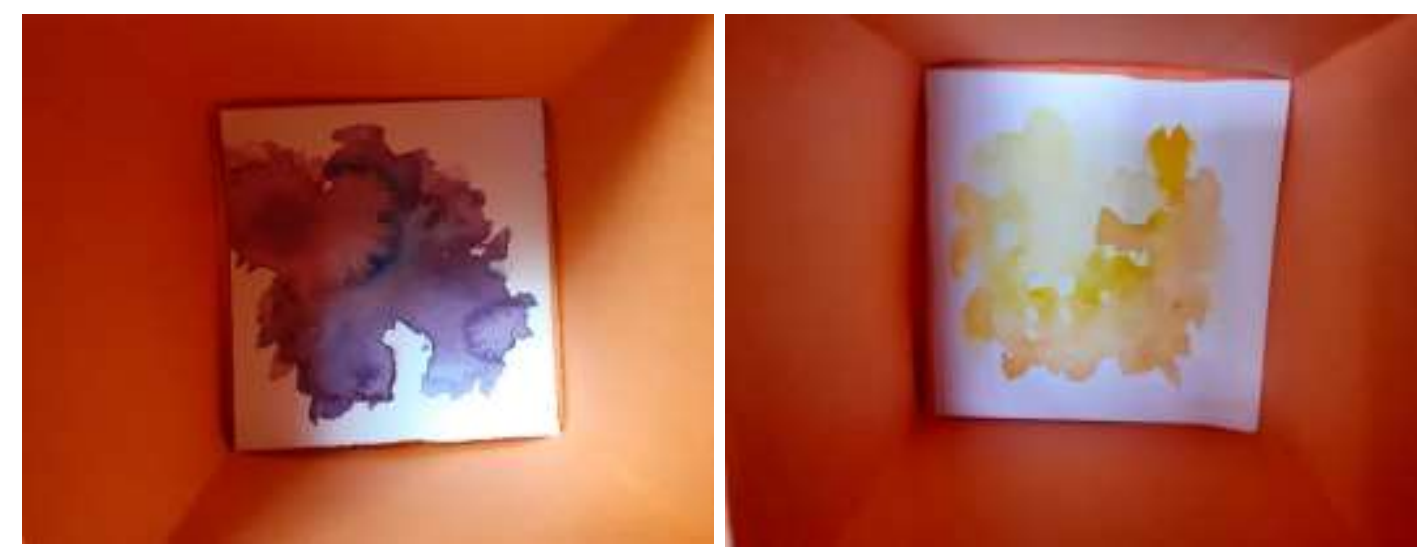

Figure 20 c: Different colours on same background 


\section{OBSERVATIONS:}

It was observed that not just object colour but also background colour and the type of lighting influenced subjects in fact, the single most important factor in determining pleasantness judgements was not object colour but the background colour.

Contrasting colours have potential to create totally different atmosphere to a space. Light and bright coloured walls have potential to brighten up a dark coloured room. Similarly, colours can also create visual illusions, a dark coloured wall in a bright coloured room can make to feel room smaller than it actually is. This is because dark coloured walls seem closer than the actual.

This experiment shows that light and colour are interconnected light plays an important role in determining how colour is viewed at the same time colour can affect the light and atmosphere of a room. Light coloured box appears to be spacious and larger than dark coloured box, even though both are of the same size. This is because lighter colours reflect more light.

\subsection{AGING EYE}

Aim of this experiment was to test colours and aging eye. It is known that aging eye may cause yellowing of the eye lens and in turn it affects colour perception.

Combinations made in watercolour experiment where photographed and arranged in a white paper digitally. A layer of yellow colour with less opacity where placed above it to imitate yellowing of eye lens. Examples are given in figure 21,22 and 23 


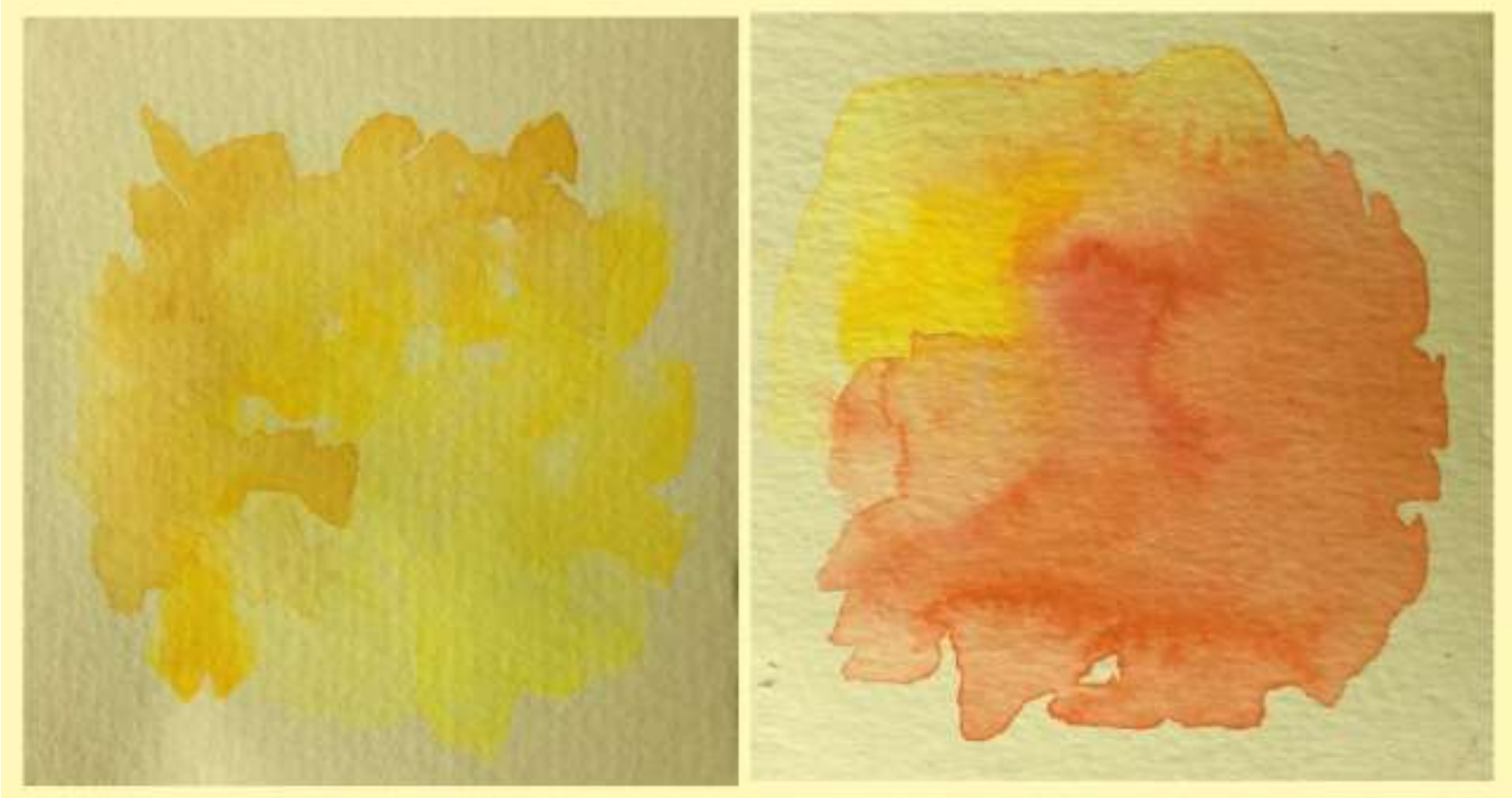

Figure 21: examples from combinations of warm colours to an aging eye
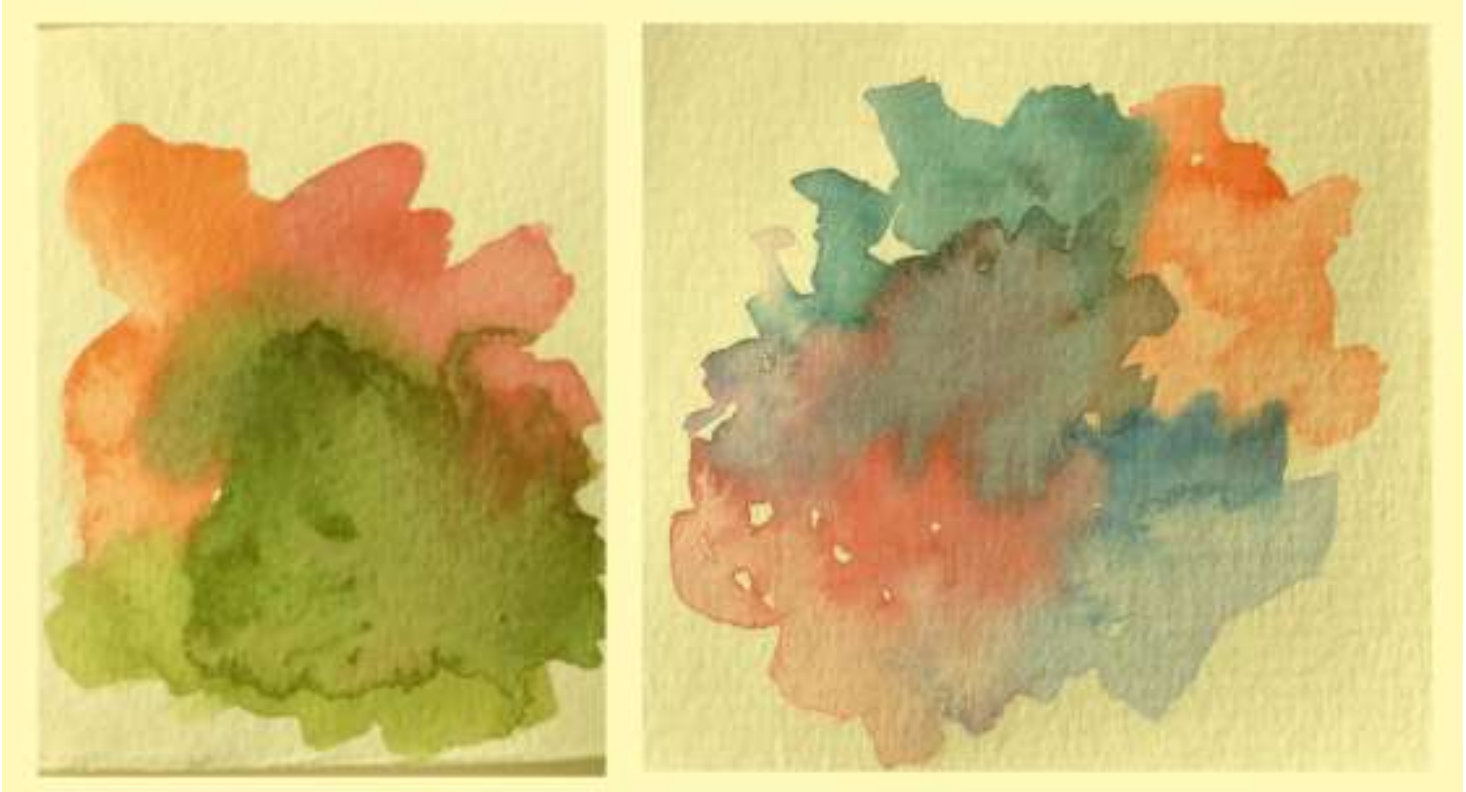

Figure 22: Examples from warm-cool combinations to an aging eye 


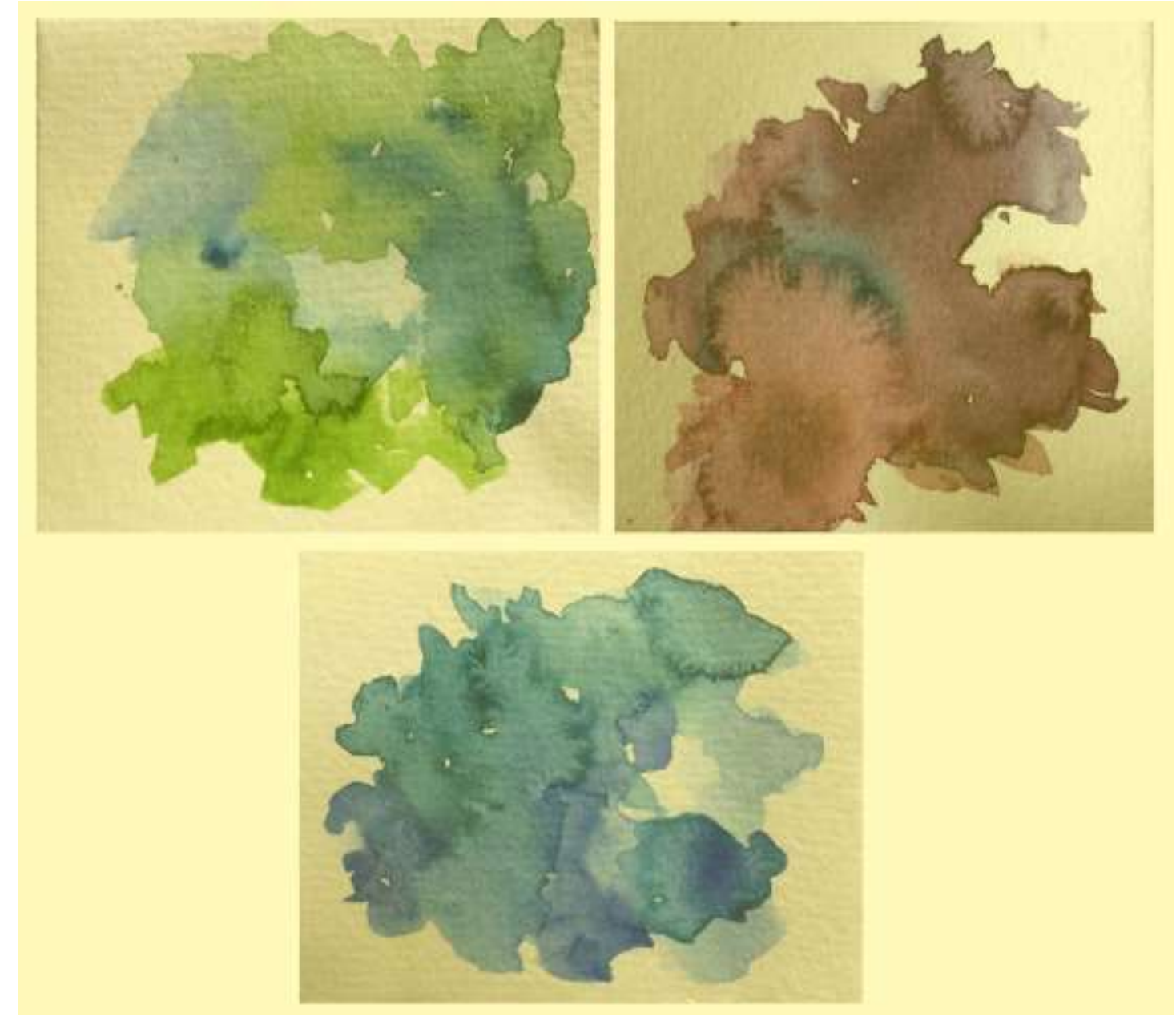

Figure 23: Examples from cool colour combinations to an aging eye OBSERVATIONS:

It was observed that this experiment supports the findings from the literature review. For example, it was observed there was a difficulty in differentiating the shades of blue green and violet.

Colours are seemed duller and contrasts between the colours are less noticeable. Most importantly there was a difficulty to distinguish similar colour tones. This shows the importance of tonal difference in colour while designing for elderly.

Combinations of warm and bright contrasting colours, such as yellow, orange, and red with cool colours are more readable than combinations of warm colour with a warm colour or cool colour with a cool colour.

This experiment also shows the importance of highly saturated colours for aging eye. Highly saturated colours are more visible and differentiable than low saturated colours. 


\subsection{SUMMARY AND REFLECTION}

All these experiments are useful to understand colour and interior relationship. Observations from experiment one, two and four shows how colour has the potential to change the whole atmosphere and ambience of a space. It is known that ambience of a room could affect the occupants in that room and evokes emotions. These experiments also helped to observe positives and negatives of each colour in interior spaces. Experiment three was useful to understand explore different colour combinations and satisfying colour relationships. With this experiment it was possible to observe how different colours complemented to each other. Experiment five helps to understand aging eye. With this experiment it was able to observe how colours are different to an aging eye. This experiment could be useful while deciding colour combinations for interiors with elderly in mind.

It is noted that observations made on some colours in first experiment which was done digitally was contrasting form the observations made in the second experiment which was a practical testing of colours in a room. This shows that practical testing of colour on smaller areas of the site will be useful. 


\section{DESIGN EXPLORATIONS}

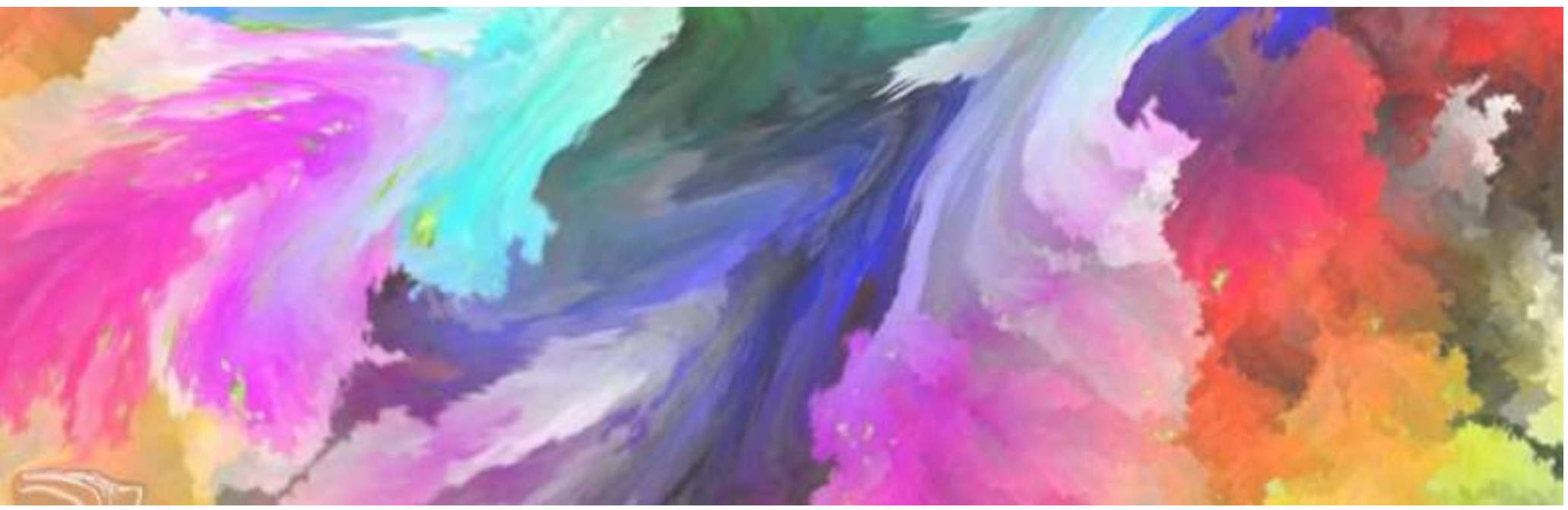




\subsection{SITE ANALYSIS FOR THE INTERVENTION}

To start with design, proposed communal lounge and dining space was rated using these key elements of healing derived in the Chapter 2 (Figure 24).

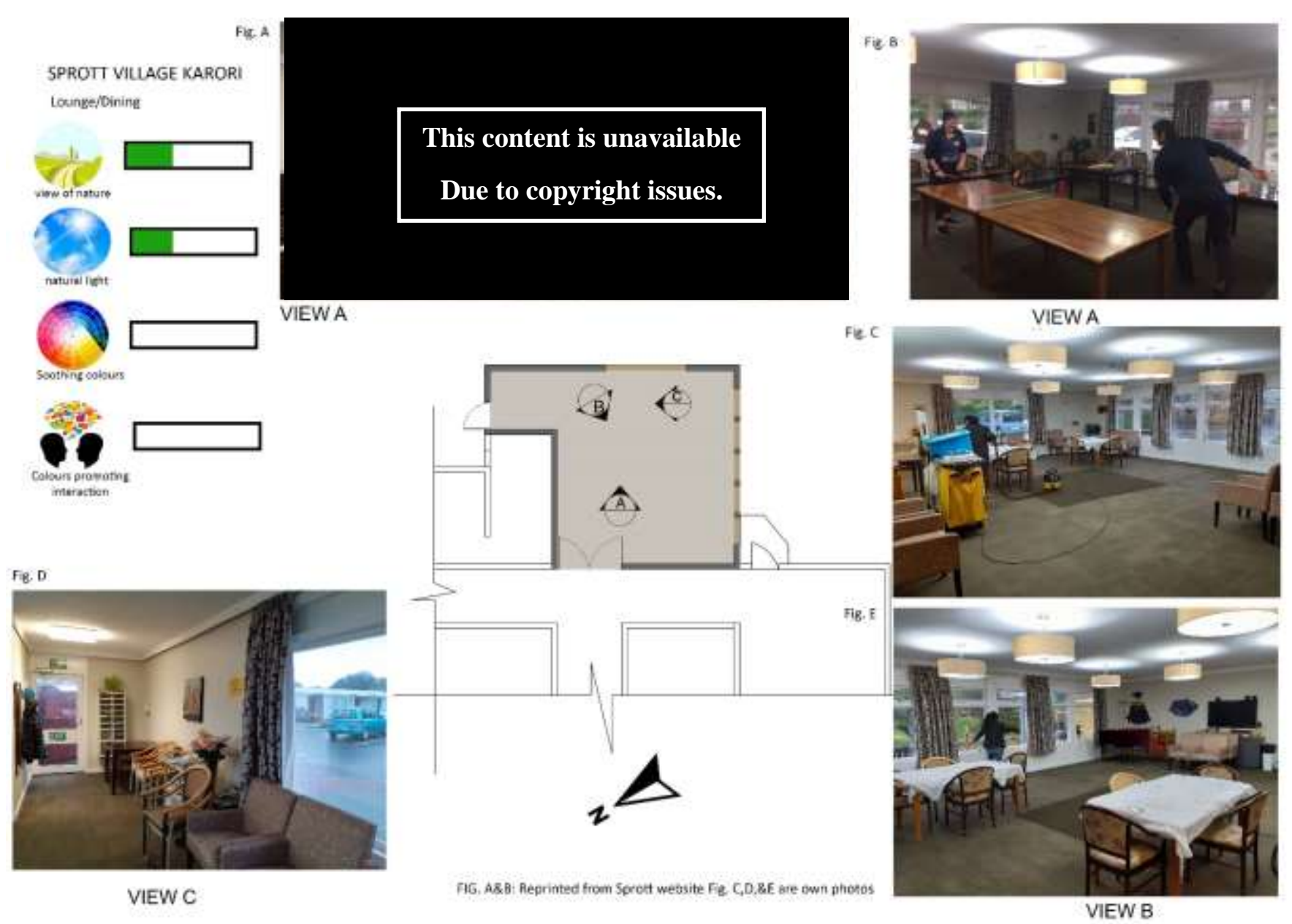

Figure 24: Analysing site with key elements of healing

Even though Figure A, B, \& C are the views of same lounge space, they look very different from each other due to the furniture arrangements and use of space. This lounge is used as a T.V room, dining room as well as from the figure B it is known that they use this lounge indoor game area. 
Main source of natural light is from the windows on the South East and South West sides of the lounge. Even in the day time they need artificial lights to brighten up the room. This shows the lack of natural light in the room.

Views from the South East window is towards a carpark area and a garden behind the car park area. Views from the South west windows are towards the landscaped area, carpark area as well as the main road (Messines road).

Lounge is uninteresting in terms of colours. Beige is the colour for walls and furniture in the room. Dull shades of grey and brown are used for floor, curtains and also for some piece of furniture. There is an absence of both soothing colours and colours promoting interaction in the room.

This site will present a challenge how to integrate the derived key objectives into the interiors to make it more interesting, stimulating and promoting healing environment through the use of colours.

\subsection{DESIGN EXPLORATIONS}

\subsubsection{HOW TO INCREASE IDENTIFIED DESIGN OBJECTIVES?}

Key elements of healing identified in the literature review were analysed and rated in the site. In this first set of design explorations the core question was to establish what the site offers in terms of elements of healing, and how these opportunities can be developed further.

\section{A. VIEW OF NATURE AND NATURAL LIGHT}

View of nature and natural light can be increased by enlarging the existing openings, creating a better connection with interior and exterior, or painting the interiors with a lighter colour as identified in the experiment 4. Lighter coloured surfaces reflect more light and boosts the natural light in the room.

Connection between interior and exterior can be made possible in two ways, with indoor gardens and bringing in the patterns of nature. 
The practice of incorporating nature and natural elements into the built environment is known as biophilic design. It has been proven to measurably reduce stress, enhance cognitive function and creativity, and expedite healing (Ryan, 2015)

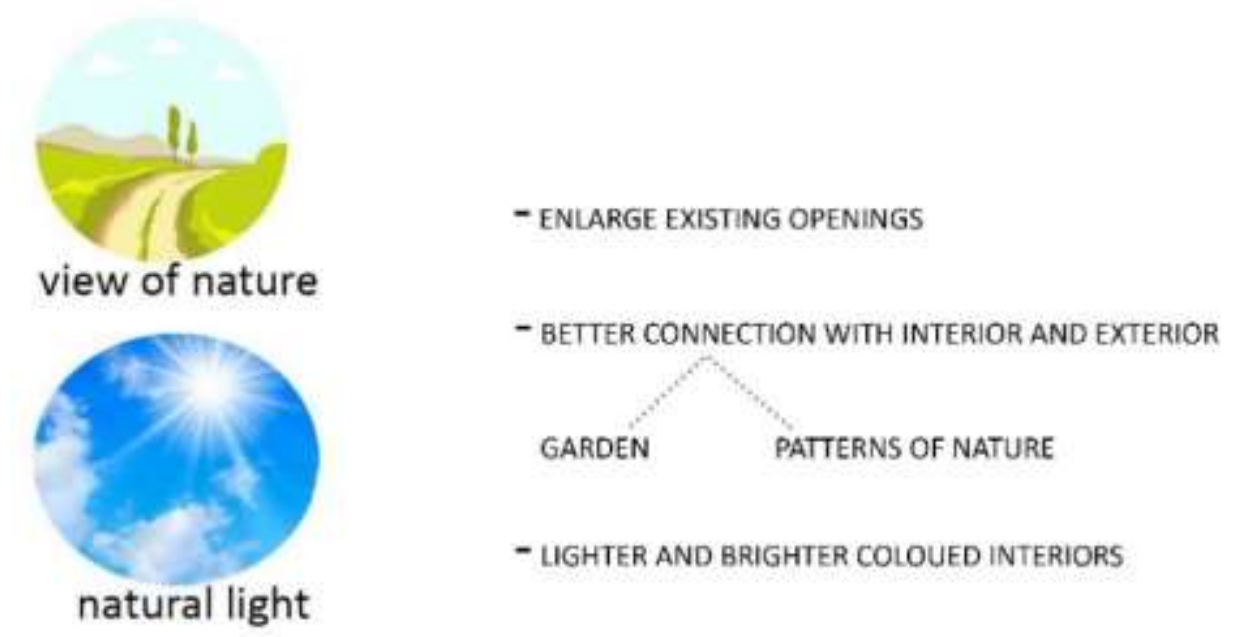

Figure 25: View of nature and natural light

\section{A.1 ENLARGE OPENINGS}

Firstly, to increase view of nature and natural light a series of options were identified and they were analysed using the key architectural strategies. Few of the options are shown in the figure 24. Expanding the room with glass roof and glass wall to the south west is identified as the best among all options. This option allowed maximum natural light and views (Figure.27). 
VIEWS OF NATURE/NATURAL UGHT

1) ENLARGE EXISTING OPENINGS
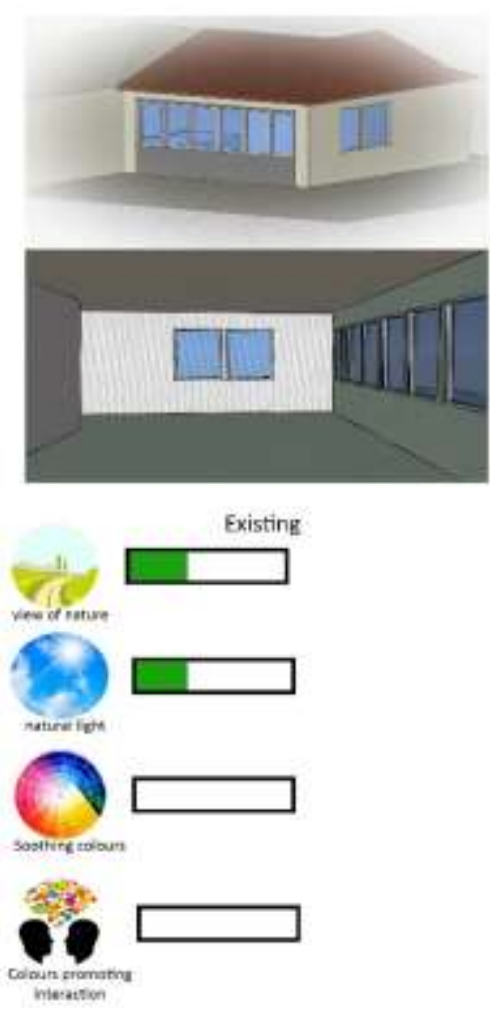
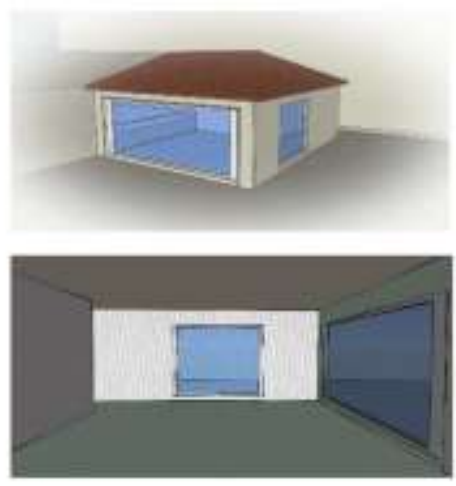

option 1
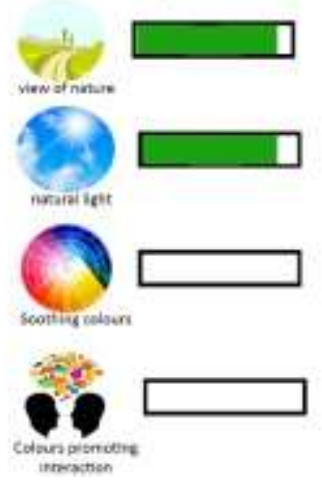
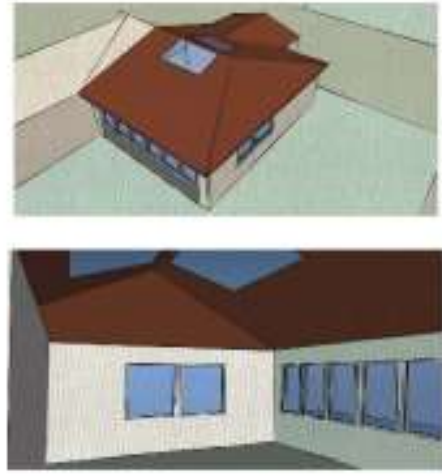

option 2
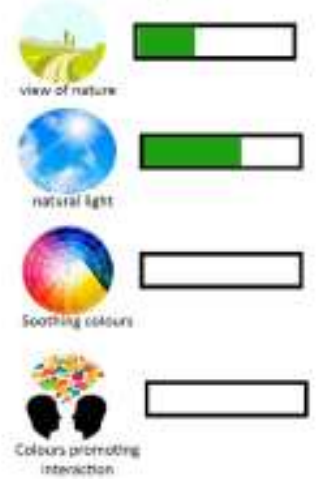

Figure 26: Option examples
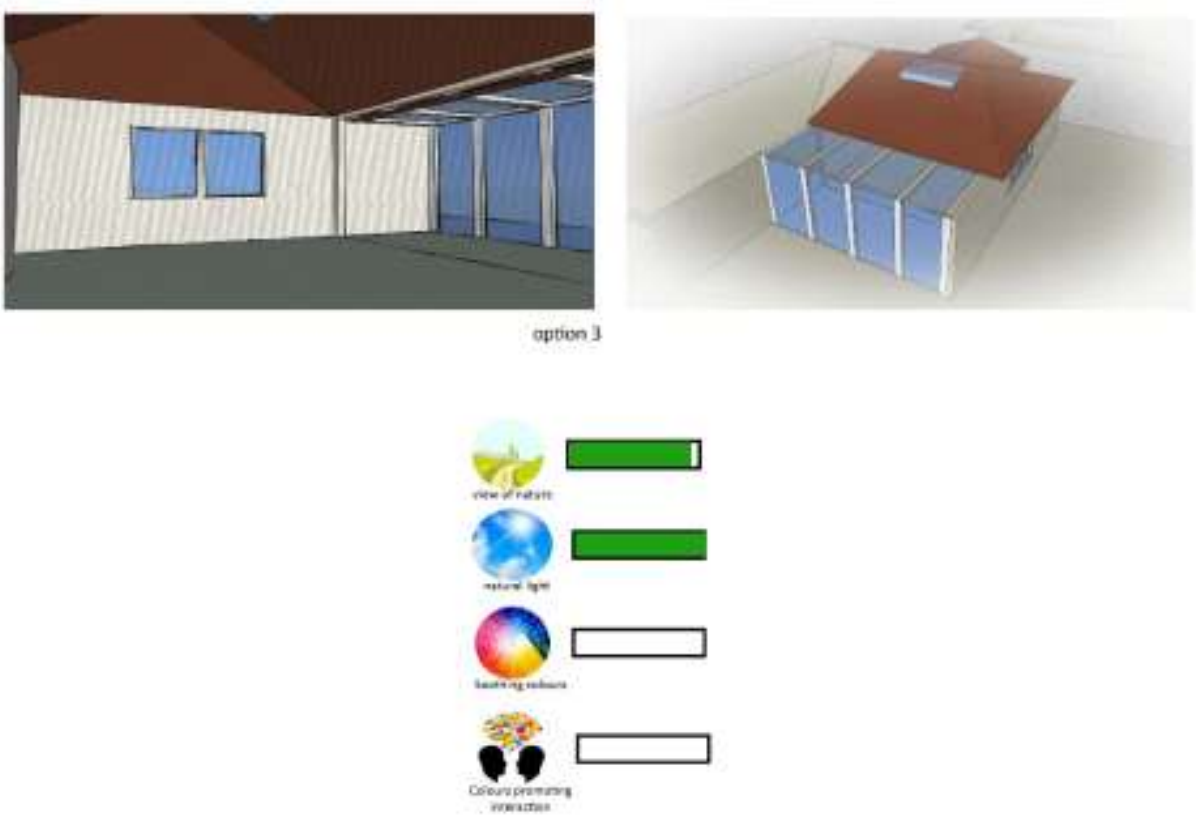

Figure 27:Option example 
Option in the figure 27 brings in maximum light and views. Extension with a glass roof and wall on the South West wall brings in more light throughout the year. If the glass walls are designed as openable doors, residents can access the garden outside or even keep it open during summer and interact more with nature.

Disadvantage of this option is need to find solution to control too much brightness when not necessary.

\section{A.2 BETTER CONNECTION WITH INTERIOR AND EXTERIOR}

Connection with nature and natural elements have proven to make humans feel more emotionally content and this has the potential to increase their life span (Bhatt, 2015)

A better connection with interior and exterior could be achieved with indoor gardens and introducing patterns of nature onto the interiors. This is another way to increase presence of nature in the interiors.

\section{A.2.1 Patterns of nature}

Many recent studies also show that emulating nature in the build environment can positively impact the well-being of residents (Totaforti, 2018). For this some patterns were derived from the nature. As shown in the figure 28

The use of botanical shapes and forms instead of straight lines is a characteristic of biophilic designs, as well as establishing a visual relationship (Stouhi, 2019)
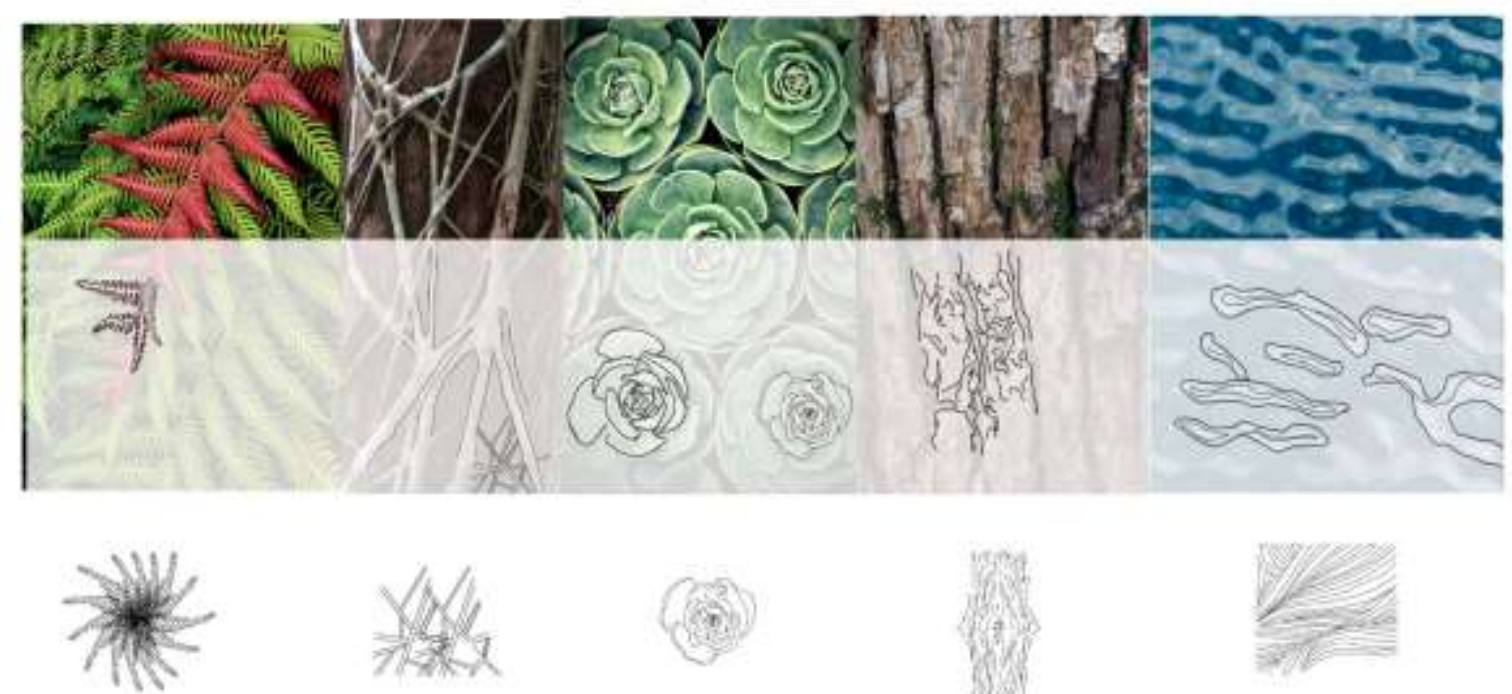

Figure 28: Few patterns of nature abstracted 
In the figure 28 few patterns are extracted from natural elements like leaves, wood and water. These patterns overlaid to create abstracted patterns of nature. These patterns represent leaves, motion of water, wood and flowers. Abstracted patterns can be used to evoke the feeling of nature in the interiors.
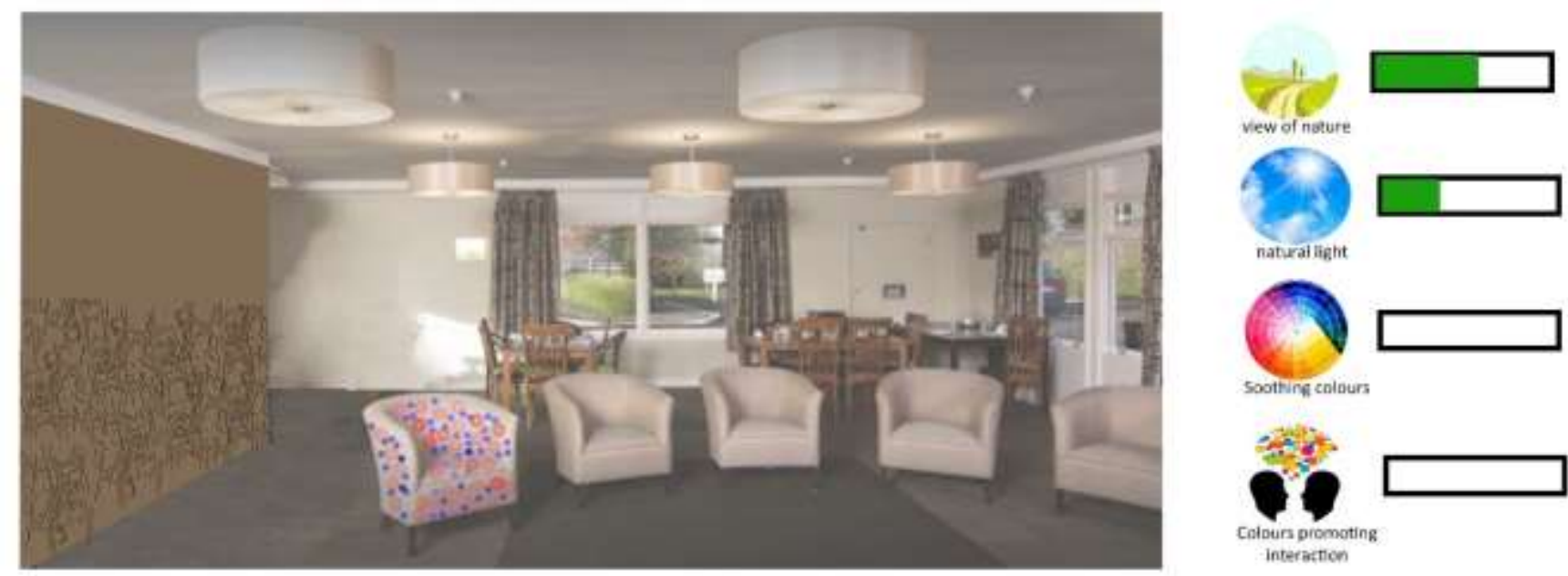

Figure 29: Example of abstracted patterns of wood used as a wall feature and

\section{Colourful floral pattern used on chair.}

\section{A.2.2 Indoor garden}

Contact with nature plays a vital role in our psychological wellbeing. Providing indoor garden is another way identified to create a better connection with interior and exterior. Indoor garden is physiologically restful and soothing to eye, since wavelength of green colour easier for the eye to perceive. Series of options of indoor gardens were analysed using the key architectural strategies as the examples shown in figure 30,31 and 32 

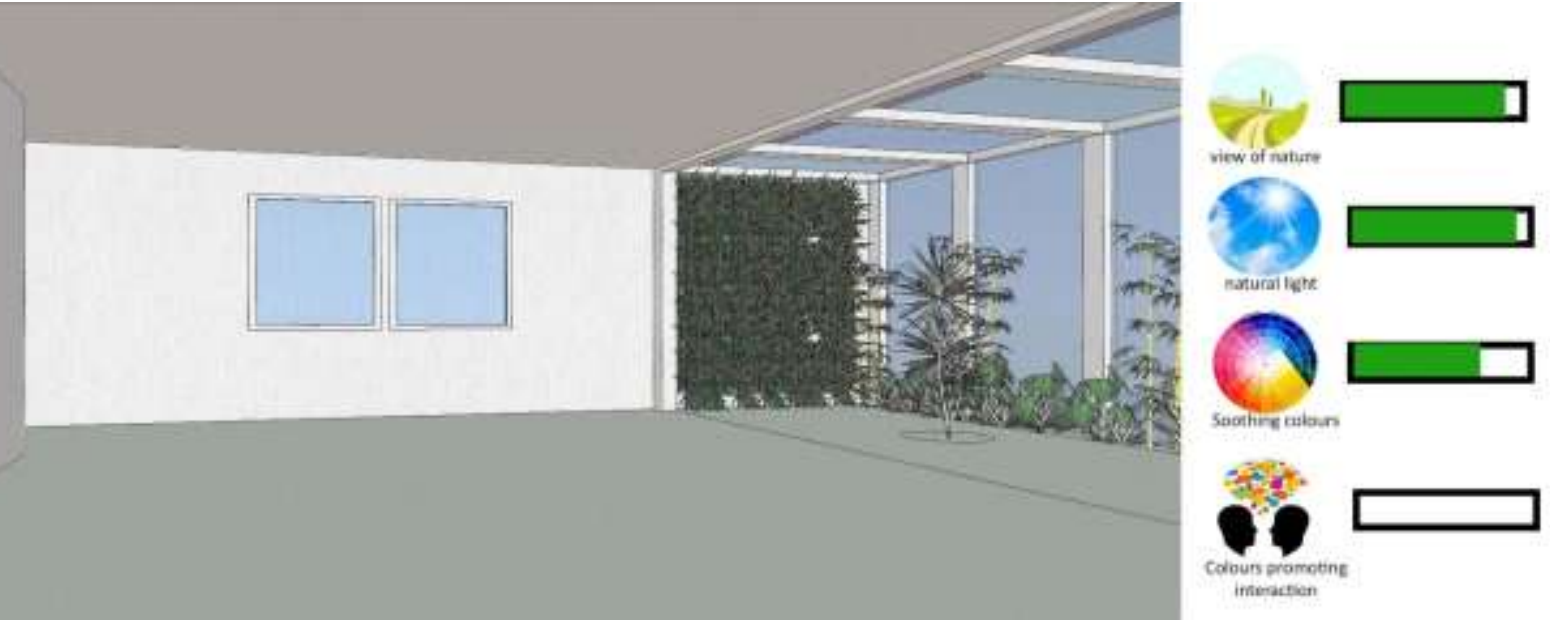

Figure 30: Design exploration of indoor garden; Option1

In the option 30 Green wall and an indoor garden is introduced into the extended portion and observations were made. Bringing in nature has increased presence of nature as well as soothing colours in the space.
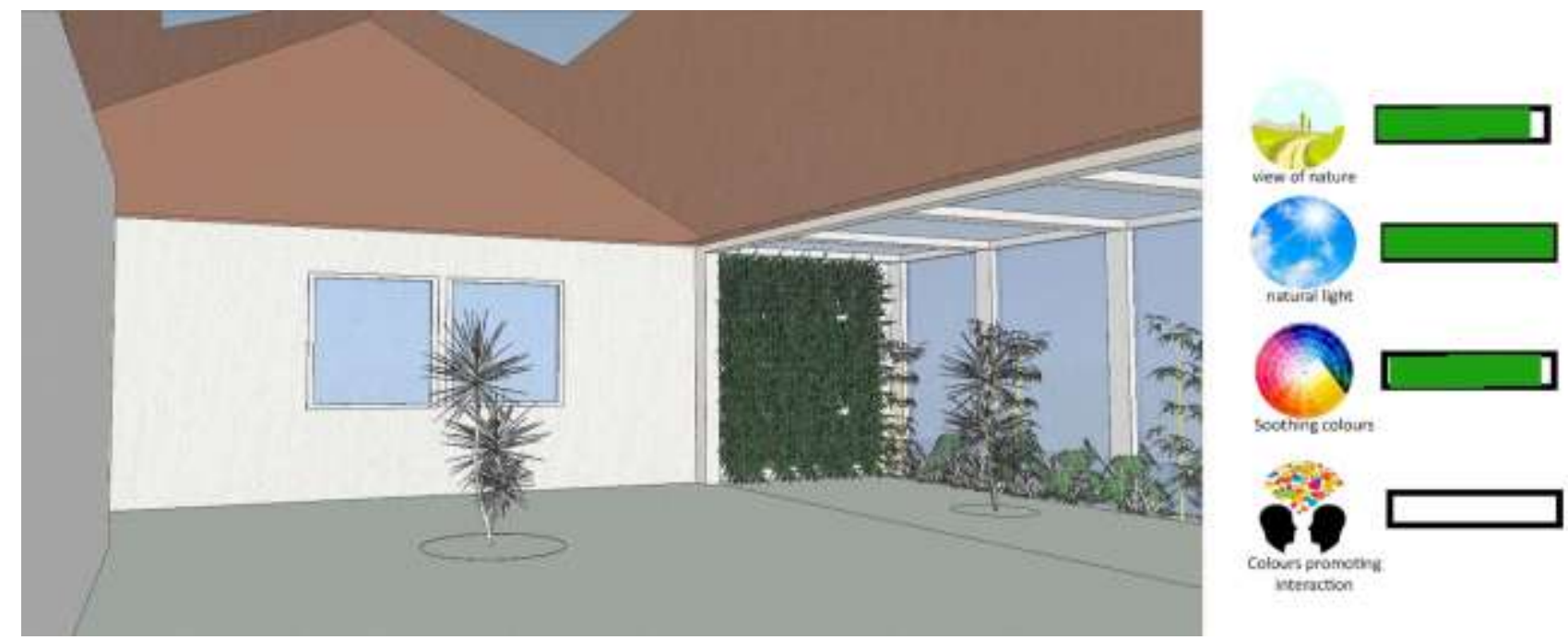

\section{Figure 31: Design exploration of indoor garden; Option 2}

In the option 2 (Figure 31) an extra skylight is introduced; this again increased the natural light in the room. 


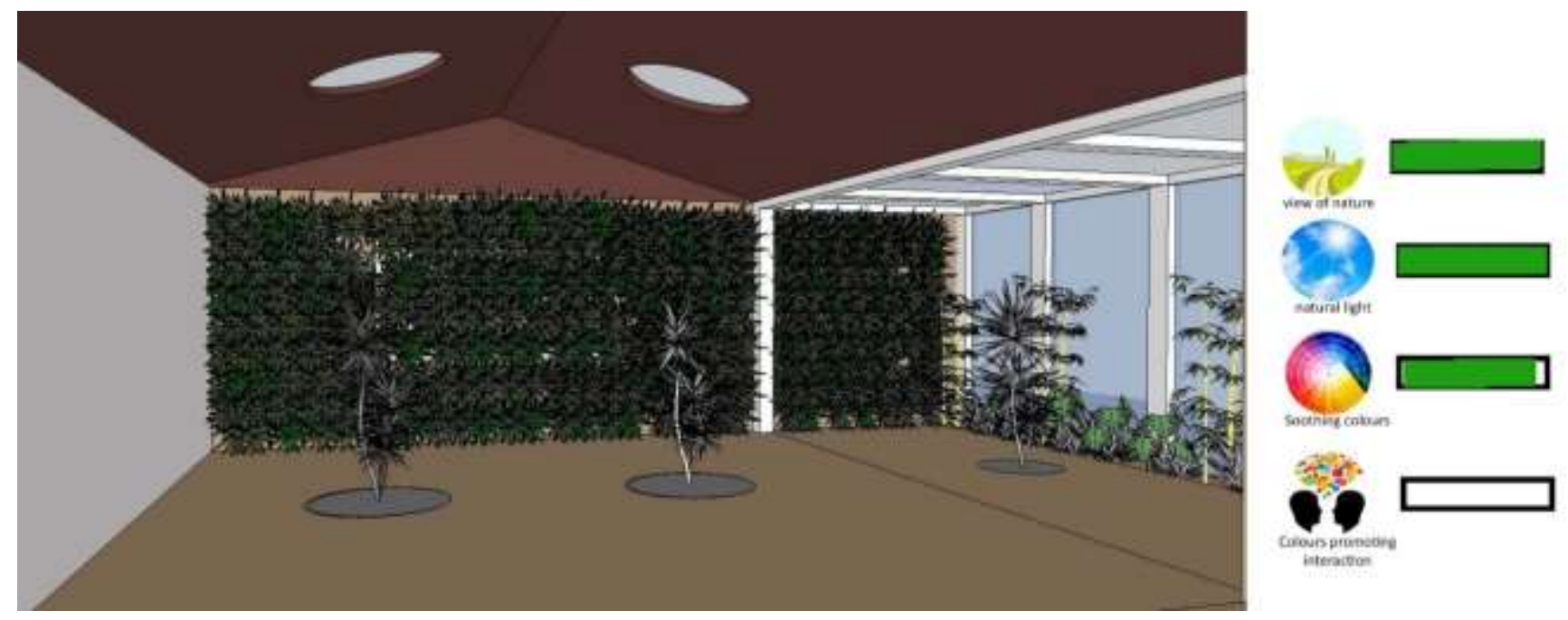

\section{Figure 32: Design exploration of indoor garden; Option 3}

In the figure 32 green wall is extended to occupy the whole south east wall. This option seems to increase visual connection with nature and interiors and also increased presence of nature. This also brings in soothing colours naturally into the space.

\section{B. SOOTHING COLOURS}

Nature is soothing as well as colours of nature are soothing especially colours of a garden. One of the best ways to introduce soothing to a built environment is through indoor gardens and elements of nature. So, through the above explorations soothing colours are already introduced to the space.

In response to these considerations a new series of design explorations was undertaken with a focus on bringing the in soothing colours through colouring the selected interior surfaces. Few of the examples are given in the figures $33,34, \& 35$ 


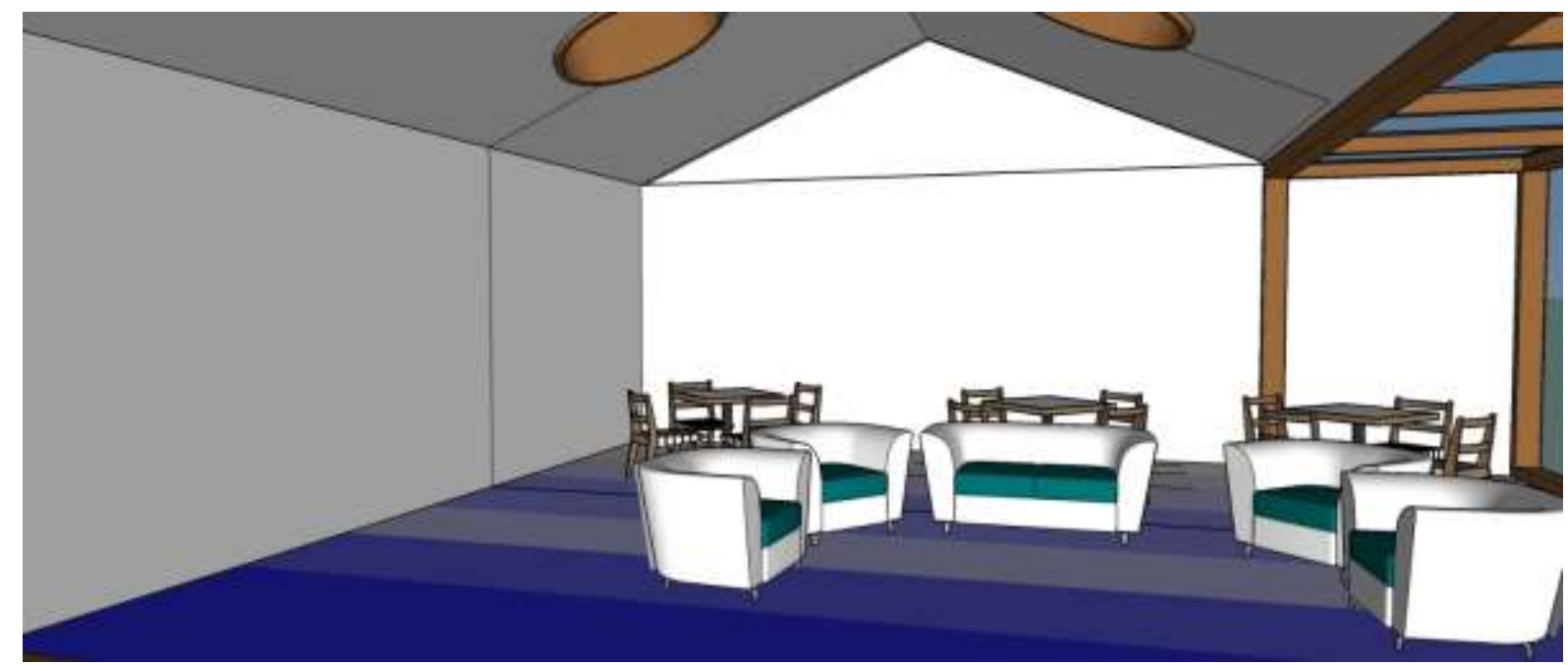

Figure 33: Example from soothing colours on floor

Floor covers large area in the interiors. It is observed that giving colours on floor could change the entire ambiance of the room.

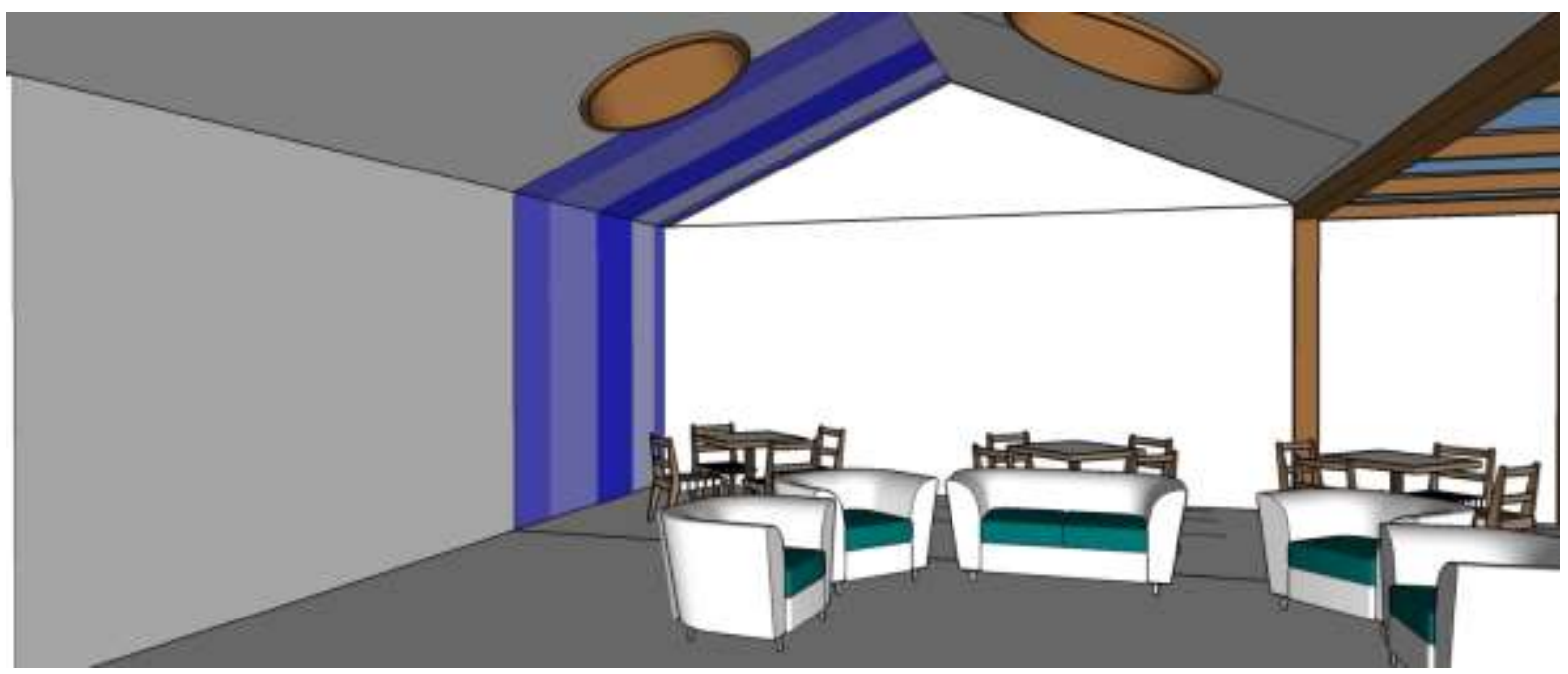

Figure 34: Example from soothing colours on wall and ceiling

From the figure 34 it is observed that giving colours similar way is having an impact on the size of the room and also tonal difference can reduce the impact of a single colour. 


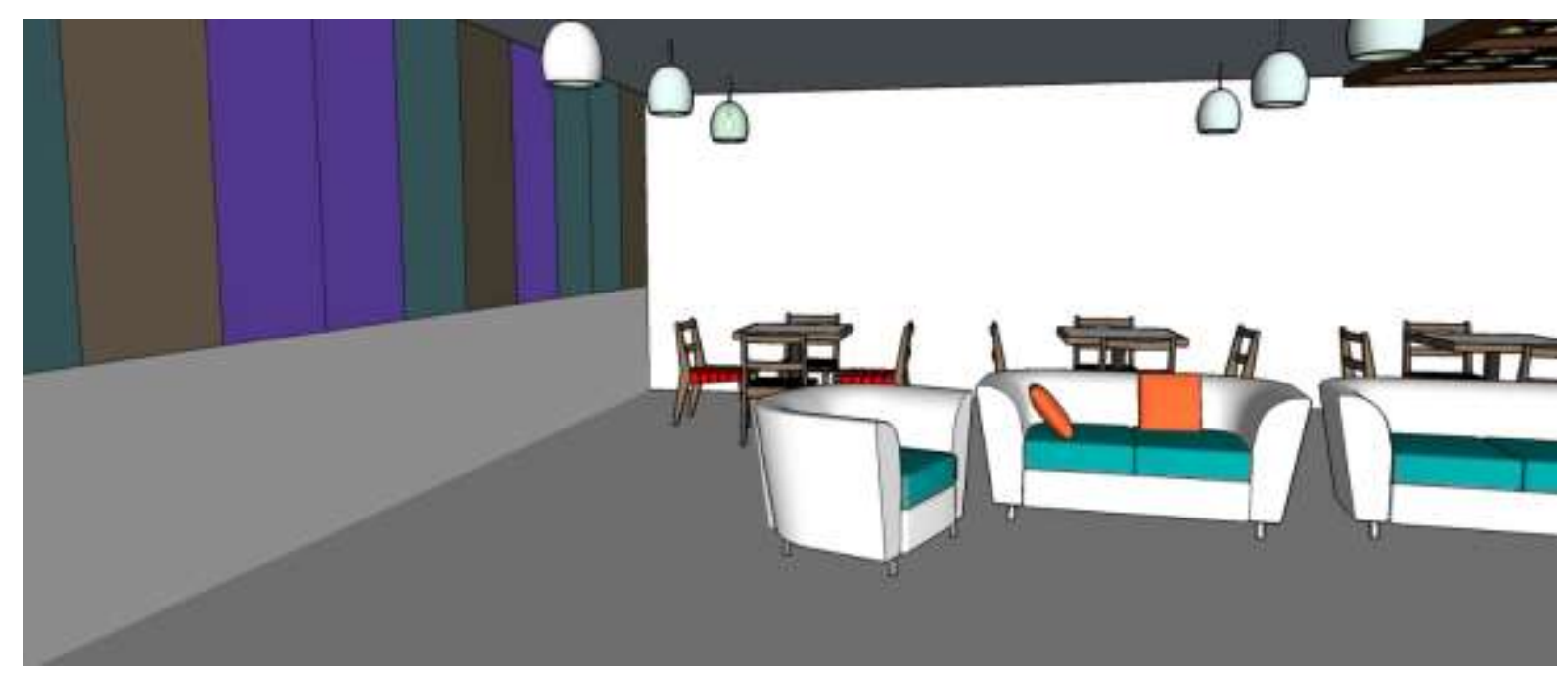

\section{Figure 35: Example of soothing colours on the wall}

In the figure 35 Intermediate colours like blue green and blue violet are mainly used on walls. Neutral colours like shades of grey are also used along this combination to create a balance. This coloured portion is suggested to be treated as a pinboard for the residents to pin their creations and photos to make the room homely.

\section{COLOURS PROMOTING INTERACTION.}

It is that interaction is vital for healing (Gesler, 2003 , p. 14). Socially engaged elderly are at lower risk for depression, loneliness, other negative health outcomes (Drageset, 2004). Interacting with fellow residents can help elderly to keep themselves happy and active. From the literature review it is known that some colours like red and orange stimulates conversations as well as can promote people to be active. Therefore, different shades and tints of both colours were applied on different surfaces and observations were made. A snapshot of applying colours promoting interaction with few examples are shown in the below figure.

In the Figure 36vcolours promoting interaction are applied on the different surfaces of the interior. It was observed that colour on different surfaces creates different ambience in the room. 

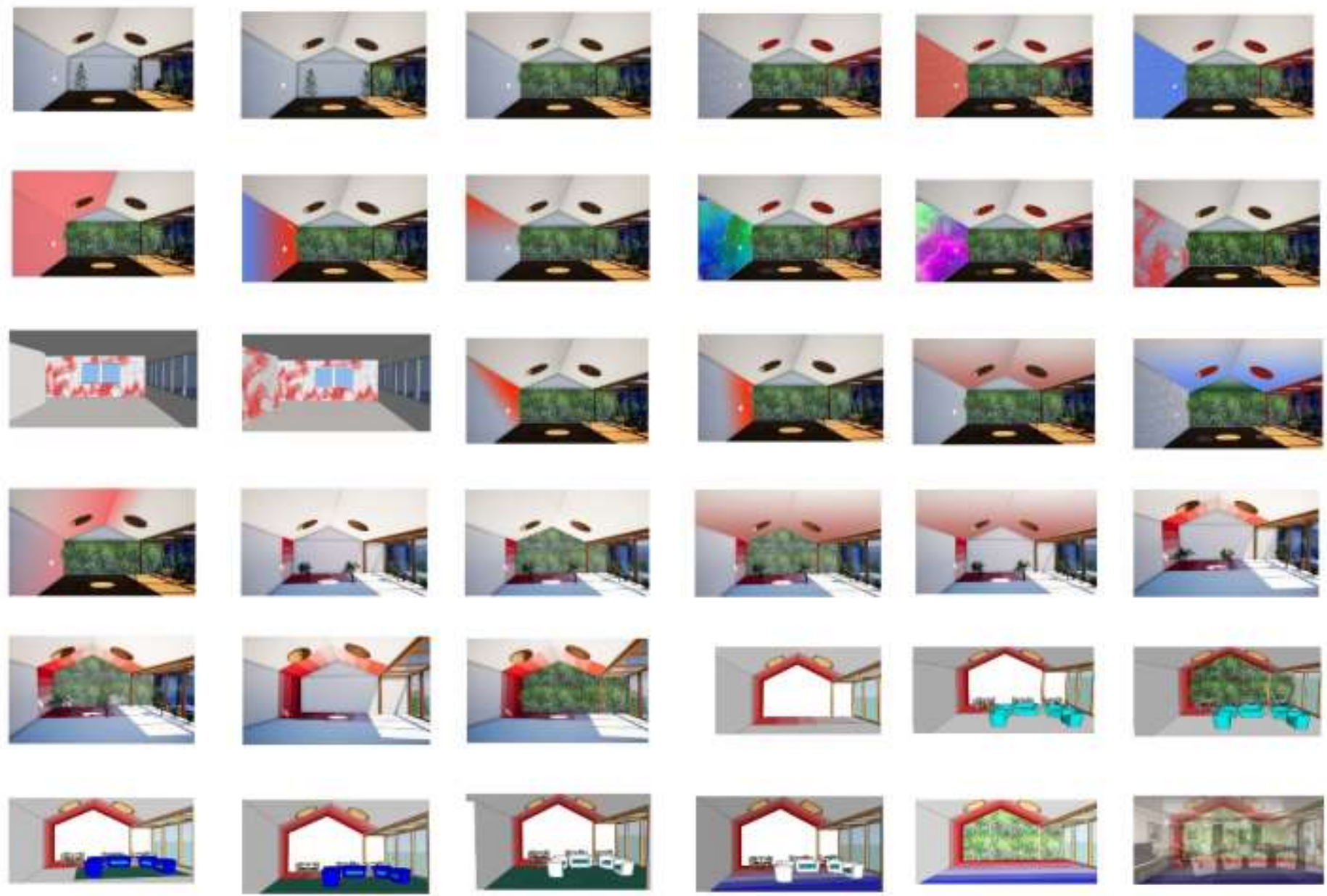

Figure 36: Snapshot of design explorations with colours promoting

\subsubsection{SUMMARY AND REFLECTION}

To begin with design explorations key architectural strategies identified by the literature review is examined and different design options are made to increase these key strategies in site. Integrating these key strategies into site give a good beginning to design process.

The first set of explorations is about bringing colour through indoor gardens, giving colour to walls, floor, ceiling and furniture. Increasing natural light and view of nature by expanding the room with grass roof and wall is considered to be a success when compared to other design variations made. As they let in more light and views. These walls are to be designed with an openable door so that residents can keep it open during summer or access garden outside.

It is known that nature is having a power to heal. Therefore, bringing in nature through green walls and indoor garden is also considered to be a success in order to promote healing. It gives 
a better connection with indoor and outdoor as well as soothing colours are brought in naturally through these plants.

Different explorations where done to bring in soothing colours and colours promoting interaction into the interiors. Even though through coloured pin boards, furniture and pin board are found to be interesting, failed to take a final decision and this set to the need for another set of design explorations

\subsection{HOW TO BRING IN COLOURS NATURALLY?}

Question how to bring in colours naturally is explored in this set of design exploration. One of the solutions for this question is coloured glass.

\subsubsection{FIRST SET}

To start with, different designs were explored on the glass wall and roof with colours promoting interaction and soothing colours. Randomly selected few examples from series of explorations are given below in figure 37. 


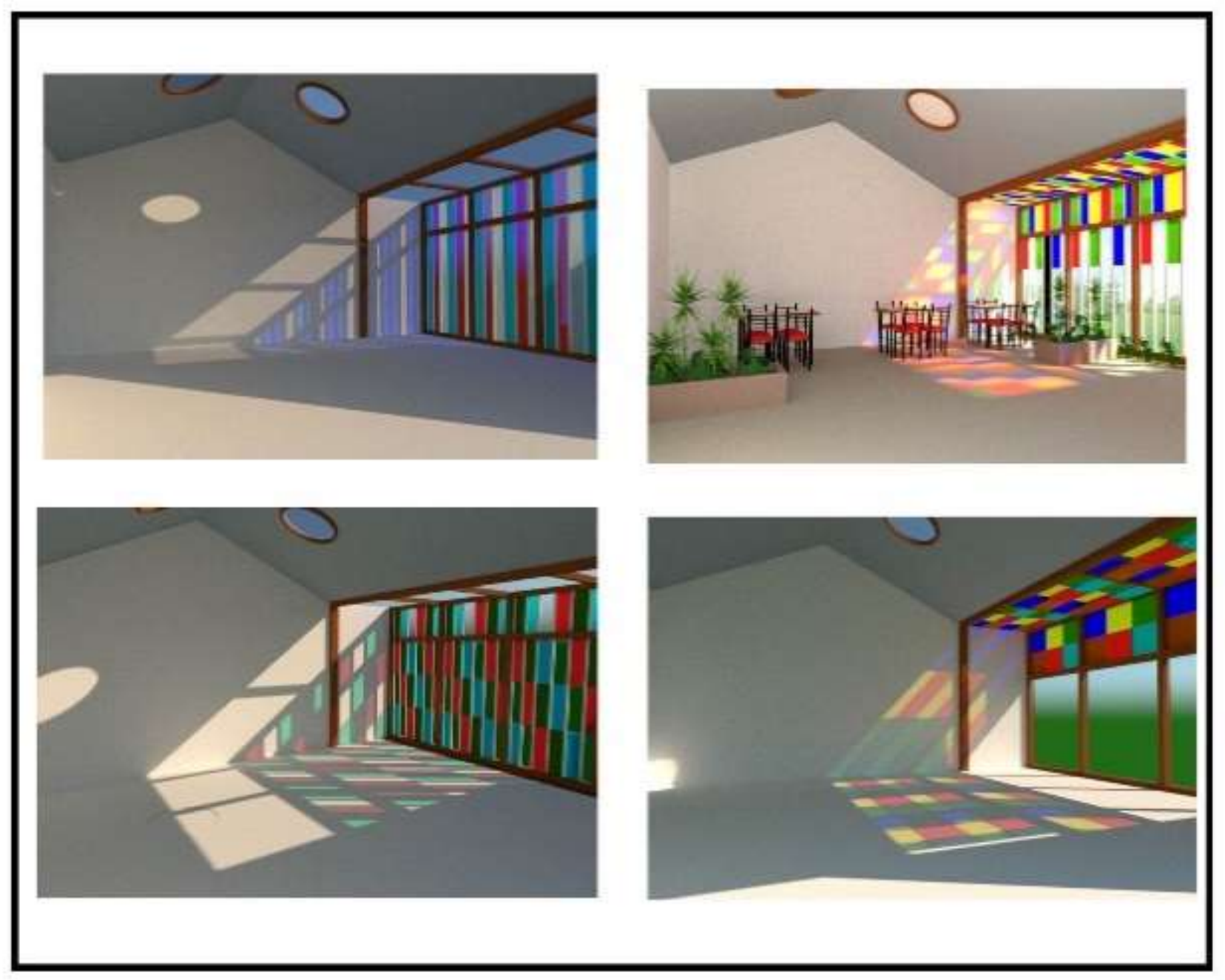

Figure 37: Few examples from first set of design

From first set of explorations (figure37), it was found that some of the designs are blocking the natural view. So, to make a selection considering view of nature and natural light figure 38 was selected. 


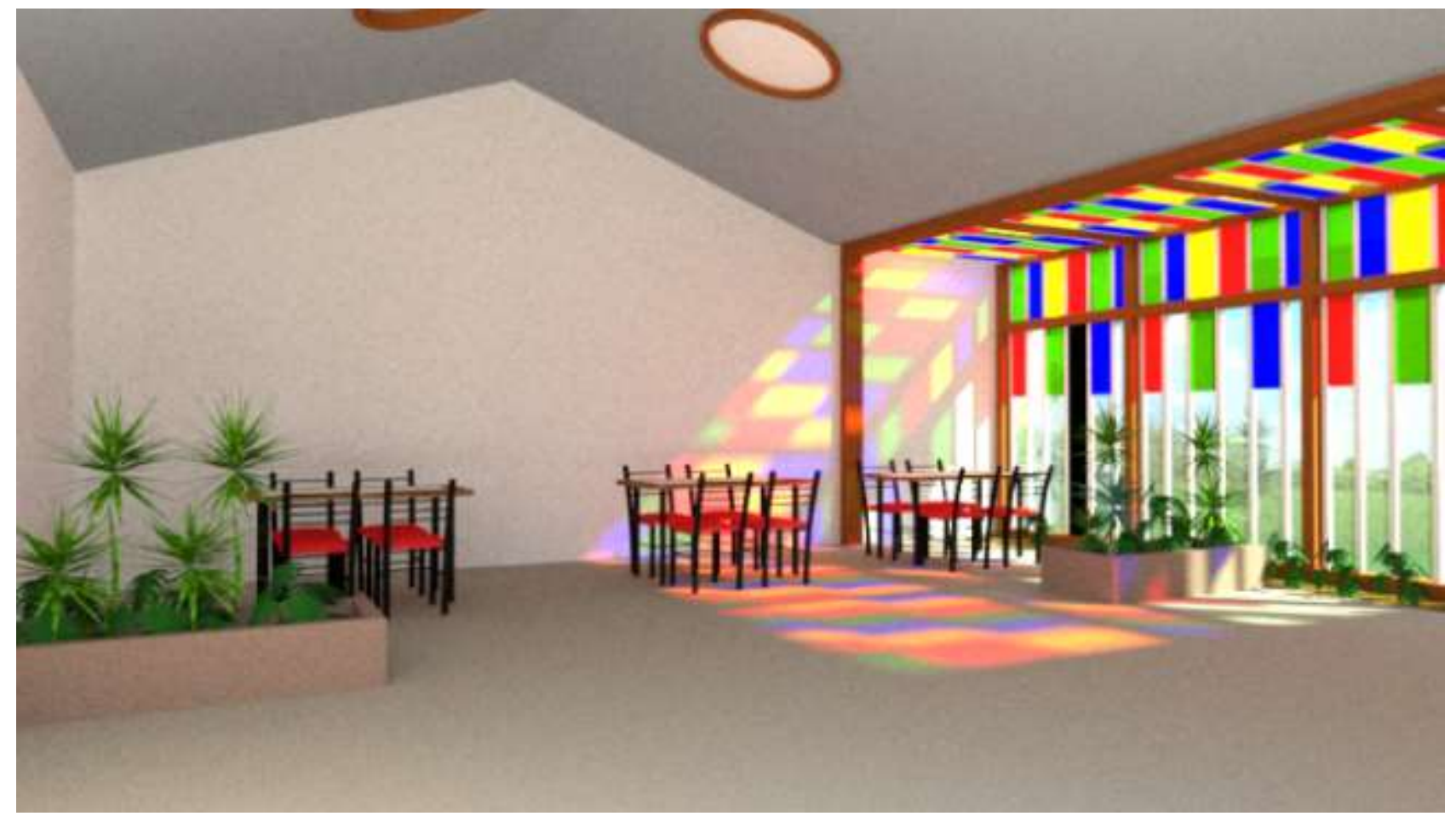

Figure 38: Selected design from first set of design exploration

Selected design in Figure 38 brings in both soothing colours and colours promoting interaction to the room without blocking views of nature and natural light. Colours mainly fall on floor and south east wall throughout the year.

\subsubsection{SECOND SET}

Again, variations of the selected design in the first set were explored considering the patterns of nature abstracted in the section A.2.1. Figure 39 shows few sets of explorations using patters of nature on coloured glass. Based on interesting pattern amoung others from this again a design was selected (Figure 40). 


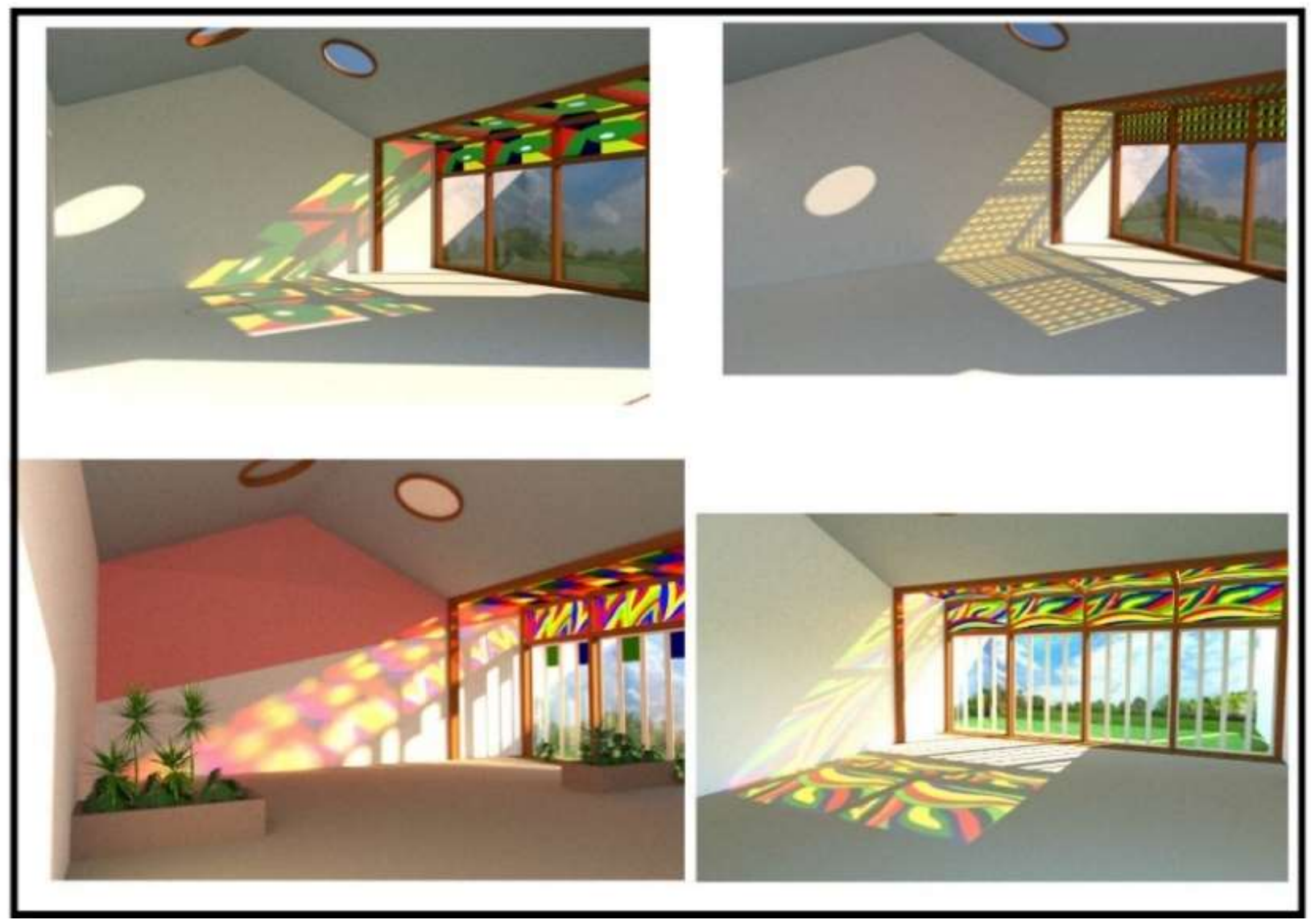

Figure 39: Examples from second set of explorations considering patterns of nature.

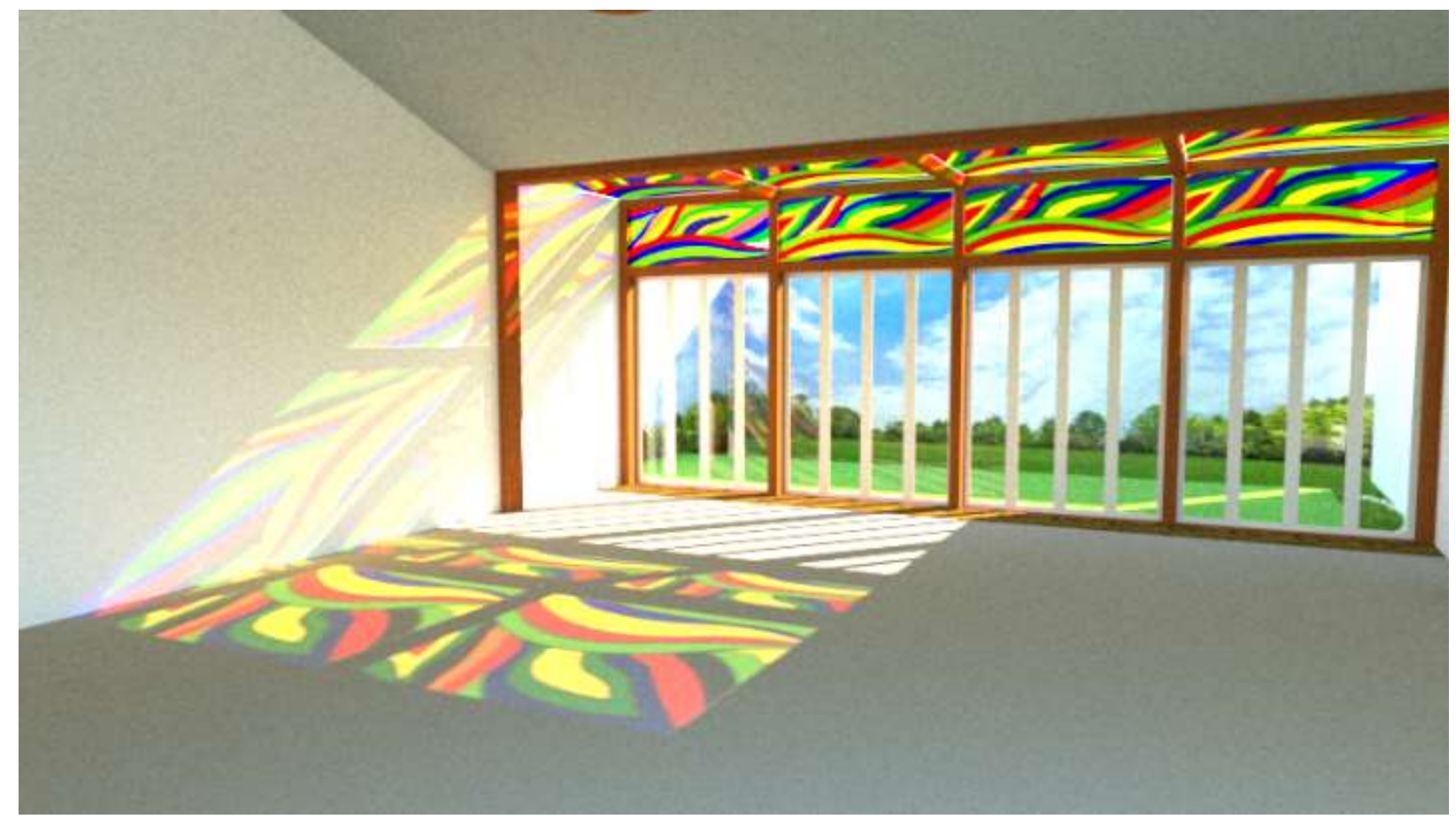

Figure 40: Selected design from second set 
Selected design from the second set (figure 40) have used colourful patterns of nature abstracted from the A.2.1. This represents motion of water and waves. Both soothing colours and colours promoting interaction are used in this design.

\subsubsection{THIRD SET}

This lounge can be divided into two zones according to the use, Dining zone and T.V zone. Dining zone needs colours promoting interaction and T.V zone needs to be soothing and calm in nature. From the literature review it is known that colours promoting interactions like red and orange are also good for increasing appetite therefore they are decided to use in dining areas. In the third set of explorations (figure 41), lounge is divided into two zones using the colour as a main driver. From the different variations design seen in figure 42 was selected from the third set.

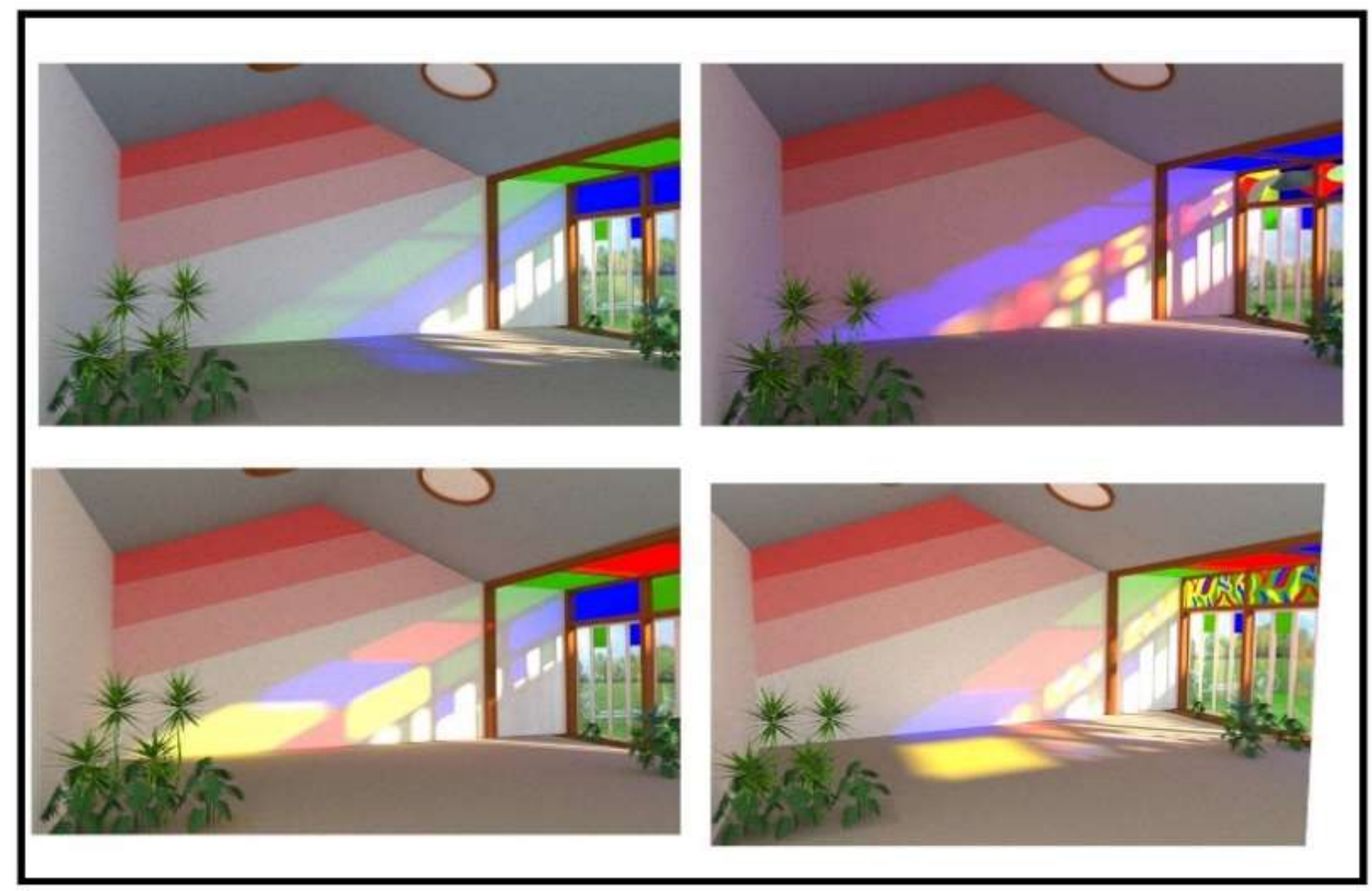

Figure 41: Examples from third set of explorations considering zoning of space 


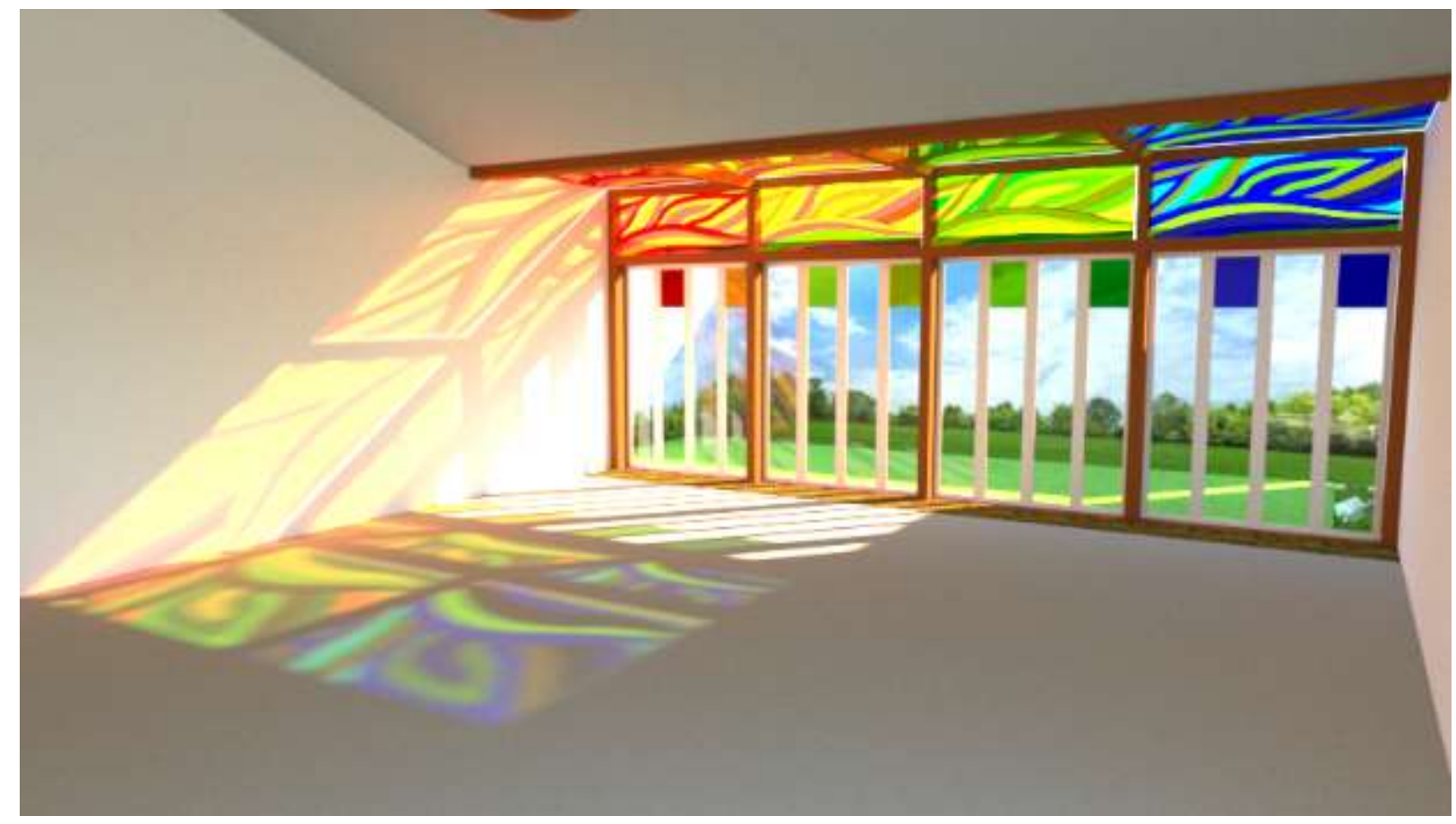

\section{Figure 42: Selected design from third set}

The design in figure 42 separates dining area and T.V area with the use of colour. In dining area colours like red, orange and yellow are used. Where as in television area soothing and relaxing colours like blue and green are used. 


\subsubsection{FOURTH SET}

Selected design from the third set was again explored for making further variations of designs. This time designs and light from roof was also explored. In this set of explorations variations with abstracted pattens were again explored along with grouping according to zone. Figure 43 shows examples of few variations made and figure 44 and figure 45 shows the selected design in this fourth set of design explorations.

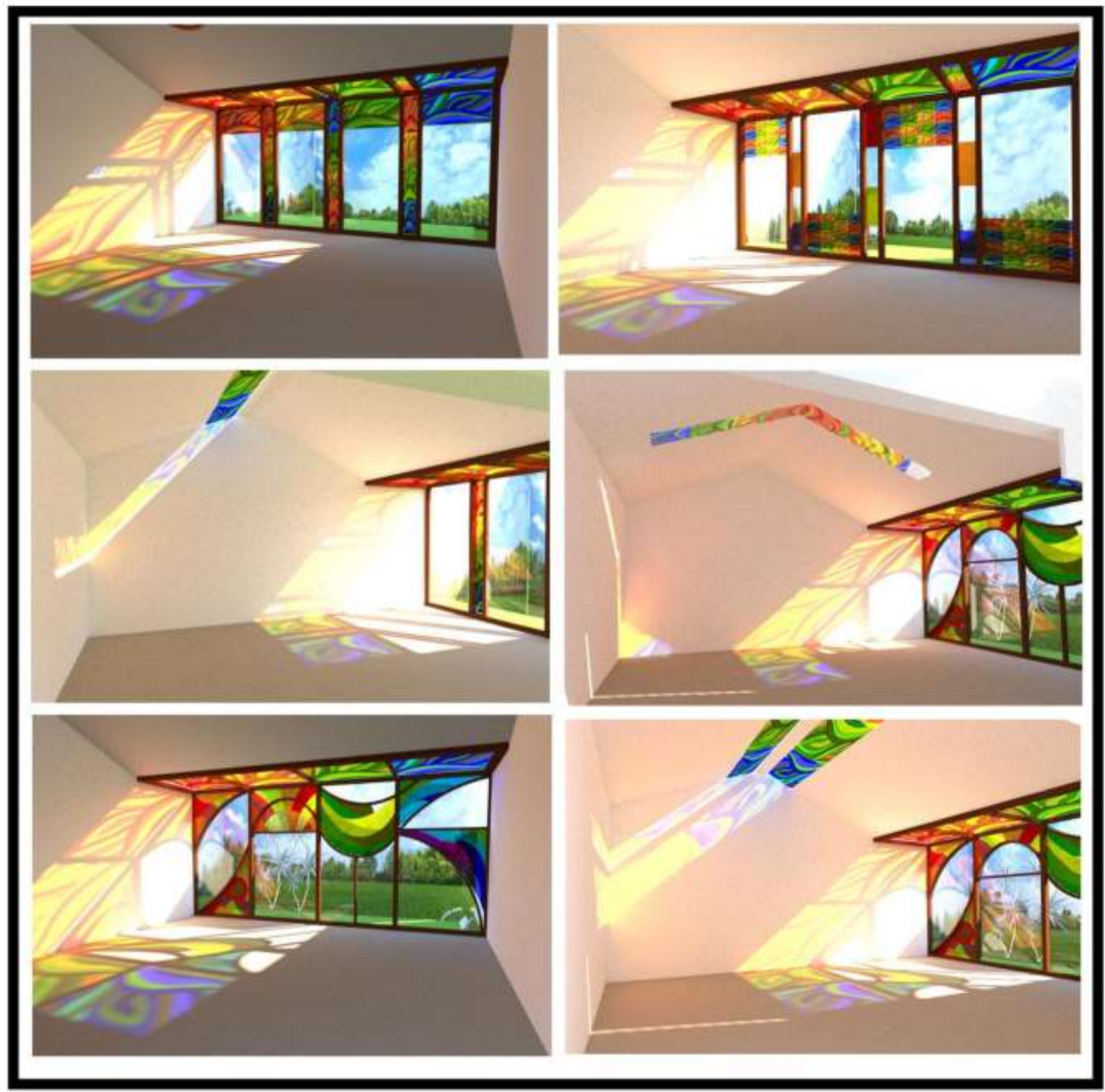

Figure 43: Few examples from fourth set of design 


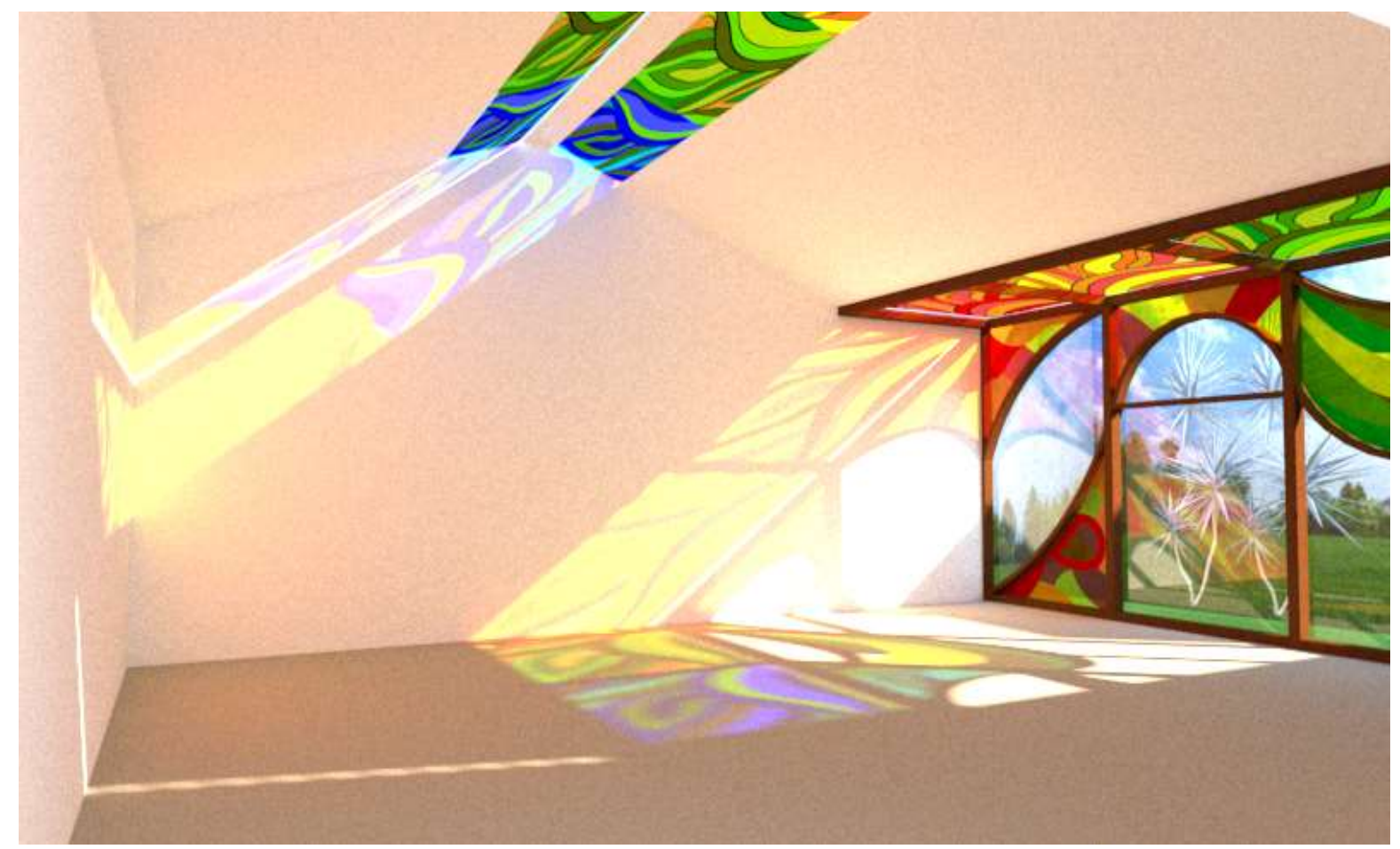

Figure 44: Selected design from fourth set; colours from the roof

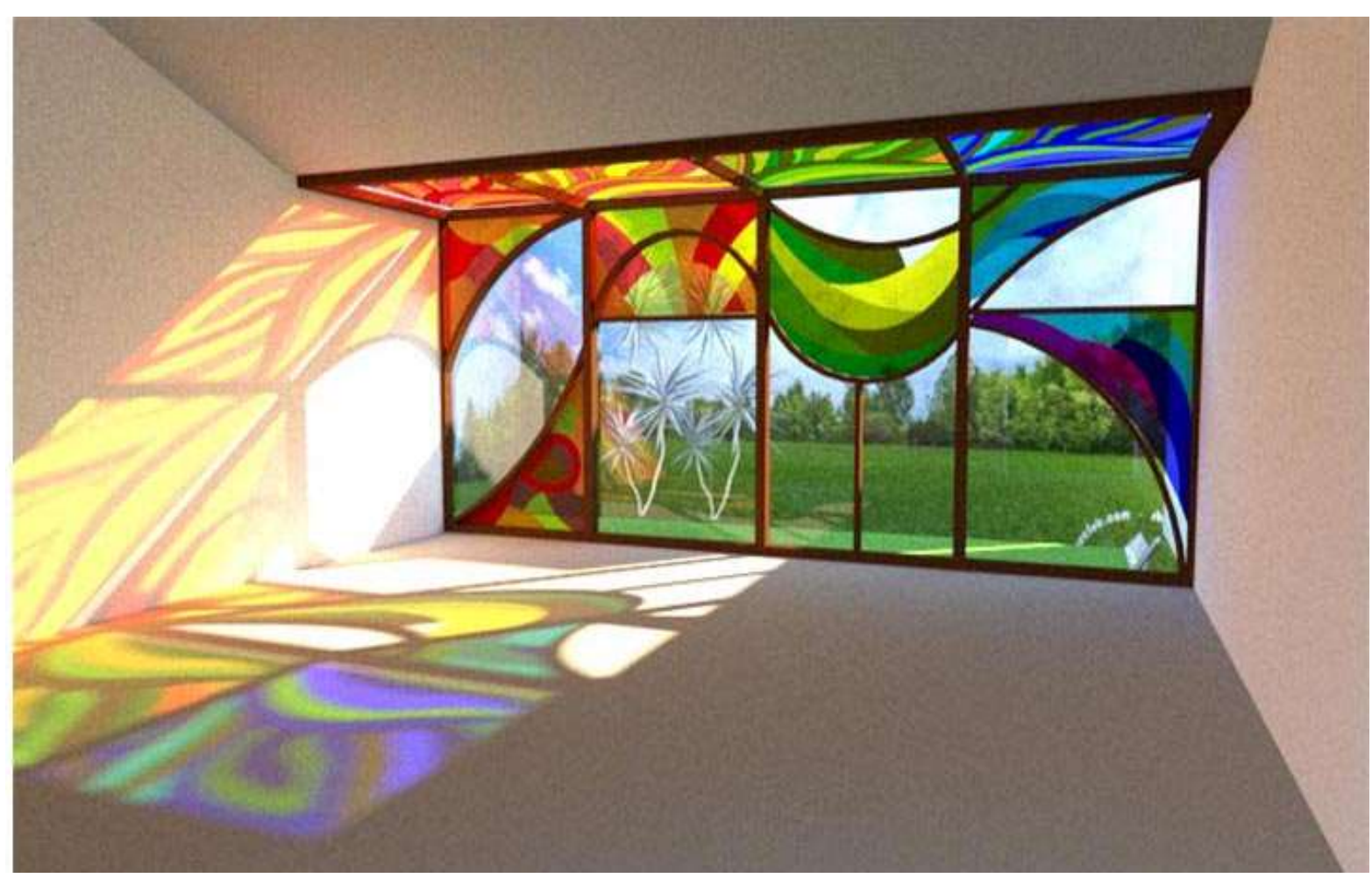

Figure 45: Selected design from fourth set; Colours from the glass wall

Selected design from the set four along with spreading colours with patterns, the whole glass wall act as a pattern. Colours on the glass wall act as a medium for separating dining and television zones in this design. 


\subsubsection{FIFTH SET}

In the fifth set of design study, reflections made through three dimensionally designed coloured glass were explored (see figure 46). Out of these explorations a final design was selected. (See Figures 47, 48 \& 49)

Coloured glass kept on the top are designed in such a way to let in energising colours like red and yellow during the morning, soothing colours like blue and green are refracted in the evening and all colours are visible when the sun is up in the noon.

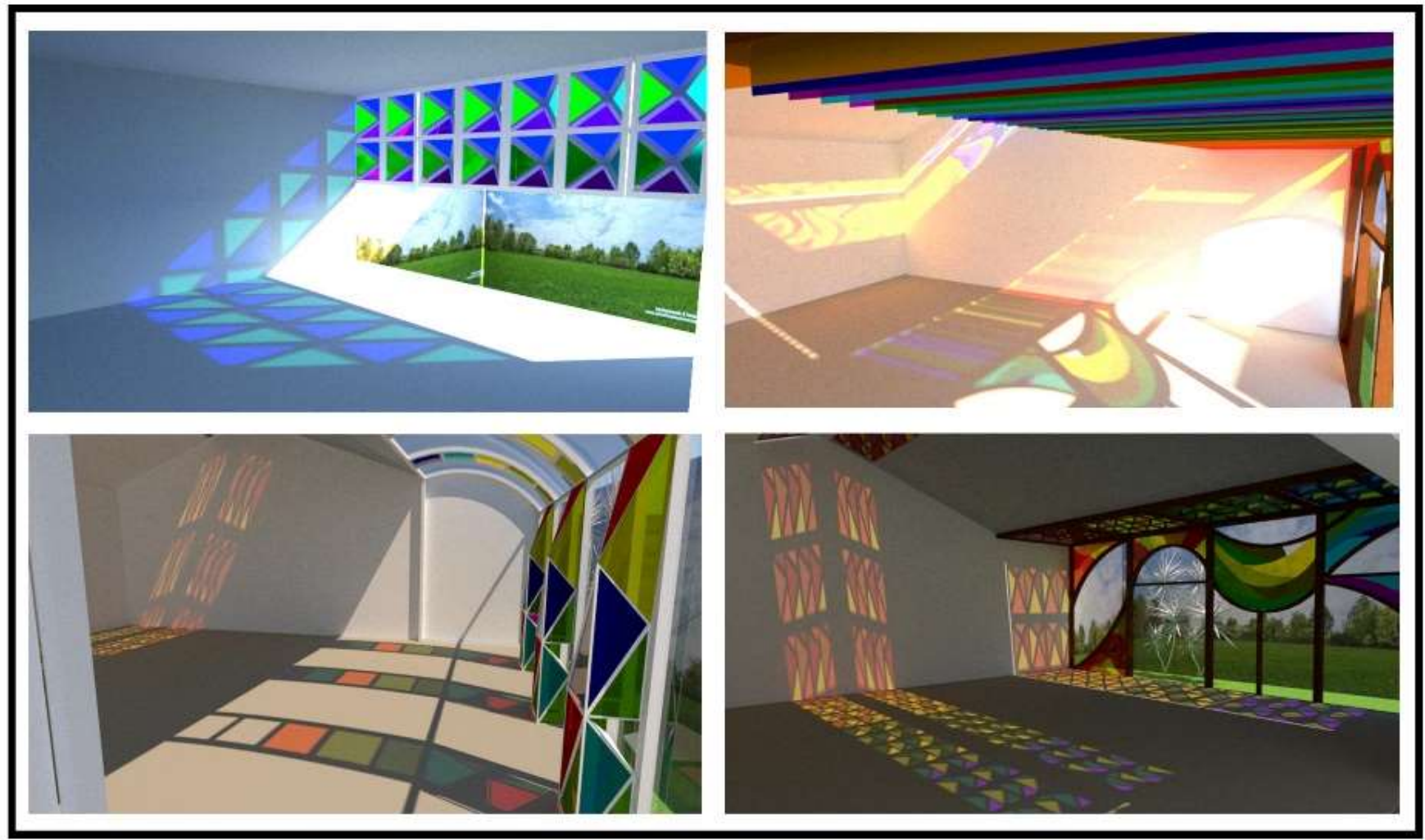

Figure 46: Examples from fifth set of design exploration 


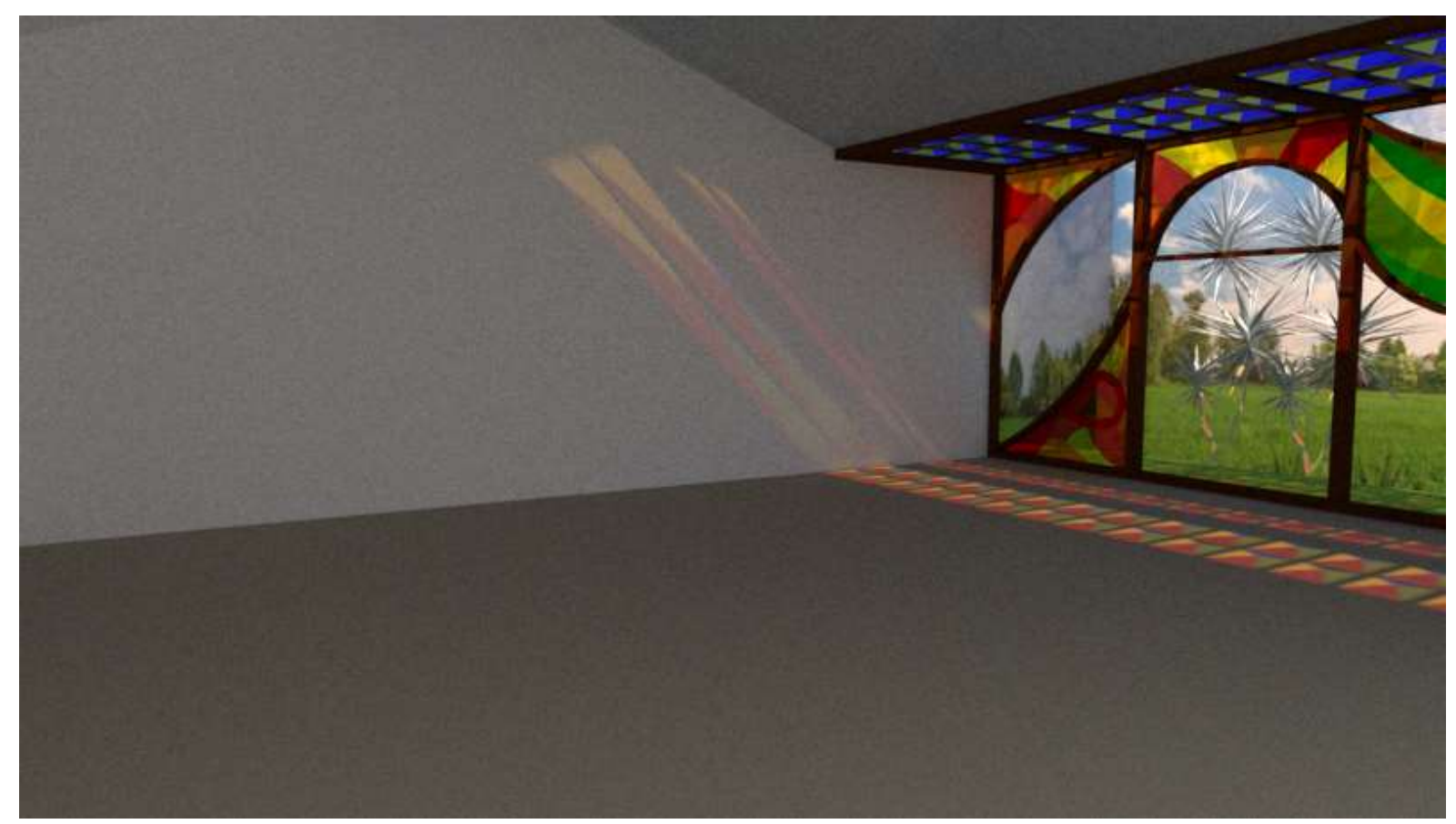

\section{Figure 47: Selected design; Morning colours}

For making mornings to be more energetic and interactive, colours like red and yellow-orange are selected as the morning colours. Over use of red seems to be irritating so to balance red complimentary colour green is also designed to let in with morning colours.

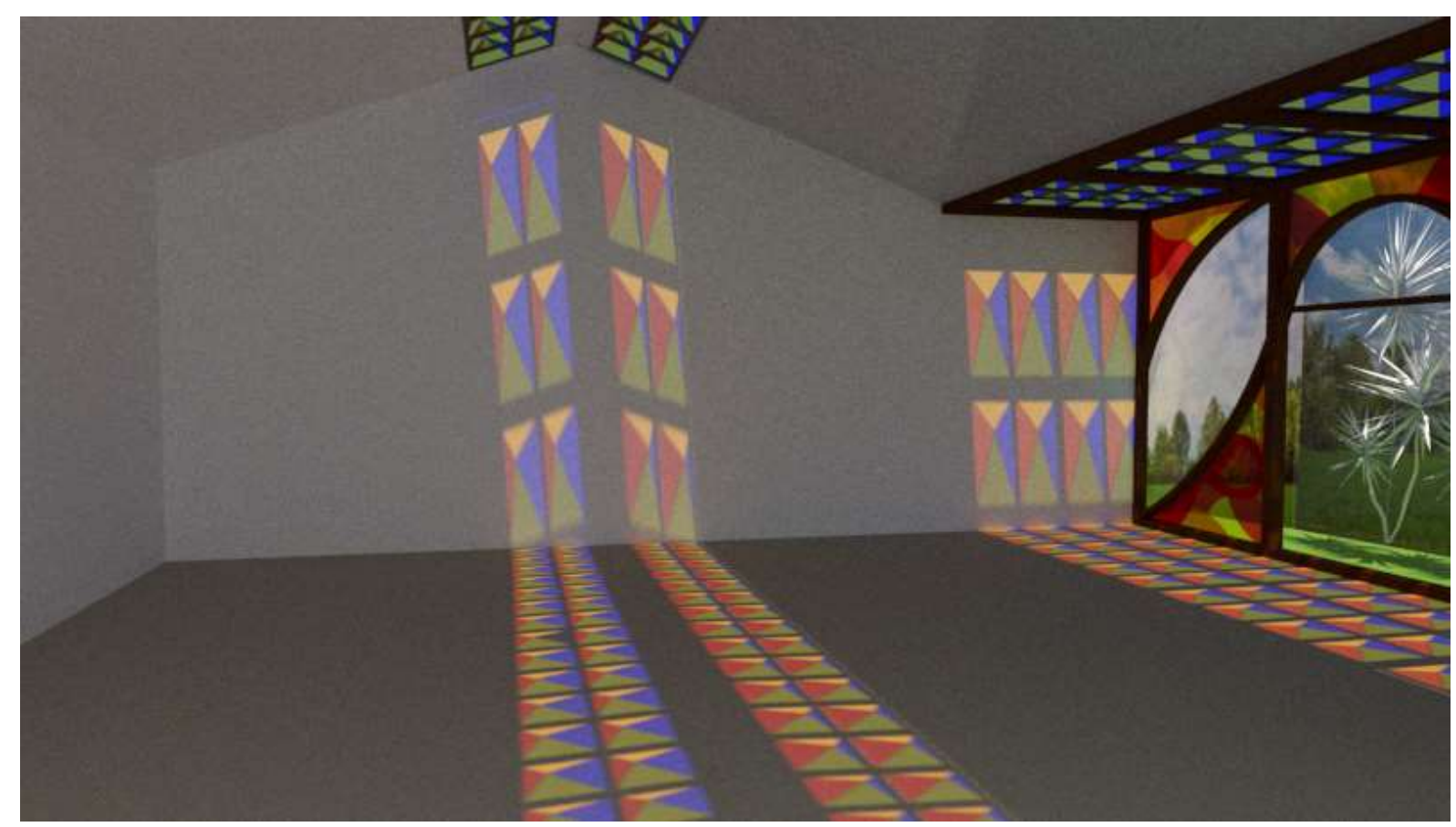

Figure 48: Selected design; Afternoon colours 
In the afternoon all four colours (Red, Yellow-orange, blue and green) are refracted inside the room.

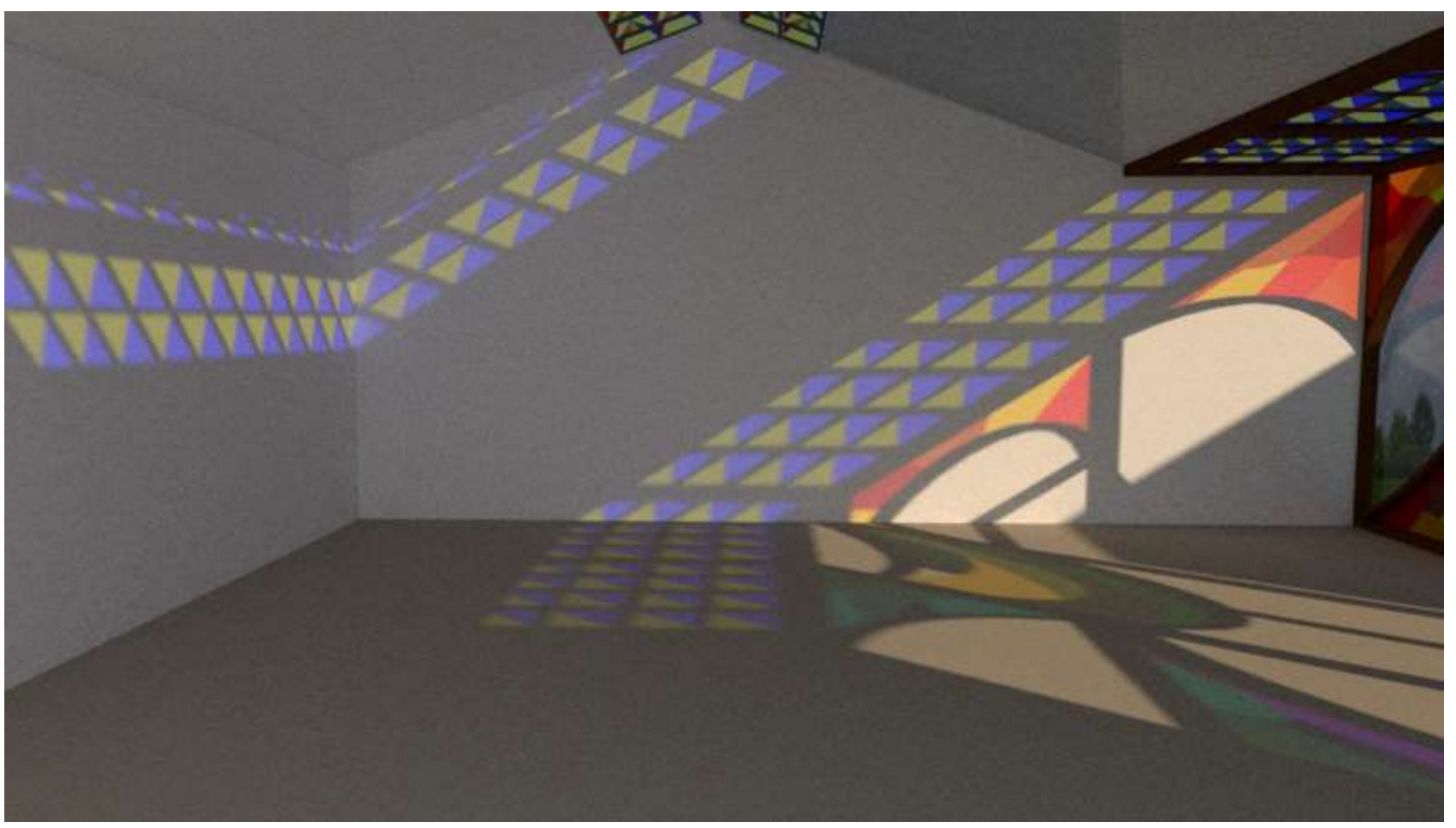

Figure 49: Selected design; Evening colours 

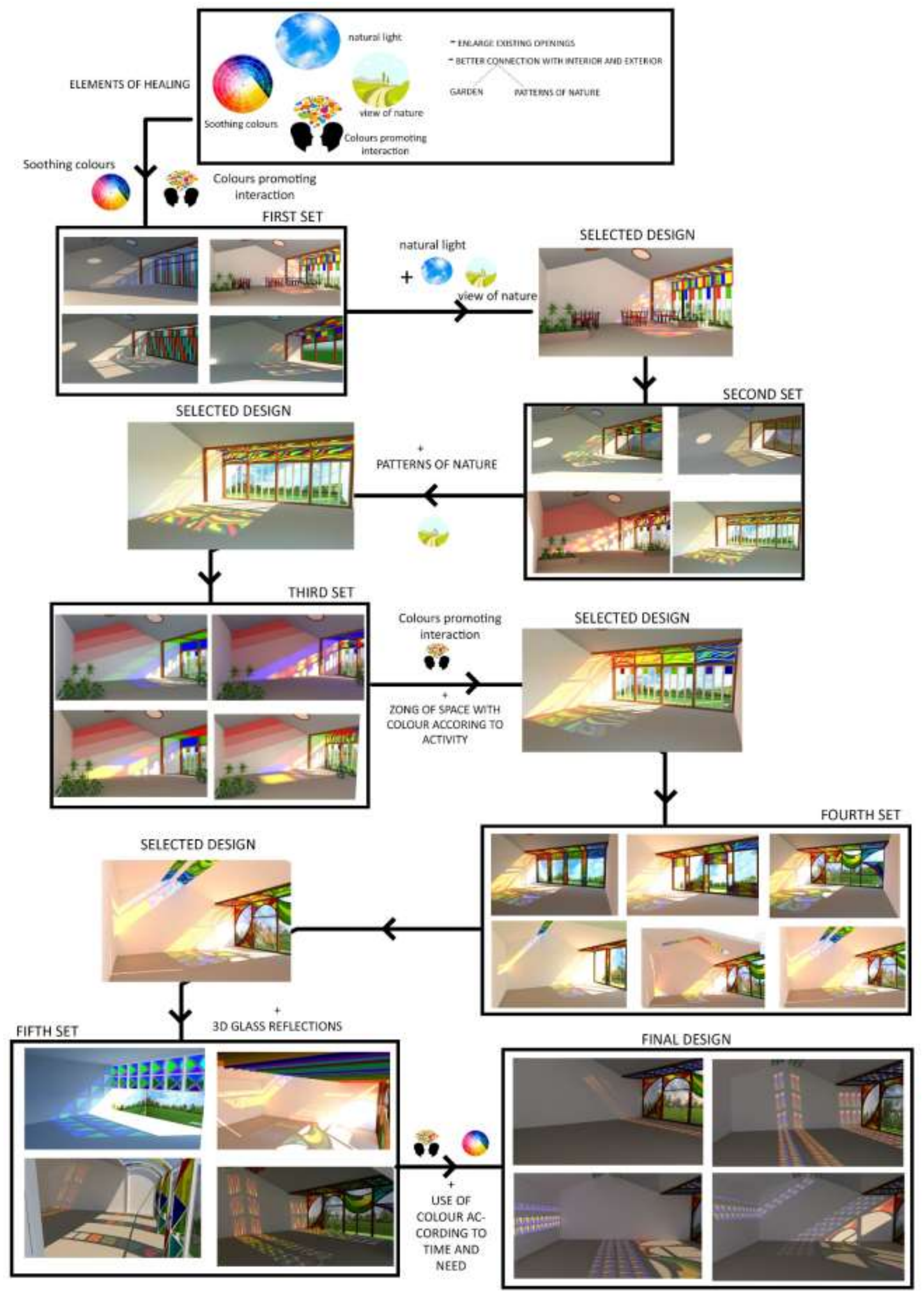
Figure 50: Work progression of section 7.3

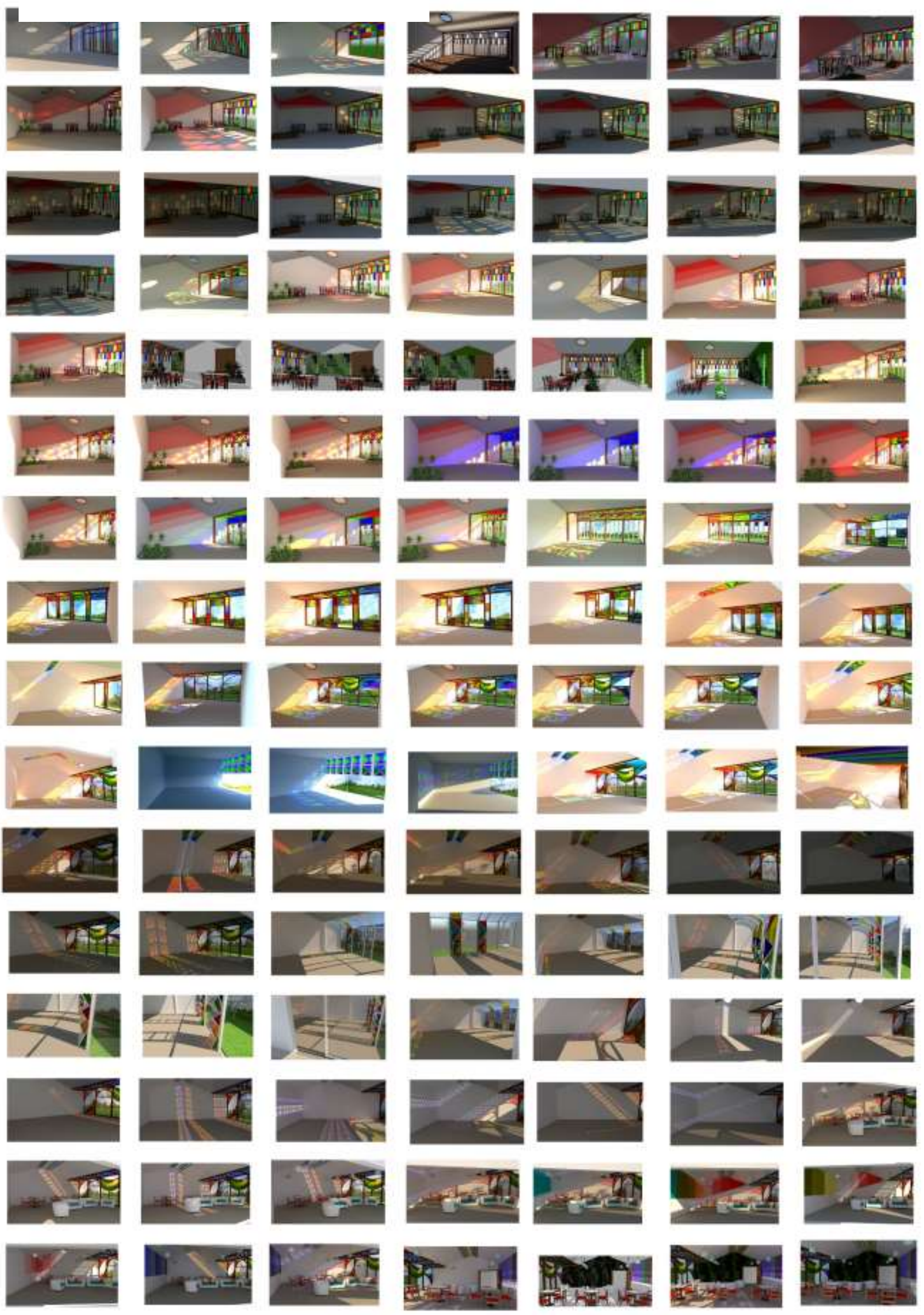




\section{Figure 51: Snapshot of section 7.3}

\subsubsection{SUMMARY AND REFLECTION}

Through this set of experiments ways to bring in colours naturally through glass is explored. Design explorations also integrates all four key design strategies for healing derived in the chapter 2. All the stages of design explorations helped to refine and develop the final selected design.

Designed three-dimensional glass roof opens an opportunity of bringing colours to the interiors according to the requirement of time. For example, mornings are designed to be more energetic and cheering to the residents by letting in colours like yellow, red and orange to the interiors. At the same time evenings are desired to be relaxing and soothing, bringing colours like blue and green is achieving this result in the interiors with this design.

Even though colours are still there on the wall, furniture and glass, future explorations need to be done on how to bring in colours on a cloudy day and winter evenings. Design need to be explored in ways to control too much light when it is not necessary. 


\subsection{COMBINING DESIGN EXPLORATIONS}

\subsubsection{DECIDING OTHER COLOURS}

Importance of background colour is explained in the section 6. From the chapter it is known that, the single most important factor in determining pleasantness judgements was not object colour but background colour. Moreover, any colour is properly visible when it is on white surface. Therefore, to enjoy the beauty of the refraction of colours to the fullest white was selected as the most suitable background colour.

In order to understand the play of shadow and light throughout the year, between the design explorations in chapter 7 a study of light and shadow was undertaken.
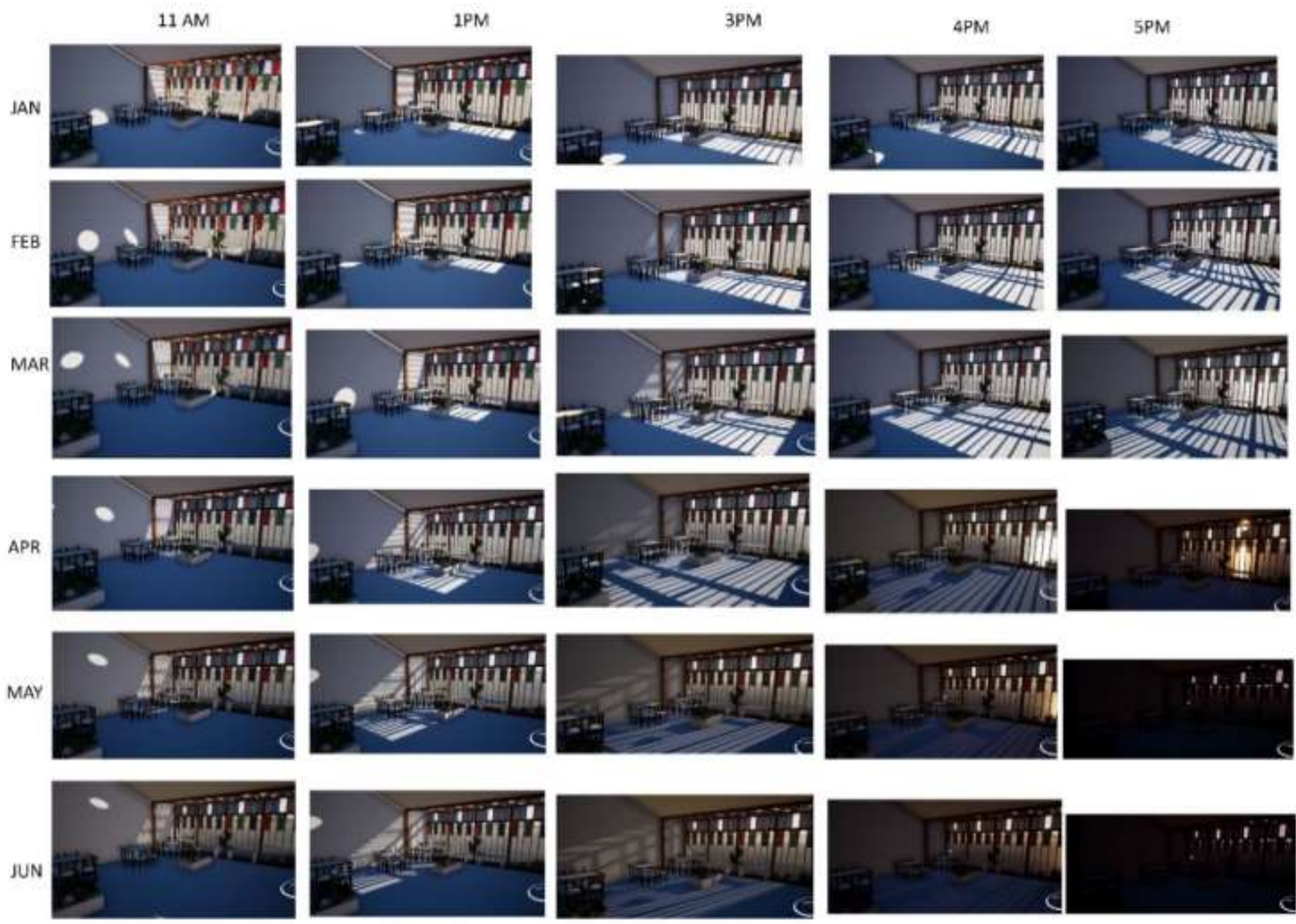

Figure 52: play of light and shadow from January to June 
It is observed that shadow mainly fall on the South-East wall and floor throughout the year. Therefore, South-East wall and floor are decided to be white in colour for this reason.

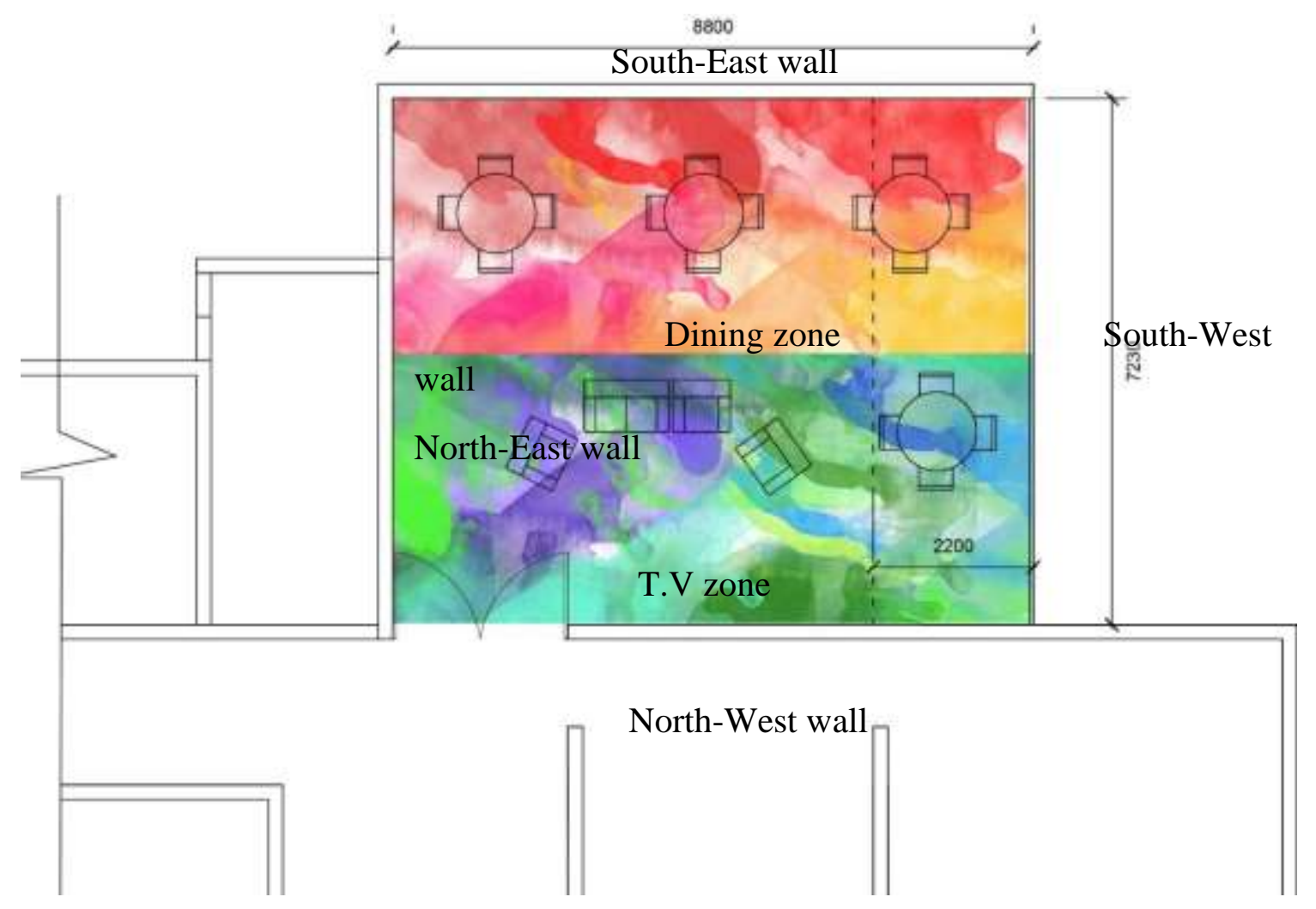

Figure 53: Plan with two zones

North-West wall is in the T.V zone, therefore it requires soothing and relaxing in colours. North-West wall is selected to be designed as a green wall with a T.V unit similar to the one in the section A2.2 (option3). This wall act as wall with natural elements of healing.

North-Est wall is designed as a wall with colourful pinboard for as in the figure 32. Residents could pin their creations and photos on the pinboard to make the room homely.

\section{FURNITURE COLOURS}

Floor is decided to be white in colour in the section 8.1.1, therefore furniture need to be in contrasting colour to avoid figure ground confusion for the elderly. Seating of the chairs in the dining zone is selected as Red in colour. Seating in the T.V zone is selected to be blue-green colour and complimentary colour Orange-red is given for the cushions to make it colourful and pleasing. 


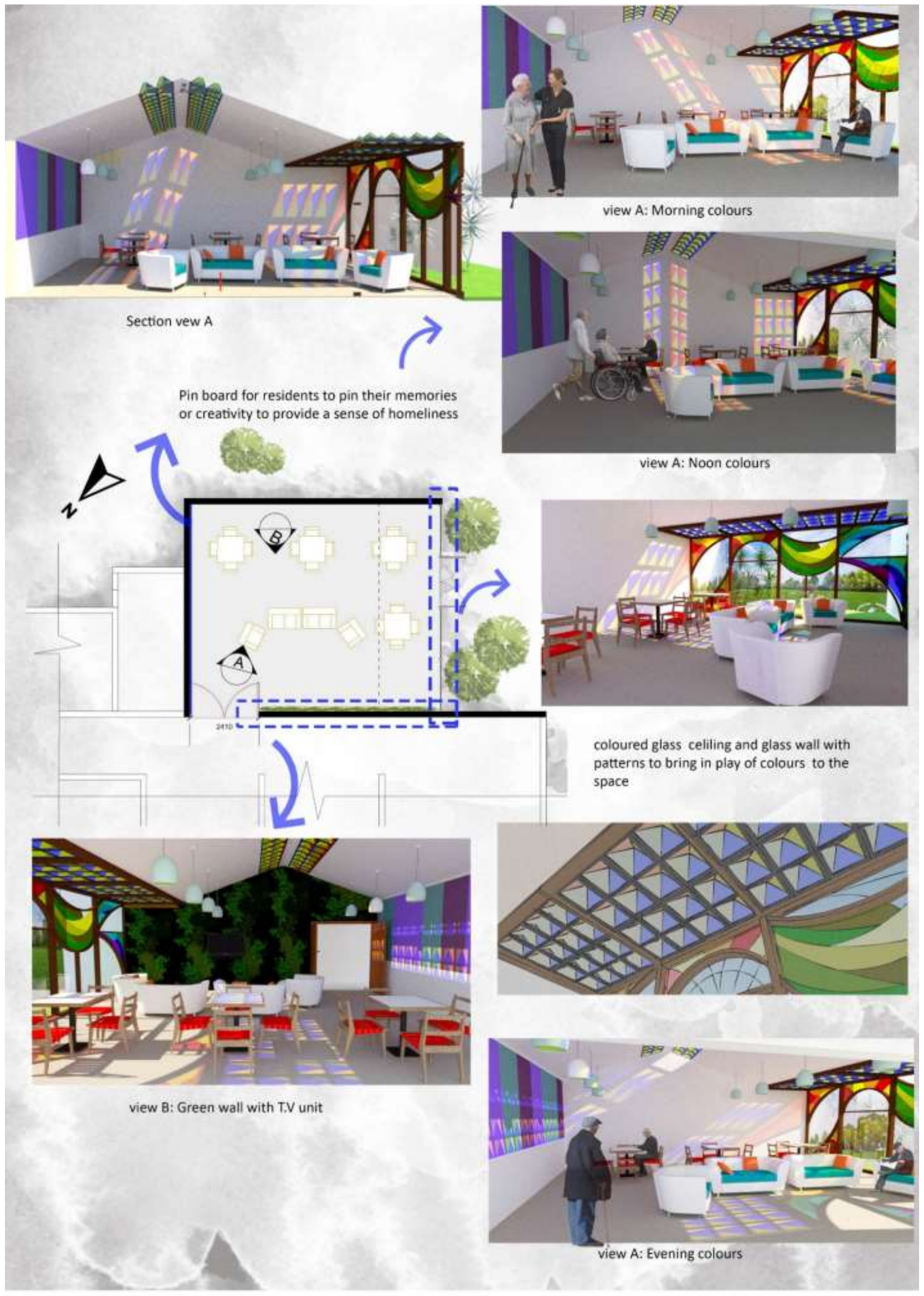


Glass openings on the roof is designed in a particular angle so as to let in colours according to the movement of sun.

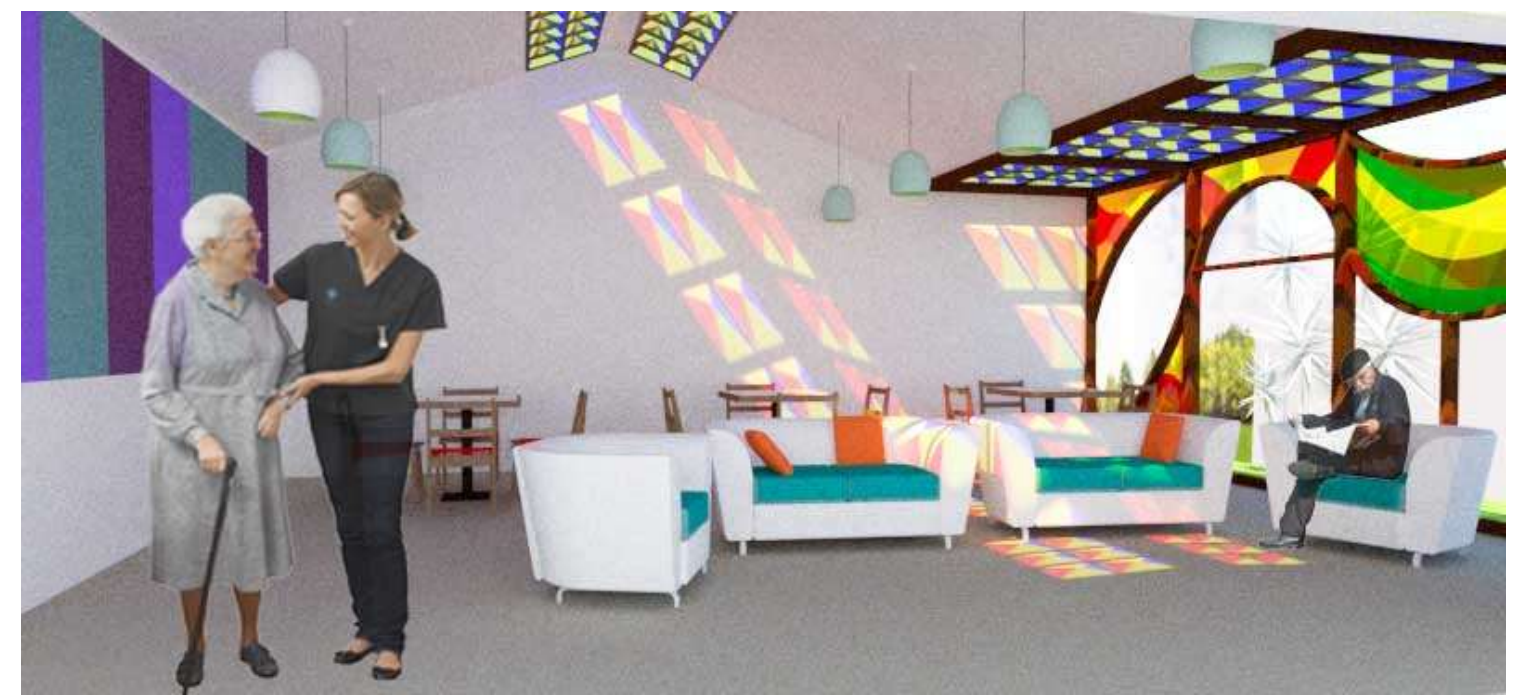

Figure 54: Morning colours

To make mornings more energetic, active and cheerful colours like red, yellow-orange and green are designed to be refracted through the glass roof in the mornings.

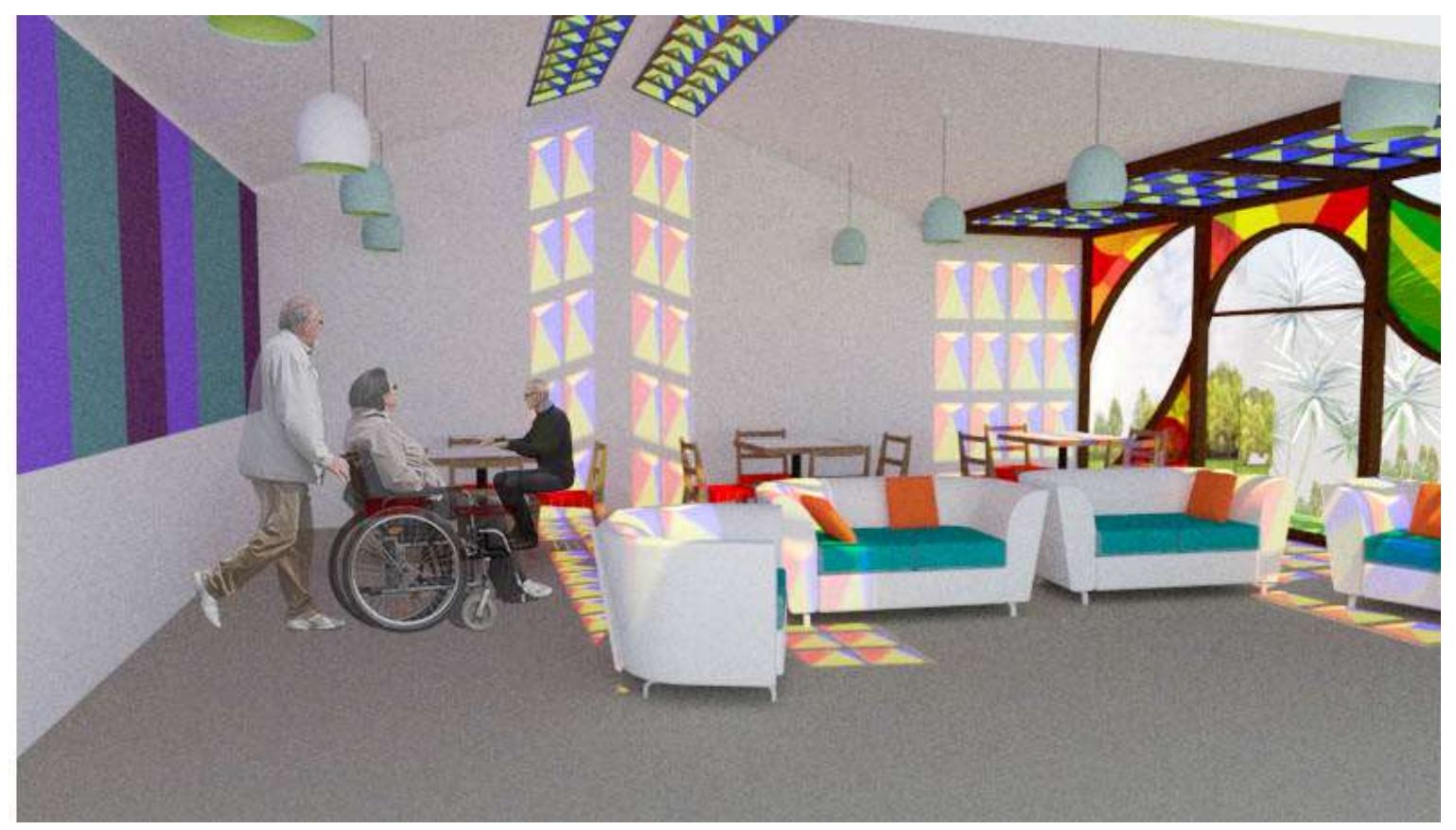

Figure 55: Afternoon colours

In the afternoon all colours are visible as the sun is exactly on the top. 


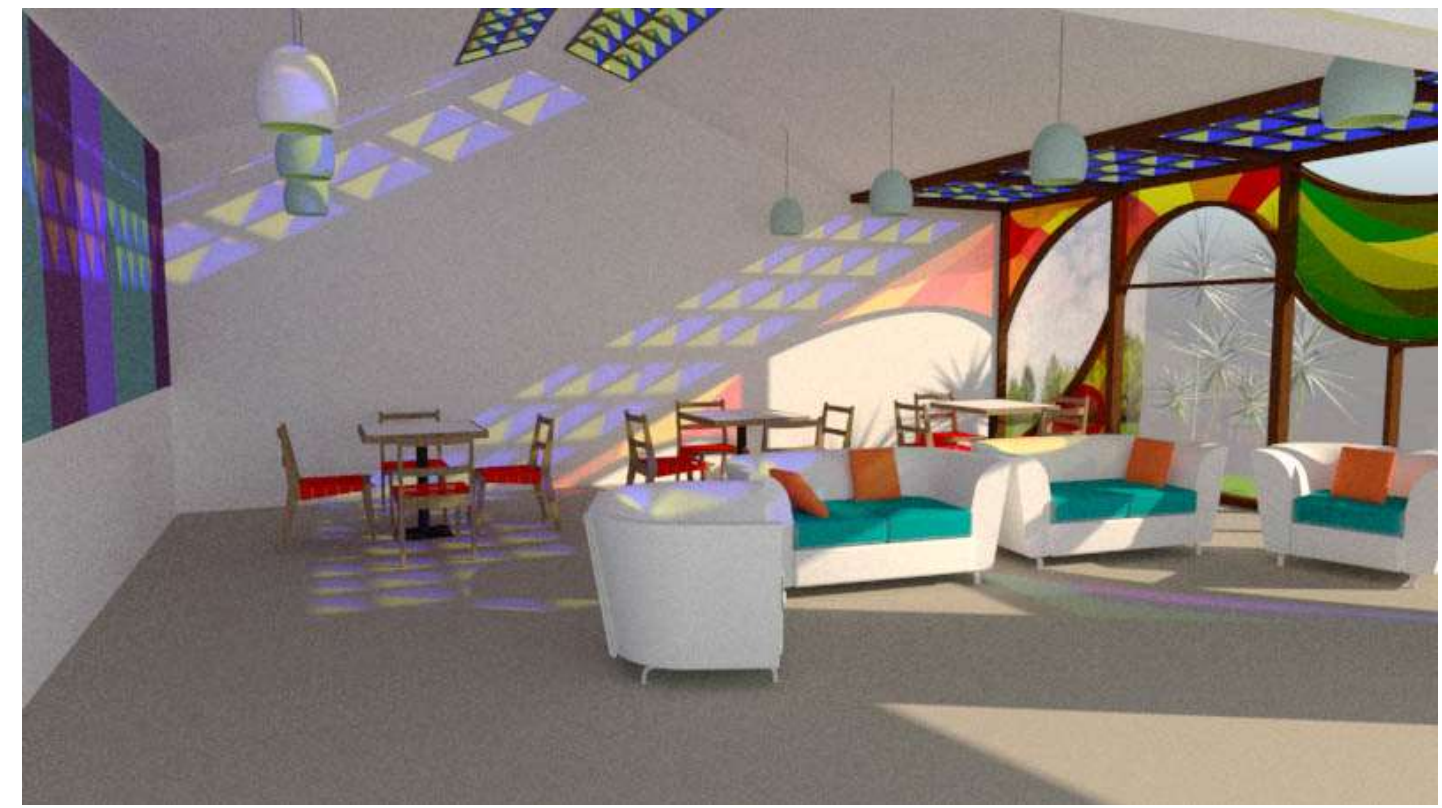

Figure 56: Evening colours

To make evenings relaxing and soothing and also to promote a good sleep colours like green and blue are refracted in the evenings.

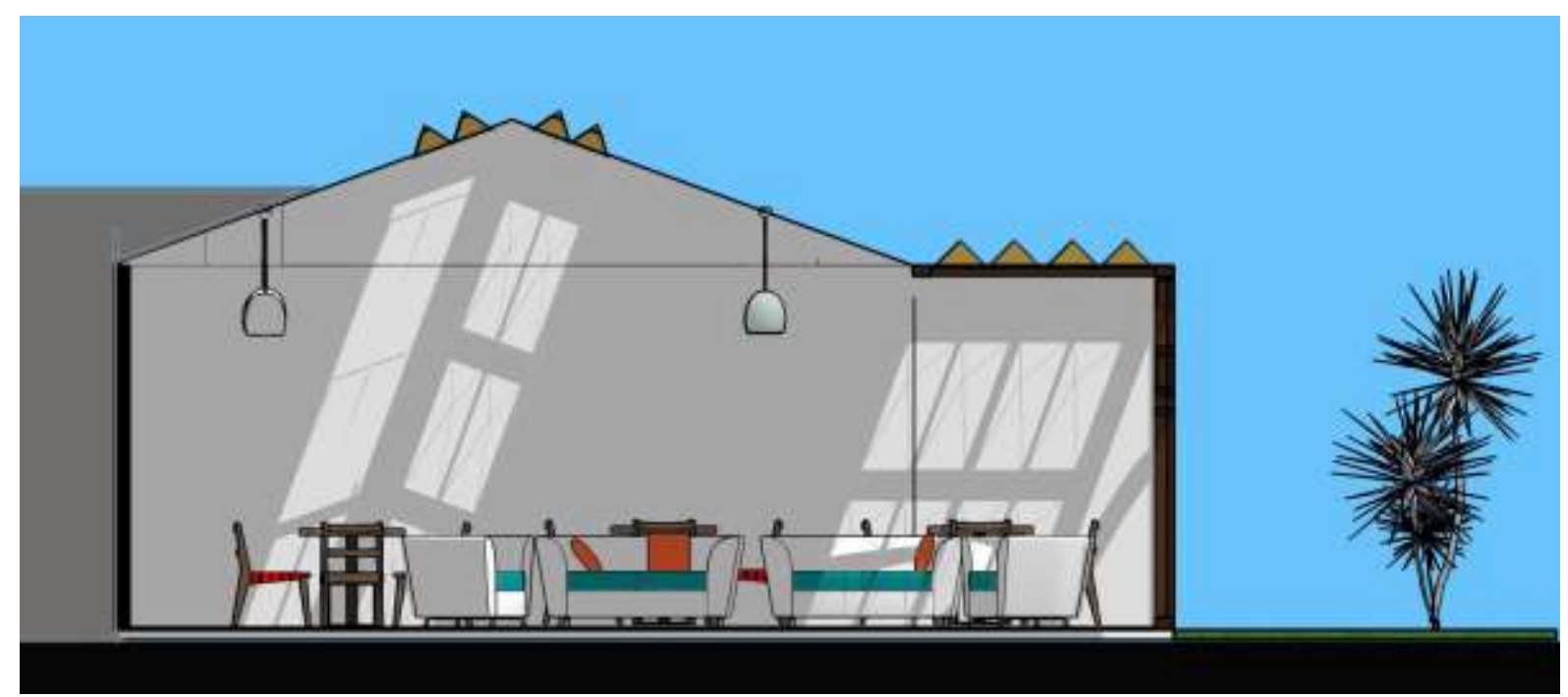

Figure 57: schematic section towards the South-East wall 


\subsection{SUMMARY AND REFLECTION}

This chapter shows the success of the study in redesigning the community lounge; making it interesting and stimulating as well as soothing and comforting. It was able to incorporate all four key design strategies for creating healing and comforting environment (established in the chapter 2) in this design.

Overuse of both warm colours and cool colours are controlled by creating a balance and providing complimentary colours. A good connection with nature is created through indoor green wall and large glass wall.

This design succeeded in bringing in required colours as well as limiting unwanted colours according to the need of time. For example, energetic colours like red and orange are brought into the interiors in the morning so as to make the residents more active, energetic and to promote interaction. At the same time soothing colours like blue and green are brought into the interiors during evening to make evenings more soothing and comforting. 


\section{TESTING ON ANOTHER SITE}

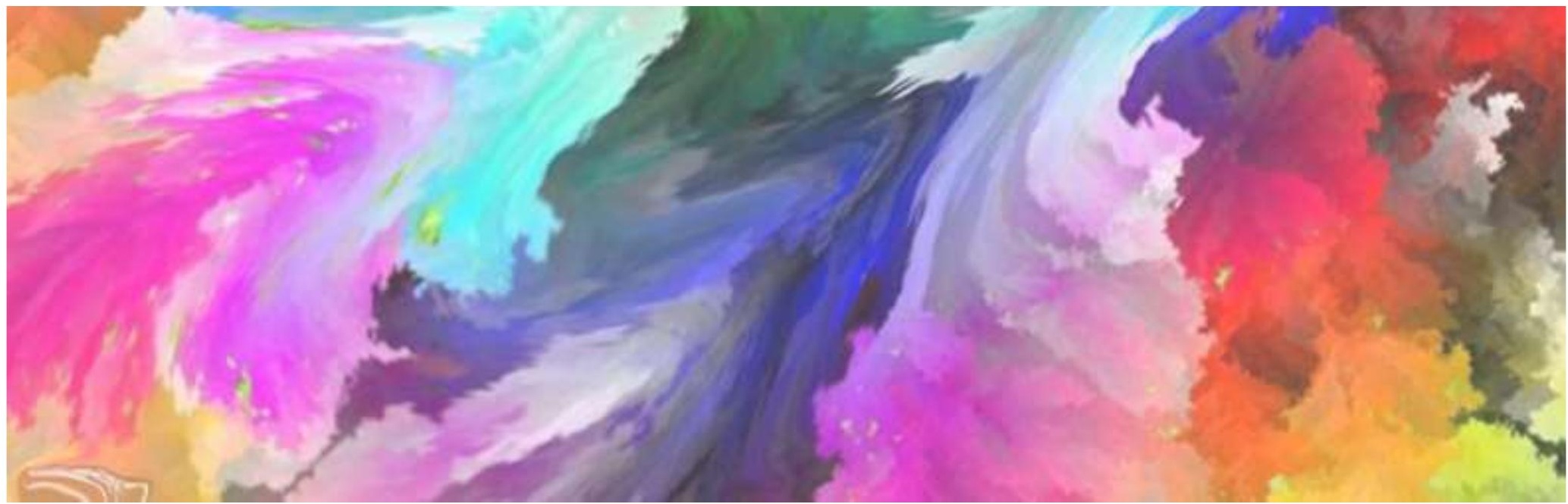


In this chapter selected roof design from the chapter seven is tested on another lounge.

\subsection{SITE}

Selected lounge is the north wing lounge of Sprott house Karori (Figure.58). Elements of healing derived in the literature review is tested on the site and observed that there is a lack of colours promoting interaction in the site.

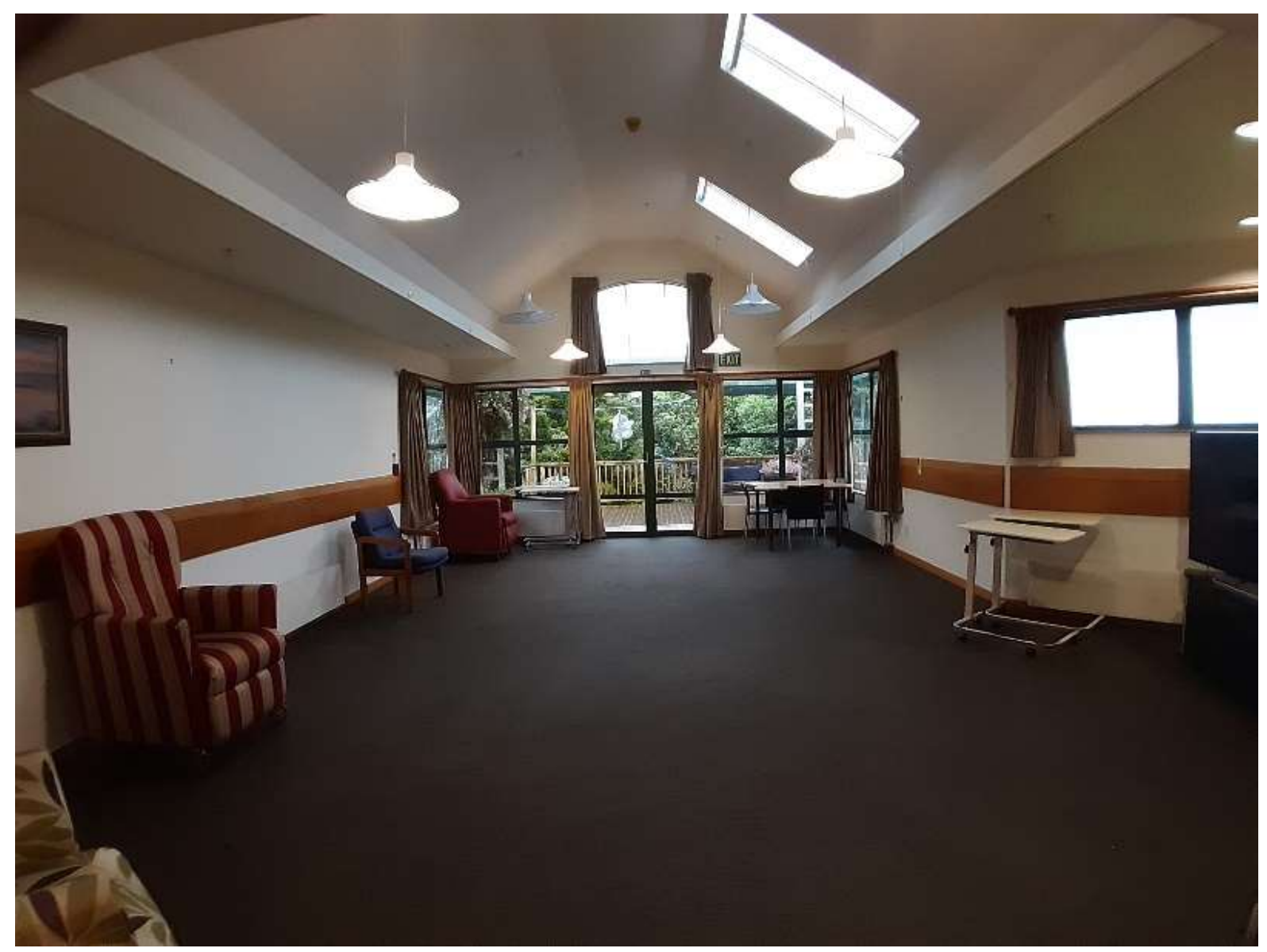

\section{Figure 58: North wing lounge}

Firstly, final selected 3D glass design was applied on the existing opening in the roof and observations are noted. See figure 59 


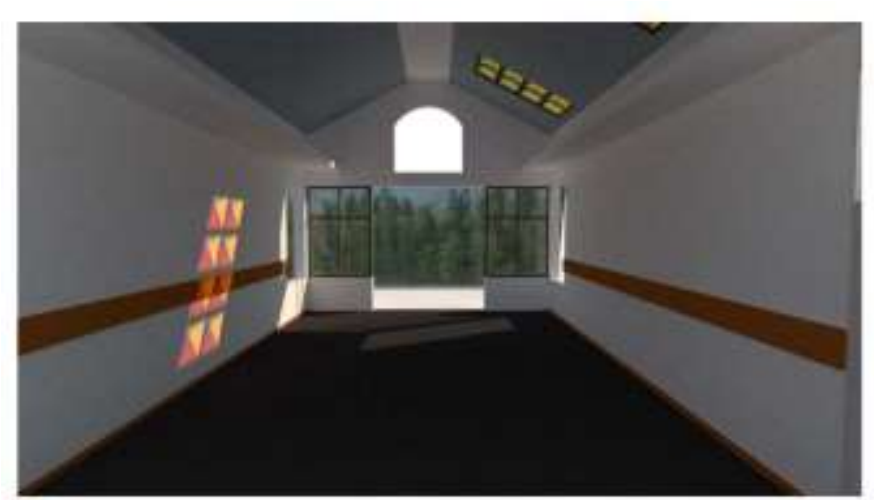

7.30 am January

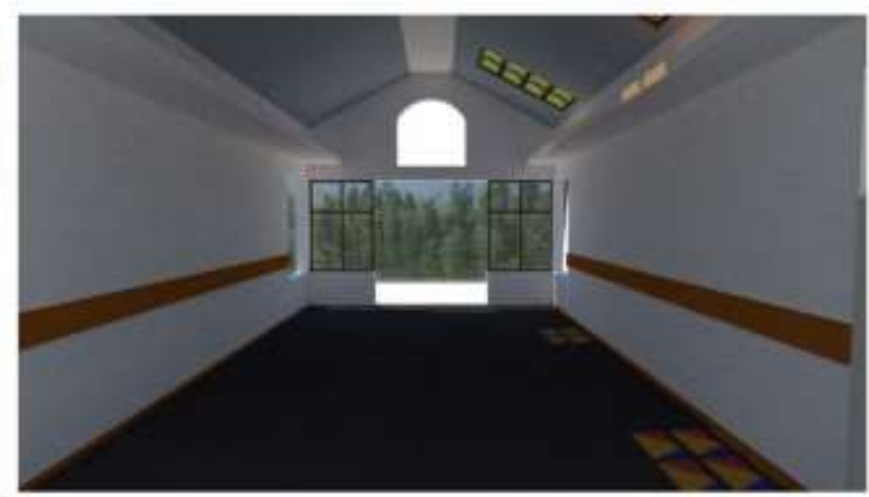

$12 \mathrm{pm}$ January

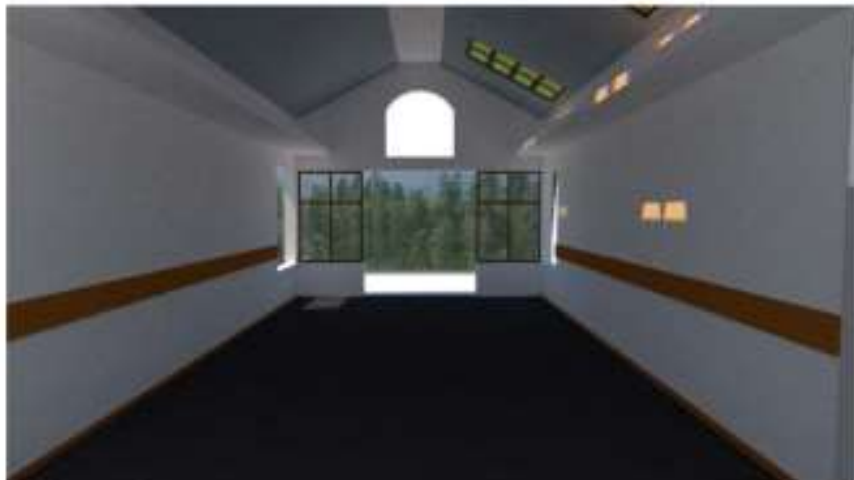

$2.30 \mathrm{pm}$ January

Figure 59: Testing on existing opening

It is observed that desired results are not obtained when the selected design is applied on the existing roof opening. Colours are not visible after $2.30 \mathrm{pm}$. 
Again, the roof opening similar to final design was tested on the new site and observations are noted. See figure 58 and figure 59

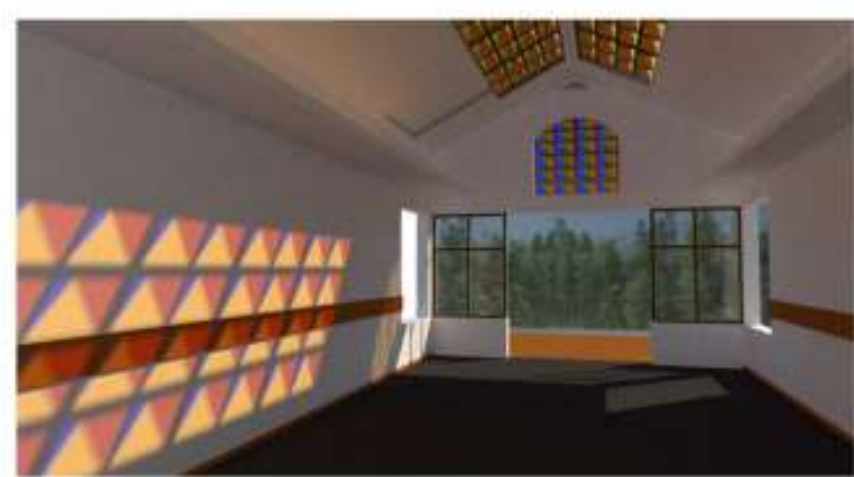

8.30 am January

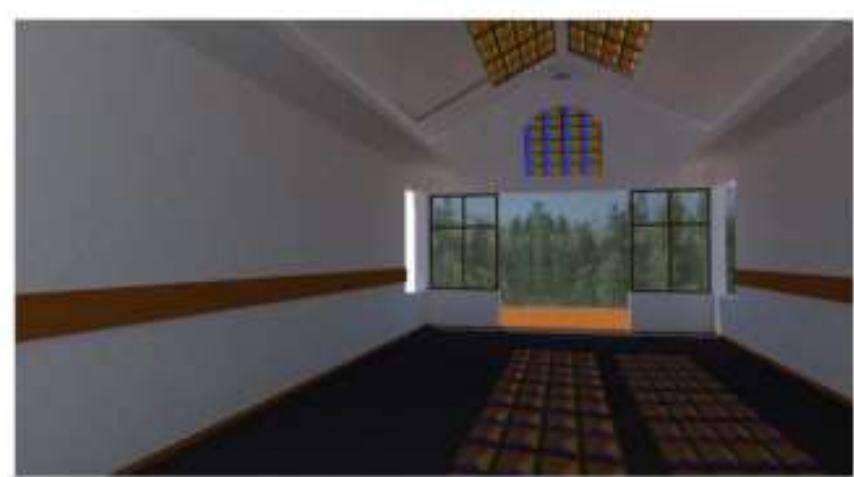

$12.00 \mathrm{pm}$ January

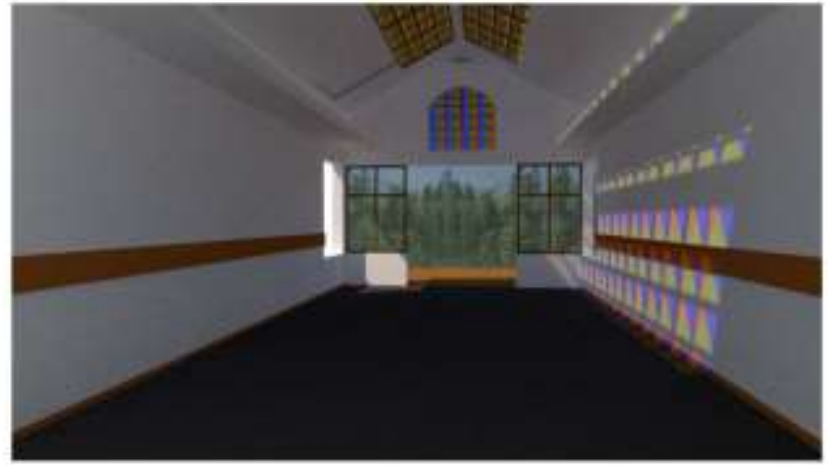

$3.30 \mathrm{pm}$ January

\section{Figure 60: Colours in summer}

Figure 60 represents the patterns of colour coming in during summer. It is observed that colours similar to the selected design in chapter 8 are obtained in this case. Energetic and colours promoting interaction are refracted in the morning, all colours are visible during the afternoon and soothing colours are visible in the evening. 


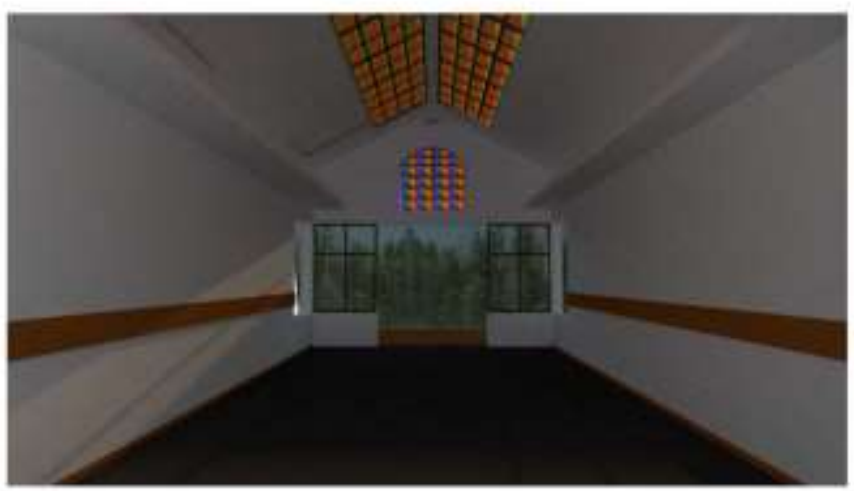

9.15 am July

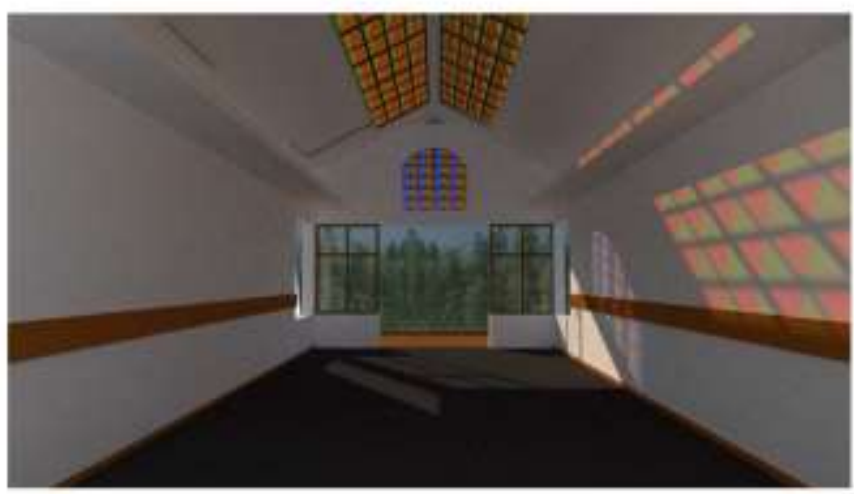

12.00 pm July

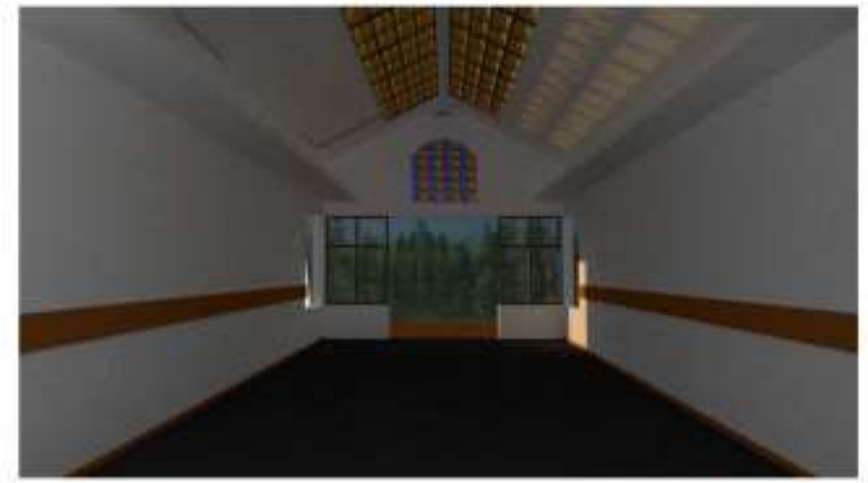

4.00 pm July

Figure 61: colours in winter

The figure 61 represents the colours obtained during winter. It is observed that desired colours are not obtained through this design in winter.

\subsection{CONCLUSION}

3D glass design in this new site is not as successful as the previous site. Even though colours are let in through the openings, it failed to let in colours according to the need of time. From this chapter it can be concluded that sun path, orientation of the room, size of the openings, proportion of room, topography of site are also the factors affecting the colours and the light in refracted in the room. 


\section{CONCLUSION}

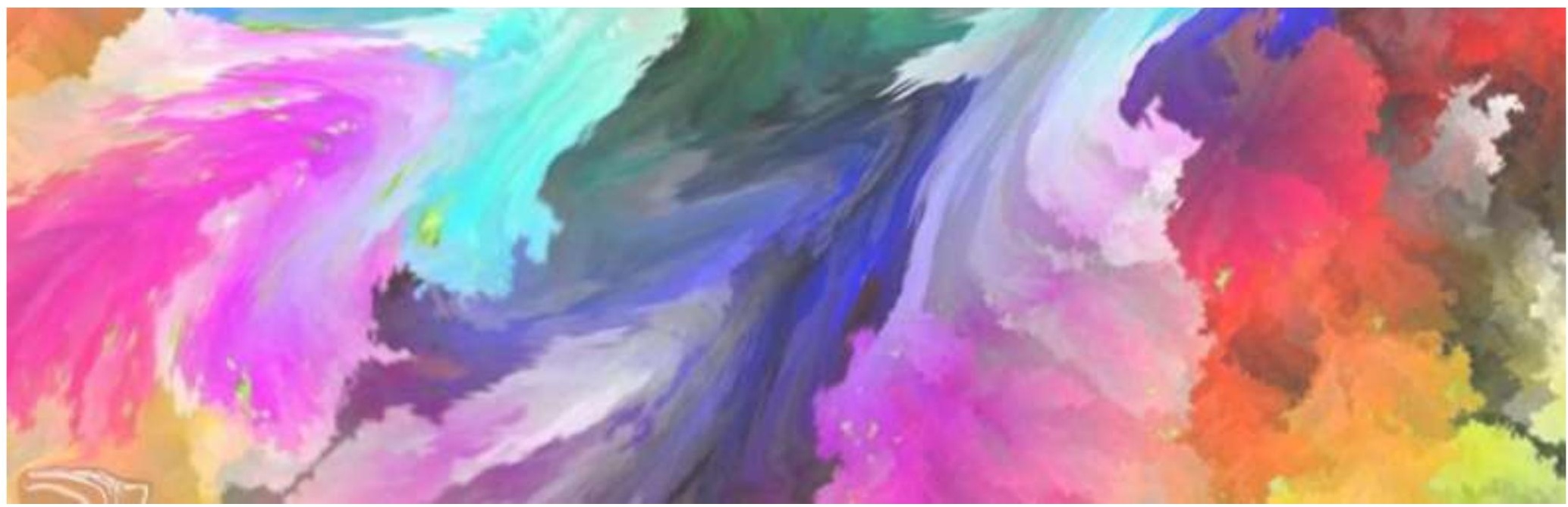

$96 \mid \mathrm{P}$ a g e 
Colour is an important part of the built interiors. Systematic review of literature suggests that colour is effective as a means of influencing mood and function of the elderly. This research argues that colours previously considered too bright for health care and retirement settings could be used as vital relaxing tools that directly promote healing. Moreover, research suggests that bright saturated colours and tonal difference in colours could prevent the adverse effect of sensory deprivation associated with aging.

From the study in the section 4.1 it is known that retirement homes in New Zealand have not completely used the potential of colours. Therefore, this is a relevant investigation as retirement homes are increasing popular and high demand. This research has tried to explore how colour could drive design interventions to create healing and comforting interior environment in retirement homes. It was possible to establish four design strategies which support the use of colour for healing and comforting environment in retirement village context through the chapter 2. It was possible to find out aging eye problems and to suggest design interventions through literature review and design experiments.

Different ways of bringing colours into the built interiors were explored in this study. Chapter 6.1 explored ways to make the site feel healing and comforting by bringing colours through natural elements and painted surfaces. These techniques can be applied to interiors to make these more interesting in terms of colour.

Chapter 6.2 explored how to bring colours naturally through the coloured glass. Through this it was possible to design glass which can bring in colour according to the different needs for different time of the day or year. For example, this design can bring in energising colours like orange and red in the mornings and at the same soothing colours like blue and green in the evening. Study shows that natural light in the room, size of the openings, size of the room, orientation of the room, are some of the factors affecting these design interventions. Artificial lighting is not considered in this research, as main in the retirement homes activities takes place during daytime.

Study succeeded in redesigning the site and making it interesting in terms of colour. It was also able to integrate four design strategies established in the literature review. 


\subsection{FINDINGS}

As part of concluding remarks it is important to present all of the findings from this study into a clear summary. Based on literature review it was possible to establish four main colour strategies for creating healing and comforting environments in retirement home context. These are: inclusion of views of nature, natural light, soothing colours and colours promoting interaction. Different ways to increase these key elements was explored in the chapter 6.

\section{Views of nature and natural light}

According to the reviewed literature, nature and light play an important role in promoting healing, and this can be stimulated in the interior environments by employing following four strategies:

Enlarging the openings: Enlarging existing openings or creating new openings on a wall or roof can introduce more natural light and views into the interior. Position of openings and orientation of the room also need to be considered while designing new openings.

Indoor gardens: Indoor garden in another way to improve better connection between interior and nature.

Patterns of nature: Patterns in nature are fascinating. Recently, many researchers have found that patterns are helpful in facilitating stress reduction in humans. Patterns need not directly replicate something found in nature. They can be used to indirectly suggest a connection with nature.

Lighter and brighter coloured interiors: Lighter and brighter colours have the ability to reflect more light than darker colours. This can boost the natural light in the room.

\section{Soothing colours}

Literature review identified that blue and green colours are deemed more soothing than any other colour. These colours are said to have the ability to make us feel calm and relaxing.

Soothing colours can be brought into interiors with the use of natural elements like water or plants and creating a better connection with nature. Soothing colours can also be introduced by painting surfaces or by using soothing colours in the soft furnishings. In the design explorations in chapter 6 . Colours are also brought in through the use of coloured glass. 
Demerit of using of too much soothing colour is it can lead to depression. Also, it is to be noted that if used poorly, colours like yellow green may feel strangely clinical especially when used with white.

\section{Colours promoting interaction}

From the literature review it is noted that Red and Orange are the colours which have the ability to promote interaction. Introducing those colours in the interiors can increase the interaction among the users. They are also said to be energizing colours as said in the literature review.

Over use of these colours can be disturbing and may feel overbearing to the residents.

\subsubsection{COLOUR AND AGING EYE NEEDS}

Finding 1: Pale and pastel colours look similar to the aging eye

\section{Solution:}

- Try to avoid going from one pastel colour to another.

- Use rich and saturated colours

Finding 2: size of pupils become smaller with age resulting reduced ability in discriminating between colours and surroundings look dimmer.

Solution: Ambient lighting and designing with bright colours, these colours bounce back more light than dull colours.

Finding 3: Figure ground confusion

Solution: Give colour contrast between object and background

Finding 4: Difficulty to discriminate colours with similar wave length especially shades of blue and green.

Solution:

- Ambient lighting could solve problem to some extent.

- Tonal difference is to be given more importance than colour difference while designing for aging eyes. 


\subsection{FURTHER STUDY}

All the conclusions and decisions in this thesis are based on literatures, experiments and the personal observations. Because different people experience colour and light differently, this research could have benefited from including a participatory step to include the opinions of the actual residents living in retirement homes. This approach was considered and carefully evaluated, but it was deemed to be impossible to fit into the one-year study. It is possible to anticipate that feedback from the participants could have influenced some important improvements in the findings of this study.

However, even without the opportunity to get feedback from others, this study shows that there is much room for an improvement in the way colour and light are considered in retirement homes. Based on the current literature, and a set of innovative design exploration, this research has proposed an early version of guidelines for designing healing environments in retirement homes considering the use of colours. That is the main contribution of this work. 
*Baby boomers are usually defined as those born between 1946 and 1961 and who are now aged between 45 and 60 .

\section{References}

Jalil, N. A., Yunus, R. M., \& Saidc, N. S. (2012, December). Environmental Colour Impact upon Human Behaviour: A Review. Science Direct, Volume 35, , 54-62.

Strawn, J. (1999, Fall). Alternative Health Practitioner, 5(2), 173-174.

Aarts , M., Schoutens, A., \& Stapel., J. (2006). Natural light exposure, healthy elderly people and sleep-a field study. In Proceedings of the 2nd CIE Expert Symposium on Lighting and Health.

Albert, T. S., \& Leung, L. M. (1998). Indoor Lighting Design Incorporating Human psychology. Architectural Science Review, 41:3, 113-124.

Altimier, L. B. (2004, june). Healing environments: for patients and providers. 4(2), Pages 8992. doi:https://doi.org/10.1053/j.nainr.2004.03.001

Amber, R. B. (1980). Color therapy: healing with color. BestHowToBooks. Retrieved from http://www.chetsbooks.com/ebooks/Color\%20Therapy.pdf

Arditi, A. (2005). Enhancing the visual environment for older visually-impaired persons. Alzheimer's Care Quarterly, Oct-Dec, vol 6(4), pg 294-299.

Bhatt, H. (2015). Biophilic design for the elderly: Design of a senior living community along the Delaware. Master of Science in Sustainable Design thesis, Philadelphia University, Master of Science in Sustainable Design.

Birren, F. (1988). Light, colour and environment. . Pennslvania: Schiffer Publishing Ltd. .

Bourn, J. (2011, janury 25). Meaning of the color. Retrieved from Bourn creative: https://www.bourncreative.com/meaning-of-the-color-green/

Brawley, E. C. (1997). Designing for Alzheimer's disease: Strategies for creating better care environments (Vol. 1). John Wiley \& Sons.

Bronson, L. (n.d.). sherwin-williams. Retrieved from Color and Senior Care: https://www.sherwin-williams.com/architects-specifiers-designers/inspiration/stylesand-techniques/SW-ART-STIR-COLOR-ELDER

Bryant, K. Y. (2018). The Color Book, Volume I. Kyb. Retrieved from https://books.google.co.nz

Cao, L. (2019). How Color Affects Architecture. Retrieved from Archdaily: https://www.archdaily.com/

Cartwright, B. ( 2018 , Oct 3). Your Guide to Colors: Color Theory, The Color Wheel, \& How to Choose a Color Scheme. Retrieved from https://blog.hubspot.com/marketing/colortheory-design 
Cavallaro, D. (2017). J.W. Waterhouse and the Magic of colour. McFarland.

Cerrato, H. (2012). The meaning of colors. The Graphic Designer.

Collyns, J. (2016, December 13). New Zealand Retirement Village Database (NZRVD) November,2016. Retrieved from https://www.seniortrustcapital.co.nz/application/files/3915/0630/3045/NZRVD_2017 _Whitepaper_20.02.17.pdf

Collyns, J. (2019, Jan 19). Many Kiwis satisfied with retirement village life. Stuff. Retrieved from https://www.stuff.co.nz/

Color Theory \& Interior Design. (2016, December 16). Retrieved from https://study.com/academy/lesson/color-theory-interior-design.html

Colour preference in the elderly. (2017). Retrieved from Filli Boya The Effect of Color (Renk Etkisi): http://renketkisi.com/en/color-preferences-in-the-elderly.html

Colour solutions. (2003). Meredith Books.

Cooper, B. A., Gowland, C., \& Mcintosh, J. (1986). The use of color in the environment of the elderly to enhance function. Volume 2, Issue 1, February Clinics in Geriatric Medicine, Volume 2, Issue 1,, 151-163.

Craig, N. (2015, jan 23). psychological effects color interior design. Retrieved from http://nataliecraigdesign.com/psychological-effects-color-interior-design/

Dalke, H., \& Matheson, M. (2007). Colour Design Schemes for Long-term Healthcare Environments. Arts and humanitis research council.

Drageset, J. (2004). The importance of activities of daily living and social contact for loneliness: a survey among residents in nursing homes. Scandinavian Journal of Caring Sciences, 18(1), 65-71.

Düzgün, G., \& Durmaz , A. (2017). Effect of natural sunlight on sleep problems and sleep quality of the elderly staying in the nursing home. Holistic nursing practice, 31(5), 295302. doi:https://doi.org/10.1097/HNP.0000000000000206

Edmunds, S. (2018, June 10). What the 'retirement village effect' brings to a neighbourhood. Stuff. Retrieved from Stuff: https://www.stuff.co.nz/

Eifler, E. (2011, november 8). The effects of Aging on Color Vision. Retrieved from color studio: http://blog.colourstudio.com/2011/11/effects-of-aging-on-color-vision.html

Elements of design part 2: Colour. (n.d.). Retrieved from Hatch design: https://www.hatchdesign.ca/elements-of-design-part-2-colour/

Fiore, A. M. (2010). Understanding aesthetics for the merchandising and design professional. A\&C Black.

Gesler, W. M. (2003 ). Healing Places. Rowman \& Littlefield Publishers,.

Hamilton, M., \& Hamilton, C. (2006). Baby boomers and retirement. Dreams, fears, and anxieties. Sydney: The Australian Institute. 
Helvacioğlu, E. (2011, July). Colour emotion assosiation in interior spaces. Doctoral dissertation, Bilkent University.

Hill, T. R. (2008). Using color to create healing environments. Healthcare Interior Designer, 12.

Hurhundee, A., \& Ramsamy-Iranah, S. (2017). Designing the Interior of a Nursing Home for the Elders of Mauritius. The Asian Conference on Aging \& Gerontology. Art Center Kobe, Kobe, Japan.

Judd, S. (2008). 'We shape our buildings . . . thereafter they shape us'. Dementia. 7(2), pp. 163-165. Retrieved from https://doi.org/10.1177/1471301208091161

Kandinsky, W. (2012). Concerning the spiritual in art. Courier Corporation.

Kelly, F. I. (2011). Improving care home design for people with dementia. .

Keystone, J. S., Kozarsky, P. E., Connor, B. A., Nothdurft, H. D., Mendelson, M., \& Leder, K. (2018). Travel Medicine E-Book. Elsevier Health Sciences.

Manav, B. (2007). Color-emotion associations and color preferences: A case study for residences. 32(2), pp. 144-150. Retrieved from https://doi.org/10.1002/col.20294

Martinson, B., \& Bukoski, K. (2005). Implication: Seeing colour. 3(5). Retrieved from www.informedesign.umn.edu

Martinson, B., \& Bukoski, K. (2005). Implication: Seeing colour. Informe Design. http://www.informedesign.umn.edu/_news/may_v03r-p.pdf.

Mastroeni, T. (2014, October 30). 10 Color Theory Basics Everyone Should Know. Retrieved from fresh home: https://freshome.com/2014/10/30/10-color-theory-basics-everyoneshould-know/

Meervein, G., Rodeck, B., \& Mahnke, F. H. (2007). Colour: communication in architectural space. Switzerland: Birkhauser Verlag.

Moghadam, Z. M., \& Reza Mirzaei. (2017, July ). The effect and role of colors and environmental psychology in designing nursing home cares. IJCSNS International Journal of Computer Science and Network Security, 17 .

N.Gohar. (2009, July). The application of colour and colour contrast in the home environment of the elderly and visually impaired individuals. Evidence Based Research: The application of colour and colour contrast in the home environment of the elderly.

Niki. (2011, april 28). Colour Perception and Ageing Eyes. Retrieved from https://unifiedspace.wordpress.com/2011/04/28/colour-perception-and-ageing-eyes/

Oakey, A. (n.d.). Interior Design and Colour Psychology. Retrieved from Aoki interiors: http://aokiinteriors.ie/design-advice/colour-psychology

Olesen, J. (n.d.). 7 Best Colors For Healing. Retrieved from colour meanings: https://www.color-meanings.com/7-best-colors-healing/ 
Othman, S. M., Elmasry, R. E., \& Shaker, S. A. (2015). The elderly color's preferences to be used in designing Printed Upholstery Fabrics. International Journal of Innovation and Applied Studies, 13(2), 430-451. Retrieved from http://www.ijias.issr-journals.org/

Palermo, P. (n.d.). How to Use the Color Wheel for Decorating. Retrieved from https://www.ballarddesigns.com/howtodecorate/2015/09/how-to-use-the-color-wheelfor-decorating/

Park, M., Chai, C., Lee, H., Moon, H., \& Noh , J. (2018). The Effects of Natural Daylight on Length of Hospital Stay. Environmental Health Insights. 12(1178-6302). doi:https://doi.org/10.1177/1178630218812817

Persaud, N. (2009). The right surroundings can promote wellbeing. Retrieved from Remedy's healthcommunities.com: http://www.healthcommunities.com/stress/creating-ahealing-space.shtml

Petru, S. (2006). Red, black or white The dawn of colour symbolism. Documenta Praehistorica XXXIII, 203-208. doi:10.4312/dp.33.18

Pomroy, K. ( 2017, June 19). Introduction To The Psychology Of Color: For Interior Designers. Retrieved from the art career and projec: https://www.theartcareerproject.com/blog/psychology-of-color

Raskin, R. (1986). Colour: An outline of terms and concepts. Denmark: Aarhus University Press.

Ryan, C. (2015, February 17). Biophilia \& the Visual Connection. Retrieved from TERRAPIN BRIGHT GREEN: https://www.terrapinbrightgreen.com/blog/2015/02/biophilia/

Selwyn Foundation. (2018, July 12). Selwyn Foundation to take over Sprott House.

Shehata. (2000). Colour: Use in design. Retrieved from http://www.hodgemony.com/pages/HCI/Color_Use_In_Design.pdf

Silva, M. P. (n.d.). Psychology of the color Green, and its effect in Interior Design. Retrieved from la healthcare design: https://lahealthcaredesign.com/psychology-of-the-colorgreen-and-its-effect-in-interior-design/

Stichler, J. F. (2001). Creating Healing Environments in Critical Care Units. Critical Care Nursing Quarterly, 24(3), 1-20.

Stouhi, D. (2019). Bringing the Outdoors Inside: The Benefits of Biophilia in Architecture and Interior Spaces. Retrieved from https://www.archdaily.com/

Strenernberg, M. E. (2009). Healing spaces: The science of place and well being. Harverd University Press.

The health benefits of strong relationships. (2010, December). Retrieved from Harvard Health Publishing Harvard Medical school: https://www.health.harvard.edu/newsletter_article/the-health-benefits-of-strongrelationships 
Tofle, R. B., Schwarz, B., Yoon, S.-Y., \& Max-Royale, A. (2003). colour in health care environments. 220 Pacific Avenue, 6B San Francisco, CA 94115: The Coalition for Health Environments Research (CHER).

Totaforti, S. (2018). Applying the benefits of biophilic theory to hospital design. City, Territory and Architecture, 5(1). doi:https://doi.org/10.1186/s40410-018-0077-5

Ulrich, R. (1984). View through a window may influence recovery . 224(4647), 224-225.

Valdez, P., \& Mehrabian, A. (1994). Effects of color on emotions. Journal of experimental psychology: General, 123(4), 394-409. Retrieved from https://doi.org/10.1037/00963445.123.4.394

Velarde, M. D. (2007). Health effects of viewing landscapes-Landscape types in environmental psychology. . Urban Forestry \& Urban Greening, 6(4), 199-212. doi:https://doi.org/10.1016/j.ufug.2007.07.001

Watson Smyth, K. (2018). Mad about the House: How to decorate your home with style. Pavilion Books. Retrieved from https://books.google.co.nz

Wilkins, L. W. (2014, February 20). Color vision problems become more common with age, study shows. ScienceDirect.

Yoo, I. Y. (2015). A study on healing environmental factors in the elderly patients with longterm care. International Journal of Bio-Science and Bio-Technology, 7(5), 267-276.

Zimring, C., Joseph, A., \& Choudhary, R. (2004). The Role of the Physical Environment in the Hospital of the 21st Century: A Once-in-a-Lifetime Opportunity. Concord, CA: The Center for Health Design. 